\title{
MELODIC ORNAMENTATION FROM MUFFAT TO TELEMANN
}

BY

\section{MEGAN WARD}

A thesis submitted to Victoria University of Wellington in partial fulfilment of the requirements for the degree of Master of Music (Performance)

New Zealand School of Music

2014 


\section{Abstract}

Writers on $18^{\text {th }}$-century musical ornamentation have traditionally focused on the execution of notated ornaments, and on certain disputes arising from ambiguous and contradictory primary sources. Less attention has been given to the addition of ornaments where not prescribed by the composer. Such ornaments can be short, defined, patterns such as trills, turns, and mordents, or larger measured or unmeasured additions known as diminutions, divisions, or passaggi.

Additions of this nature are only in the rarest of cases compulsory. However, the practice of more or less spontaneous embellishment by the performer was so integral to pre-1 $9^{\text {th }}$-century musical culture that this must have had a significant effect on composition.

The scope of this thesis is loosely defined by its titular composers, covering the period between Georg Muffat's later publications in the last years of the $17^{\text {th }}$ century and G.P. Telemann's death in 1767. Both lived and worked in the German states, a region which had traditionally looked to Italian models of composition and performance. This period saw a flowering of German composition into its own unique and diverse genre which integrated aspects of various styles, most prominently Italian and French music.

This thesis centres on stringed instruments, but is directly relevant to woodwind players. Many aspects are also transferrable to the keyboard and to vocal music; however, these musicians will find a large volume of more targeted research elsewhere. 


\section{Preface}

\section{On citations of eighteenth-century treatises and their translations}

The numbered chapters, sections and paragraphs in the treatises of Johann Mattheson, Leopold Mozart, J.J. Quantz, and D.G. Türk allow citations which apply equally to the original German texts and the $20^{\text {th }}$-century English translations. References to the Essays of Mozart and Quantz are given by chapter and paragraph. Mattheson's Der Vollkommene Capellmeister is, in addition, divided into three 'Parts', and citations are given in the format part/chapter/paragraph. Türk's Klavierschule contains subsections within chapters, and citations are in the format chapter/subchapter/paragraph.

Edwin R. Jacobi's 1961 translation of Giuseppe Tartini's Treatise on Ornaments includes the page numbers from the 1771 French publication, in which form the treatise survived. The page numbers cited in this thesis apply to this French version.

This was unfortunately not possible in the works of C.P.E. Bach, J.F. Agricola, and Georg Muffat. In these cases, the page numbers given refer to the English translations listed in the bibliography and at the start of the second chapter.

\section{Acknowledgements}

I would like to offer special thanks to my primary supervisor, Dr Erin Helyard. I am further grateful for the assistance provided by Emeritus Prof. Peter Walls and Associate Prof. Greer Garden, and by my father, Dr Chris Ward. 


\section{Table of Contents}

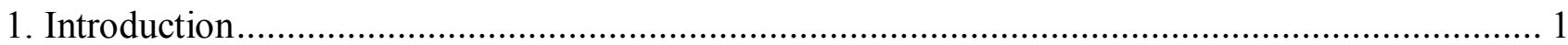

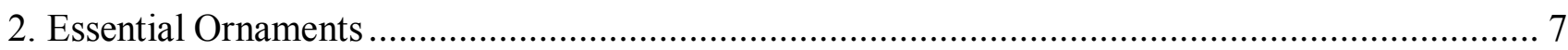

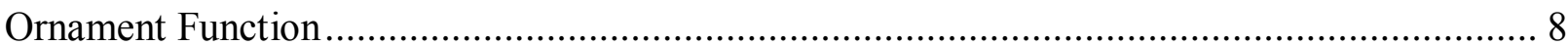

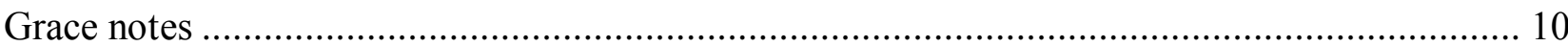

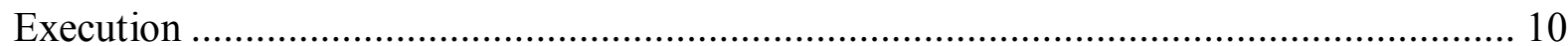

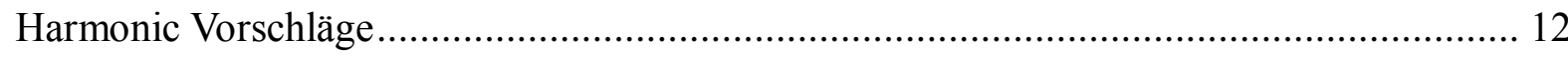

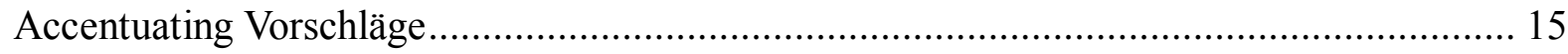

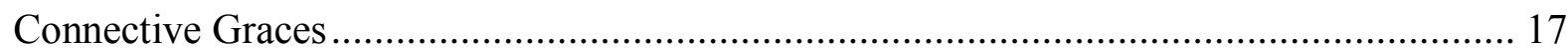

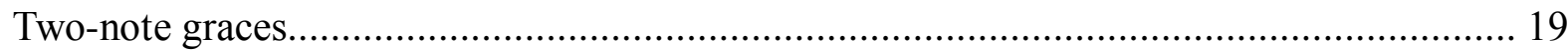

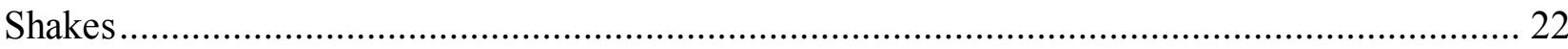

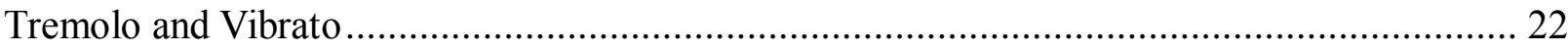

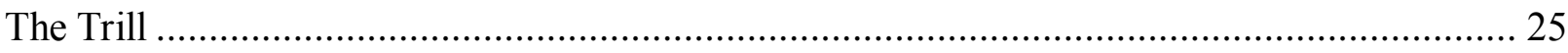

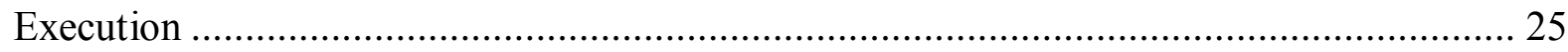

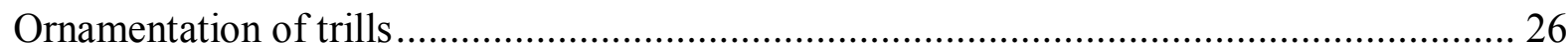

Extempore introduction of trills .................................................................... 30

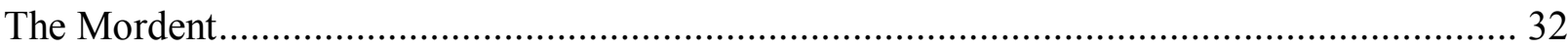

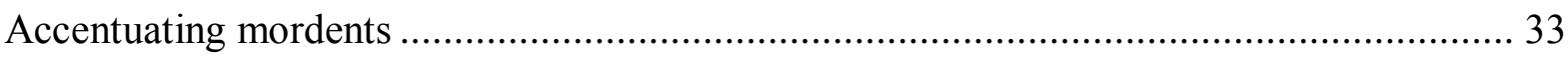

Connective mordents ................................................................................... 33

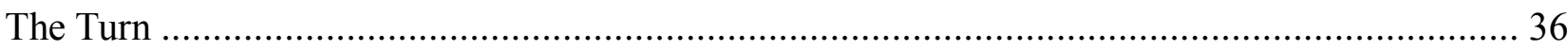

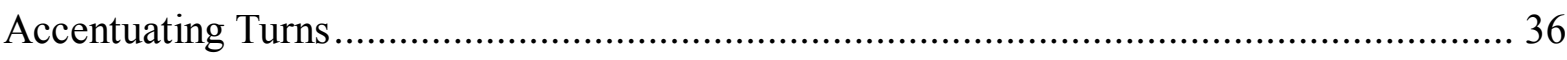

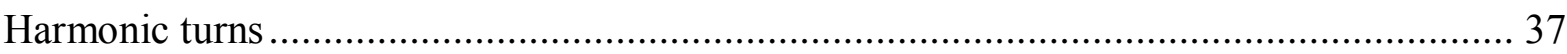

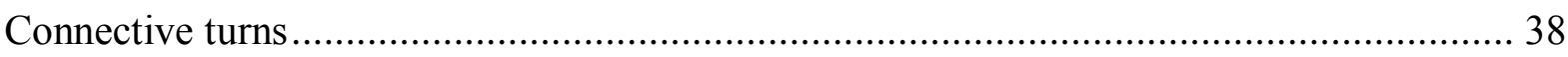

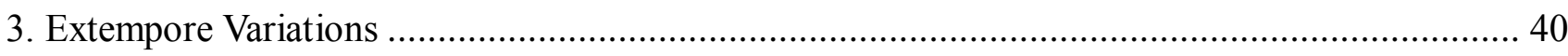

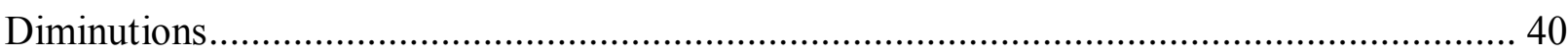

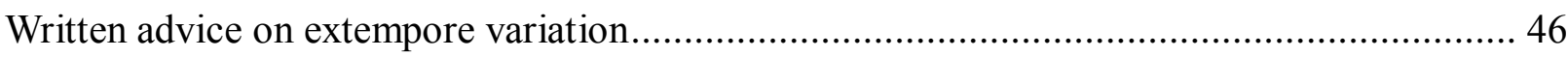

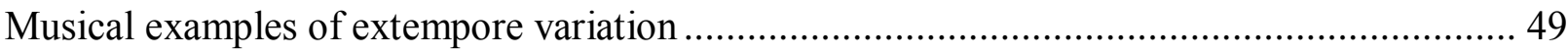

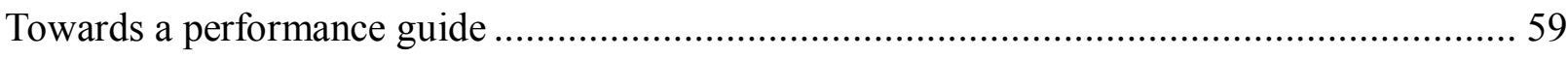

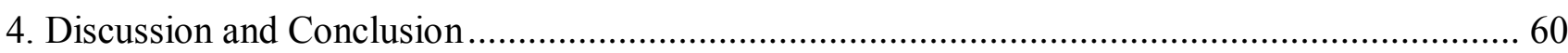

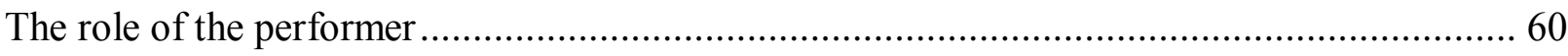

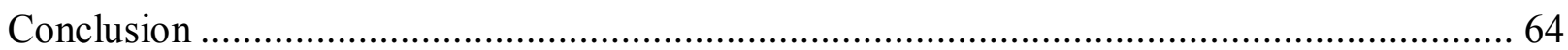




\section{Introduction}

Scholarly and practical interest in the music of past periods has a relatively short history. With few exceptions, music composed before the $19^{\text {th }}$ century existed in a culture of the present. The high percentage of significant $17^{\text {th }}$ - and $18^{\text {th }}$-century works for which all scores have been lost clearly demonstrates this lack of regard for all 'old' music.

The early $19^{\text {th }}$-century revival of the works of J.S. Bach, which were largely overlooked in his own time, was the first such instance in the history of Western music. This unprecedented interest in Bach's works, most famously represented by Mendelssohn's heavily romanticised arrangement of the St. Matthew Passion in 1829, quickly expanded to other composers of the $17^{\text {th }}$ and $18^{\text {th }}$ centuries. The high esteem which Bach was accorded necessitated a critical edition of his works, and the BachGesellschaft's effort in this regard, produced over the second half of the century, was a milestone for scholarly music editing. The elevated stature of J.S. Bach also had a decisive influence on composition, which continues to this day.

By the last decade of the $19^{\text {th }}$ century, a new focus had emerged from the desire to perform the music of J.S. Bach and his contemporaries correctly and respectfully - that of historically informed performance, popularly advertised as 'authentic'. This field, a union of performance and research, has steadily gained momentum over the last century, growing in scope to encompass the romantic period, and gaining significance to the point where it has become a part of mainstream performance.

Among the first substantial texts on historical performance practice are Edward Dannreuther's two volumes on Musical Ornamentation, published in 1893 and 1895. This early survey of the subject first presents resources from 1600-1750, intended "to illustrate J.S. Bach's ways by reference to the practice antecedent to and contemporary with him". In the second volume, "an attempt is made to trace the use, partial perversion, and gradual disuse of Bach's ornaments up to the present day [Berlioz, Liszt and Wagner]."

The Bach-centric view demonstrated by Dannreuther persists in more recent surveys on ornamentation, including the famously opposing works of Robert Donington and Frederick Neumann. ${ }^{2}$ This focus on a single atypical composer not only results in a rather skewed perspective of music history, but also prioritises questions regarding the execution of notated ornaments rather than the introduction of new ornamental material by the performer. The focus here on the latter explores some relatively new ground, while also avoiding one of the major philosophical challenges of the historical performance practice movement. While it is theoretically possible that a single 'correct' realisation of an ornament symbol exists, the same can hardly be said of free ornamentation.

This thesis aims to provide the theoretical knowledge necessary for an instrumentalist to begin to ornament melodies in an $18^{\text {th }}$-century style. While the revival of this practice is underway among historical performance practice enthusiasts, melodic embellishment remains something of a taboo or at the least a neglected field in mainstream classical music education. ${ }^{3}$ Discussion of the reasons for this

\footnotetext{
${ }^{1}$ Edward Dannreuther, Musical Ornamentation (London: Novello, Ewer \& Co, 1893), part 1, viii.

${ }^{2}$ Robert Donington, The Interpretation of Early Music (London: Faber and Faber, 1974); Frederick Neumann, Ornamentation in Baroque and Post-Baroque Music (New Jersey: Princeton University Press, 1978).

${ }^{3}$ Andrew Manze and Pavlo Beznosiuk are highly respected examples.
} 
state of affairs features in the final chapter of this thesis.

One of these causes concerns the lens of $19^{\text {th }}$-century musical culture. The music of Bach and his contemporaries was revered for its purity, modesty, and piety, often placed in opposition to the perceived worldliness and decadence of current romanticism. Perhaps conscious that ornamentation did not fit well within this view, Dannreuther's introduction includes what appears to be a disclaimer:

No-one will care to advocate the revival of a host of obsolete curlicues and twirligigs, or the resuscitation of a habit of improvising facile variantes or running into division. Divisions and graces have had their day and have served their purpose. They are interesting, however, and we ought at least to understand them. ${ }^{4}$

I am not alone in protesting that variations, divisions, and graces are so interesting as to be worthy of revival. However, the heavily ornamented works of J.S. Bach are only dubiously suitable for additional ornamentation. ${ }^{5}$ One can find more suitable subject matter elsewhere in the style or movement to which Bach belonged.

Georg Muffat (1653-1704) and G.P. Telemann (1681-1767) both lived and worked in the German states but travelled extensively and incorporated the idioms of the surrounding countries into their compositional style. By the early $18^{\text {th }}$ century, this trend was known simply as the 'mixed style'. Although this movement became popular throughout Europe, its involvement in promoting German music as a unique and widely respected style was among its most notable effects.

The technological, economic, and cultural developments which created the modern world would have been impossible without the exchange and adaptation of ideas between different cultures. In music, this process surely stretches almost as far back as the singing of songs, and has been a major driving force throughout the development of Western art music. That the simple expression 'mixed style' can be recognised as a specific term applying to the period from about 1710-1770 is testament to a real difference between this and previous exchanges.

In the arts and sciences, Italy had led the way throughout the Renaissance. The harmonic and expressive vocal innovations of around 1600 that began the so-called 'common practice period' were an Italian development. What made the early 18th-century mixing of styles different from previous national borrowing and development was the existence of a second musical source as strong as Italy. This mid-17th-century French style was exemplified, and to a certain degree created, by Jean-Baptiste Lully (1632-1687). Himself an Italian expatriate, Lully built on Italian forms to create several new genres of music, the most famous being the so-called 'French Overture'.

Georg Muffat began his musical career as a disciple of Lully in Paris, and ended it as one of the first composers of the German mixed style. In the foreword to his Auserlesene Instrumentalmusik of 1701, he reflects on the sources of his music and his own influence in the creation of the mixed style:

I now present to you ... this first collection of my instrumental concertos of

\footnotetext{
${ }^{4}$ Dannreuther, Ornamentation, vii (original italics).

5ohann Adolf Scheibe's oft-quoted words on Bach's music (Der Critische Musikus, 1737) indicate that the level of surface detail which many of Bach's scores contain may have been similar to a performance version of contemporaneous pieces which were written much more simply. This is not to say that further additions on the part of the performer should be categorically forbidden.
} 
choicest harmony, both serious and light-hearted; so named because it not only contains intact the brisk liveliness of the ballet arias which spring from the Lullian fountain, but also contains certain melancholy, exquisite affects of the Italian manner. ... The first thoughts of this ingenious mixture came to me some time ago in Rome, where I was learning the Italian style on the keyboard under the world-famous Bernardo Pasquini, ... I heard with great excitement and amazement some concertos of the talented Arcangelo Corelli ... As I noticed the many contrasts in these pieces, I composed some of these present concertos, and I tried them out in the home of the above-mentioned Arcangelo Corelli ... and with his approval, I was the first to bring some samples of this hitherto unknown mixture to Germany, just as previously, upon my return from France, I was the first to introduce the Lullian Ballet style. ${ }^{6}$

Muffat's claim to be the first envoy of the Lullian style in the German states may be exaggerated, but the timing, from around 1670, is correct. His first publication of concertos in a true mixed style, after his time in Rome, was in 1682 as Armonico Tributo; recompositions of these works form part of the Auserlesene Instrumentalmusik.

Muffat was born in Alsace, a region with both German and French ties and a frequent victim of war before and during his lifetime. In the foreword to the Florilegium Primum (First Bouquet) of 1695, he expresses hope that cultural ventures like his own might lead to greater understanding between nations:

I dare not employ only a single style or method, but rather the most skilful mixture of styles I can manage through my experience in various countries. ... Since I had my start in France with the most experienced masters of this art in music, I realise that I could be accused of favouring that nation more than is appropriate, and in this time of war with France I could be considered unworthy of the kindly disposed ear of the Germans. ... as I mix the French manner with the German and Italian, I do not begin a war, but perhaps rather a prelude to the unity, the dear peace, desired by all peoples. ${ }^{7}$

The union of the French and the Italian styles, in which Muffat certainly played a part, rapidly became a defining feature of musical composition throughout Europe. A strong movement began within France, known as les goûts réunis (the combined tastes) and championed by François Couperin (1668- 1733), who coined the term. In 1725, Couperin composed l'Apothéose de Lully, in which he imagined a meeting between the two towering figures of the last generation, Lully and Arcangelo Corelli (16531713). In this musical fable, Apollo convinces the two musicians that the union of the French and the Italian styles will result in unprecedented musical perfection. ${ }^{8}$ Example 1.1 shows the opening phrases of the two violin duets which follow.

\footnotetext{
${ }^{6}$ Georg Muffat, Auserlesene Instrumentalmusik (Passau: publisher unknown, 1701), foreword, trans. David K. Wilson in Georg Muffat on Performance Practice (Bloomington, Indiana University Press, 2001), 71. The German title of this collection is commonly translated as Select Instrumental Music, but is perhaps better understood as Choice Instrumental Music.

${ }^{7}$ Georg Muffat, Florilegium Primum (Augsburg: Koppmayr, 1695), dedication, trans. Wilson, 13-14.

${ }^{8}$ François Couperin, L'Apothéose de Lully (Paris: engraved by Louis Hüe and published by the author, 1725), 12-15.
} 


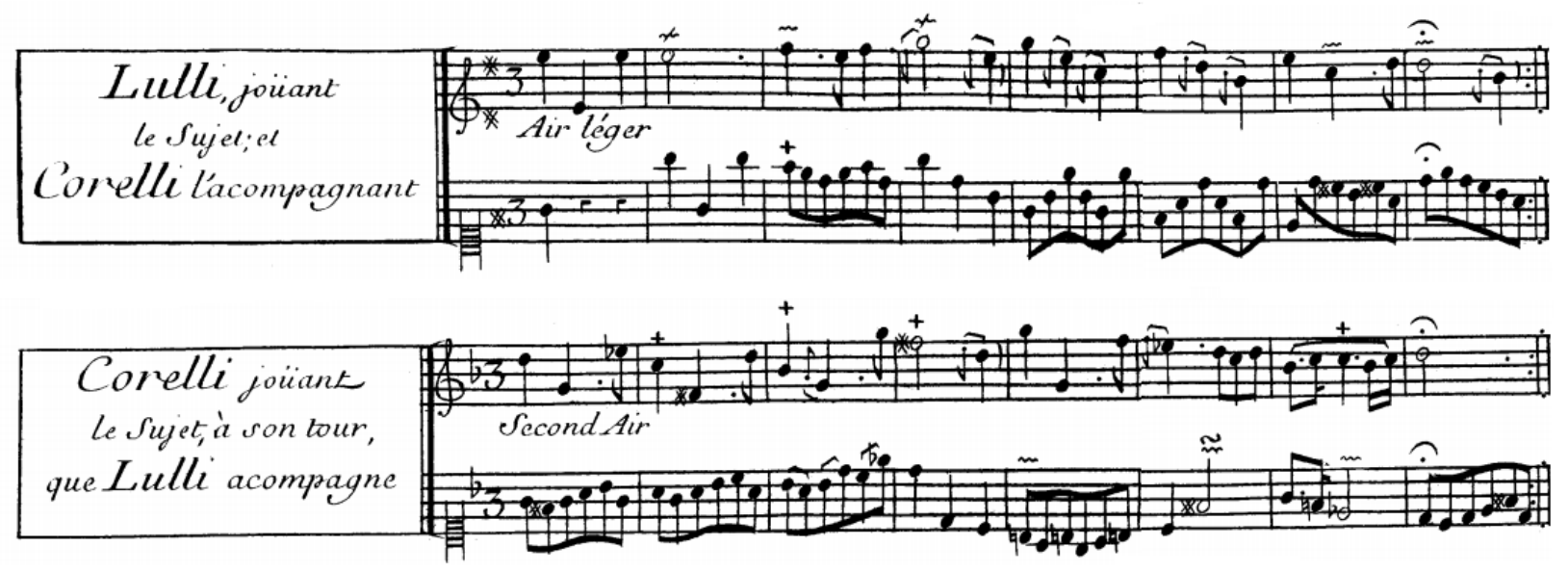

Couperin's 'Corelli' plays an arpeggiated accompaniment and a melody featuring diminished intervals and an iconic phrygian cadence. Lully's melody features such quintessentially French ornaments as the combination of lower appoggiatura and mordent in b. 4, and tierces coulées in bb. 5-6. His accompaniment is largely in conjunct quavers, suitable for inegalés treatment.

Musicians of the German-speaking states, as well as enjoying the advantages of a well-established publishing industry, were particularly well-placed to absorb the influences of the surrounding nations. Numerous German writers from 1710 onwards advocated the superiority of a style consisting of the best of the Italian and the French. ${ }^{9}$ By 1752, Quantz recognised this as a defining characteristic of German music:

If one has the necessary discernment to choose the best from the styles of different countries, a mixed taste results that, without overstepping the bounds of modesty, could well be called the German taste, not only because the Germans came upon it first, but because it has already been established at different places in Germany for many years, flourishes still, and displeases in neither Italy nor France, nor in other lands. ${ }^{10}$

Quantz considered the mixed style to be superior to either of its primary sources, and believed it to be exemplified by Telemann and G.F. Handel (1685-1759), naming the two most popular and successful composers of his lifetime. ${ }^{11}$ My focus on the former is partly due to the latter's choice of vocal and keyboard music as primary mediums. Telemann also blessed us with one of the finest examples of instrumental ornamentation of the period, in the form of the Methodical Sonatas for violin or flute, which feature in the third chapter of this thesis.

\footnotetext{
${ }^{9}$ Steven Zohn, in Music for a Mixed Taste: Style, Genre, and Meaning in Telemann's Instrumental Works (Oxford; New York: Oxford University Press, 2008), 3-4, names and cites Johann Mattheson, Ernst Gottlieb Baron, and Johann David Heinichen on the superiority of the mixed style.

${ }^{10}$ Johann Joachim Quantz, Versuch einer Anweisung die Flöte traversiere zu spielen (Berlin: Johann Friedrich Voß, 1752 ), trans. Edward R. Reilly as On Playing the Flute (New York: The Free Press; London, Faber \& Faber, 1966), chapter 18, par. 87 (hereafter 18/87).

${ }^{11}$ Edward R. Reilly, Quantz and his Versuch (New York: American Musicological Society, 1971), 62.
} 
The artistry with which Telemann combined the French and Italian, and also the English and Polish, with the German style was frequently described as one of his most distinctive skills. ${ }^{12}$ Telemann described this in his own libretto for a 1721 cantata:

The flattery of Italy's pieces,

That unrestrained liveliness

That flows from French songs;

Britain's leaping, obliging nature;

Yes, Sarmatia's [Poland] exquisite pleasure,

To which the notes' jesting is devoted:

German diligence combines all this

To the honour of its country,

All the more to please the listener here

Through pen, mouth and hand. ${ }^{13}$

This mixed style in which Telemann excelled was commonly referred to by German writers as the 'galant' style. This term, imported from France but used with similar frequency to discuss Italian music, had come to mean flattering and elegant. Galant music was periodic and song-like in melody and simple in harmony, with a clear division between soloist and accompaniment. C.P.E. Bach repeatedly distinguished between the galant and 'learned' styles, while Heinrich Koch and Daniel Gottlob Türk contrasted the galant and 'strict', setting galant music apart from the more contrapuntal forms of what is now known as the Baroque style. ${ }^{14}$

The genesis and development of the mixed style had a huge influence on the music of the $18^{\text {th }}$ century and beyond, and its effects naturally reach far beyond the scope of this thesis. Quantz relates the matter of the mixed style back to ornamentation:

The Adagio may be viewed in two ways with respect to the manner in which it should be played and embellished; that is, it may be viewed in accordance with the French and Italian style. The first requires a clean and sustained execution of the air, and embellishment with the essential graces, such as appoggiaturas, whole and half-shakes, mordents, turns, battemens, flattemens, etc., but no extensive passage-work or significant addition of extempore embellishments. $\ldots$ In the second manner, the Italian, extensive artificial graces that accord with the harmony are introduced in the Adagio in addition to the little French embellishments. ... With good instruction the French manner of embellishing the Adagio may be learned without understanding harmony. For the Italian manner, on the other hand, knowledge of harmony is indispensable, or, as is the mode with most singers, you must keep a master constantly at hand from whom

\footnotetext{
${ }^{12}$ Zohn, in Music for a Mixed Taste, 4, names and cites Johann Christoph Gottsched, Johann Adolf Scheibe, and Johann Mattheson on Telemann's mastery of the mixed style.

${ }^{13}$ G.P. Telemann, Wie? Ruhet ihr, versteckte Saiten? (TWV 20:13, 1721, music lost), trans. Zohn, Music for a Mixed Taste, 4.

${ }^{14}$ Carl Philipp Emanuel Bach, Versuch über die wahre Art das Klavier zu spielen (Berlin: Christian Friedrich Henning, 1753); Heinrich Koch, Musikalisches Lexicon (Frankfurt: August Hermann, 1802), trans. Leonard G. Ratner in Classic Music: Expression, Form and Style (New York: Schirmer Books, 1980), 23; Daniel Gottlob Türk, Anweisung zum Generalbassspielen (Leipzig and Halle, 1791). The terms galant and 'mixed' are unusual in being used frequently and positively within the periods which they actually described. In this respect they differ from 'Baroque', which was used only from the 1730s and then only as a pejorative. 'Renaissance' and 'Classical' were both applied retrospectively from the $19^{\text {th }}$ century.
} 
you can learn variations for each Adagio; and if you do this, you will remain a student all your life, and will never become a master yourself. But you must know the French manner before you venture upon the Italian. Anyone who does not know ... how to introduce the little graces at the correct places ... will have little success with the large embellishments. And it is from a mixture of small and large embellishments that a universally pleasing, reasonable and good style in singing and playing arises. ${ }^{15}$

The style that Quantz describes as ideal combines small, defined, French ornaments with larger and freer Italian 'diminutions' or variations. ${ }^{16}$ These two components of good embellishment are the subjects of the internal chapters of this thesis. In accordance with Quantz's advice, I first investigate the small 'Essential Ornaments' before venturing into the broader subject of 'Extempore Variation'.

\footnotetext{
${ }^{15}$ Quantz, Versuch, 14/2-3. Slow movements, commonly referred to as 'adagios' regardless of actual tempo indication, naturally allow greater scope for ornamentation than fast.

${ }^{16}$ Quantz in fact defines the Italian style as containing both of these - the Italian style which he had in mind may well have been a 'mixed' style. Regardless of terminology, Quantz's ideal style is clearly defined.
} 


\section{Essential Ornaments}

This chapter explores laws, rules and suggestions for the usage of common $18^{\text {th }}$-century ornaments. The focus of this chapter is the introduction of defined ornaments where none are written, although to be of practical use, it is also necessary to cover the execution of these ornaments. This field has already been well excavated, although disagreements persist on many issues.

It is an unfortunate truth, as Robert Donington warns, that

[ornament] signs, the names attached to them and the interpretation allotted to them all show an extreme inconsistency, and the reader is warned that the same sign or the same name may have many different meanings in different sources, indeed often in the same source.

While taxonomy and the meaning of symbols are not explicitly related to my purpose, these issues often complicate the interpretation of contemporary records. It is tempting to take Donington at his word when he goes on to assure us that

[m] uch of this inconsistency cancels itself out, however, and it is not impossible to trace certain principles fundamental enough to give the musician what he chiefly needs: a clear account of the standard practices underlying the countless variations of detail. These standard practices are adequate to ninety-nine situations out of a hundred. ${ }^{17}$

Donington's works are peppered with similar assumptions of common practices across regions, schools, nations, and centuries. In a remark directed implicitly at Donington, Frederick Neumann laments that

[t]he prevailing standard procedure [of deriving rules from Baroque treatises] ... has been one borrowed from medieval theology rather than from modern jurisprudence; it consists in simply quoting chapter and verse of a single treatise and considering the evidence established, the case proved, and any further doubt proscribed to heresy. ${ }^{18}$

In limiting the scope of this thesis to the German instrumental mixed style from Muffat to Telemann, I already have an easier task than either Donington or Neumann. However, even within this field, a plurality of practice is clearly in evidence. Within the space available, I aim to present the opinions of all theorists with relevance to this style, and to reconcile these opinions to the greatest possible degree while avoiding such academic sins as those described above.

Muffat himself provides a concise, informative, and very French-oriented chapter on ornaments in the foreword to Florilegium Secundum of 1698. ${ }^{19}$ Johann Mattheson's section on ornaments in his 1739 treatise Der Vollkommene Capellmeister is the only significant resource between Muffat's directions

\footnotetext{
${ }^{17}$ Robert Donington, The Interpretation of Early Music ('New Version', London: Faber and Faber, 1974$), 189$.

${ }^{18}$ Frederick Neumann, 'The use of Baroque treatises on musical performance', Music and Letters, Vol. 48 , No. 4 (October 1967), 317.

${ }^{19}$ Georg Muffat, Florilegium Secundum (Passau: publisher unknown, 1698), trans. David K. Wilson in Georg Muffat on Performance Practice (Bloomington: Indiana University Press, 2001), 24-65.
} 
and the so-called 'triad' of mid-century treatises. ${ }^{20}$ This consists of the Essays of Johann Joachim Quantz (1752), Leopold Mozart (1756), and C.P.E. Bach (1753). ${ }^{21}$ Hereafter in this thesis, 'Mozart' and 'Bach' will refer to these theorists and not to the better-known members of their immediate families.

Quantz, writing for the flute, was the most French-oriented of the three, while Mozart's text for the violin was heavily influenced by the Italian master Giuseppe Tartini's Treatise on Ornaments (c. 1752$6){ }^{22}$ Bach's focus on keyboard instruments makes his work less explicitly relevant to this thesis, but his very thorough treatise adds many details not found elsewhere. His work also heavily influenced later German writers, including Johann Friedrich Agricola and Daniel Gottlob Türk. Agricola's main contribution to history is the 1757 German translation, with extensive commentary, of Pier Francesco Tosi's 1723 Opinioni on singing; a very rare early example of a full-length Italian treatise. ${ }^{23}$ Türk's $^{2}$ Klavierschule of 1789 brings together the pedagogical efforts of his predecessors, although its relevance to the music of a half-century earlier must naturally be questioned. ${ }^{24}$

Francesco Geminiani is representative of a rather personal mixed style incorporating Italian, French and English aspects. As is the case with this thesis' titular musicians, Geminiani's nationality is secondary to the 'mixed' nature of his style. For this reason, and the paucity of resources for string players, I count his Art of playing on the Violin of 1751 among my primary references. ${ }^{25}$

\section{Ornament Function}

Robert Donington's discussion of individual ornaments puts considerable emphasis on the function of each ornament. He identifies three overlapping functions, distilled out of a statement from C.P.E. Bach's Essay. Ornaments, Bach says, serve to

join notes; they enliven them ... they give them emphasis and accentuation ... they bring out their expression. ${ }^{26}$

\footnotetext{
${ }^{20}$ Johann Mattheson, Der Vollkommene Capellmeister, (Hamburg: Christian Herold, 1739), trans. Ernest C. Harriss as Johann Mattheson's Der Vollkommene Capellmeister: A Revised Translation with Critical Commentary (Michegan: UMI Research Press, 1981).

${ }^{21}$ Carl Philipp Emanuel Bach, Versuch über die wahre Art das Klavier zu spielen (Berlin: Christian Friedrich Henning, 1753), trans. William J. Mitchell as Essay on the True Art of Playing Keyboard Instruments (New York: W. W. Norton \& Co, 1949); Johann Joachim Quantz, Versuch einer Anweisung die Flöte traversiere zu spielen (Berlin: Johann Friedrich Voß, 1752), trans. Edward R. Reilly as On Playing the Flute (New York: The Free Press; London: Faber \& Faber, 1966); Leopold Mozart, Versuch einer gründlichen Violinschule (Augsburg: Johann Jacob Lotter, 1756), trans. Editha Knocker as A Treatise on the Fundamental Principles of Violin Playing (Oxford; New York: Oxford Univeristy Press, 1951).

${ }^{22}$ Guiseppe Tartini, Treatise on Ornaments in Music (originally unpublished, c. 1752-56). English translation by Erwin R. Jacobi (Celle; New York: Moeck Verlag, 1961) from 1771 French edition by P. Denis (Traité des Agréments de la Musique). Jacobi proposes (39) the date of authorship based on extensive references in Leopold Mozart's 1756 Essay, and the absence of any such references in Quantz's 1752 Essay, despite the acquaintance of the writers.

${ }^{23}$ Johann Friedrich Agricola, Anleitung zur Gesangkunst (Berlin: George Ludewig Winter, 1757); translation and commentary on Pier Francesco Tosi's Opinioni de'cantori antichi e moderni o sieno osservazioni sopra il canto figurato (Bologna: publisher unknown, 1723). English translation of Agricola by Julianne Baird as Introduction to the Art of Singing (Cambridge: Cambridge University Press, 2006).

${ }^{24}$ Daniel Gottlob Türk, Klavierschule (Leipzig: Schwickert; and Halle: Hemmerde und Schwetschke; 1789), trans. Raymond H. Haggh as School of Clavier Playing (Lincoln: University of Nebraska Press, 1983).

${ }^{25}$ Francesco Geminiani, The Art of Playing on the Violin (London: publisher unknown, 1751).

${ }^{26}$ Bach, Versuch, 79, trans. Donington, Interpretation, 194.
} 
Donington states that melodic ornaments, such as the turn and tirata, "join notes" and "enliven them". Such figures tend to be unaccented, falling between beats, and be long enough to fill out a significant amount of the original note. Rhythmic ornaments are those which "give them emphasis and accentuation". He gives the mordent, slide and acciaccatura as examples. Finally, harmonic ornaments such as appoggiaturas and cadential trills "bring out their expression".

The identification of function is extremely important to the fundamental question of this chapter, and I have found Donington's threefold division to be a very useful starting point. However, there are several ways in which it can be refined.

Harmonic ornaments are the least problematic, although it is unhelpful to apply the term 'expressive' to this family alone, as expression is surely the primary function of all ornaments.

'Joining' and 'enlivening' are two very different things. The first is a relatively simple case, and ornaments whose primary function is to join notes can conveniently be called connective, a term used by Neumann. ${ }^{27}$ Ornaments of this type are generally unaccented and connect notes by pitch, rhythm, or both. Examples include trills, passing notes, and the aforementioned tirata.

Ornaments that 'enliven' notes overlap in part with those that give emphasis and accentuation. The mordent, slide, and others of a similar nature can simply be called accentuating. A few longer and less crisp ornaments, such as the turn, fall between this group and the connective family. Overlaps naturally abound, and this will be expanded over the course of this chapter.

While these three terms lack the rhetorical quality of Donington's triptych, I believe that they more accurately describe the purposes of the different types of ornaments.

\footnotetext{
${ }^{27}$ For example, in Ornamentation, 47-48.
} 


\section{Grace notes}

The German terms Vorschlag and Nachschlag are commonly translated as 'appoggiatura' and 'termination' respectively. In the latter case, this is a reasonable translation of what literally means 'after-strike'. However, where the Italian appoggiatura derives from the word 'to lean', the German Vorschlag translates as the more general 'pre-strike'. I will therefore use Vorschlag and Nachschlag as primary terms. Both words will be used without italics hereafter, while retaining their original plural forms. Due to the modern confusion about the exact meaning of 'appoggiatura', I have found it best to avoid the word completely. ${ }^{28}$

\section{Execution}

Unravelling issues of the length of different types of Vorschläge, and their placement within the beat, is a task far too large for the purpose of this chapter. I will therefore structure this section around the differentiation of ornament function.

Most grace notes create dissonance which then resolves onto the original note. However, for this dissonance to have effect, the note must be relatively long and on the beat. In its mid-century German form, this harmonic Vorschlag took the value of half of a binary note, two-thirds of a ternary note, and all of a tied one. ${ }^{29}$

It is commonly taught that harmonic Vorschläge must be played louder than the main note which follows. This increases the tension of the dissonant ornament while highlighting the resolution onto the consonant main note. In addition to this rule, it was widely agreed that where length allows, the ornament must be performed with a dynamic swell. Agricola describes this execution most concisely:

[E]ach Vorschlag, whether long or short ... must always be more loudly performed than its main note which follows. The discretion of the performer dictates how much louder ... If the Vorschläge are long, they should start softer and become louder like all long notes of a melody, and thereafter diminish as they are slurred onto the main note. ${ }^{30}$

A very short, crisp Vorschlag functions as an accent. Bach, Türk and other like-minded writers left no doubt that this accentuating Vorschlag should fall directly on the beat. ${ }^{31}$ However, Mozart

\footnotetext{
${ }^{28}$ Clive Brown, in Classical and Romantic Performance Practice (Oxford; New York: Oxford University Press, 2004), 459, defines an appoggiatura as a one-note conjunct grace which takes a significant amount of time from the note it precedes, in the manner of my harmonic Vorschlag. However, other writers commonly allow a much wider interpretation, such as the English translation of the German Vorschlag found in all three of the mid-century treatises listed above. In modern practice, small notes are widely considered to be either appoggiaturas or acciaccaturas. While this division does have an implication for performance, it is primarily a notational distinction, dependent only on the presence or absence of a cross-stroke. It is for these reasons that I have chosen to avoid the term.

${ }^{29}$ Donington, Interpretation, 201-04, provides a list of references for these rules, and also for a fourth rule regarding the performance of Vorschläge which decorate a note immediately before a rest. In this case, the Vorschlag may take the entire length of the note, displacing the main note to the rest. This may in some situations be a valid interpretation, although as Donington himself points out, it is often rendered impossible or undesirable by harmonic or rhythmic context.

${ }^{30}$ Agricola, Anleitung, 97. See also Bach, Versuch, 88, Mozart, Versuch, 9/8; Geminiani, Art, preface, ex. 18; Quantz, Versuch, 8/4; Tartini, Traité, 4-5.

${ }^{31}$ Bach, Versuch, 91: “...played so rapidly that the main note loses scarcely any of its length”; Türk, Klavierschule, 3/3/20:
} 
recommends achieving accentuation by performing the Vorschlag quietly, allowing the stress to fall on the main note. ${ }^{32}$ This implies pre-beat performance - an interpretation supported by Quantz, who apparently presents both on-beat and pre-beat examples of the ornament. He describes example a) of ex. 2.1 as depriving the main note of none (i.e., as little as possible) of its value, while the pre-beat execution of example b) is explicitly notated. ${ }^{33}$

\section{Ex. 2.1: Quantz's on-beat and pre-beat accentuating Vorschläge}
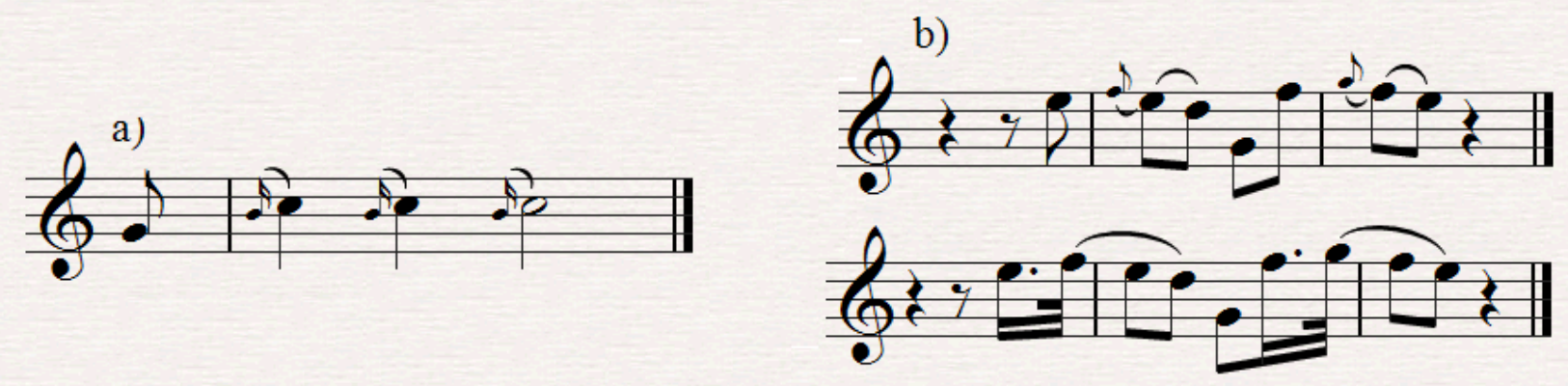

Grace notes of significant length which fall between beats are primarily connective ornaments. These may belong to, and be slurred to, either the preceding or the following note, although they always take time from the preceding note.

It is often far from explicit which of the above three ornaments is intended. It is fairly orthodox to apply the mid- $18^{\text {th }}$-century view of the dominance of the long, harmonic Vorschlag to a century or more either side. ${ }^{34}$ Neumann concludes that long Vorschläge were more suited to the galant style than the more contrapuntal Baroque, and proposes that short and pre-beat executions were far more common in the $17^{\text {th }}$ and early $18^{\text {th }}$ centuries than is currently accepted. ${ }^{35}$

Overlaps naturally exist between each of these three functions. For example, Bach's own 'invariable' (accentuating) Vorschlag could take a smoother, longer and therefore more harmonic character in slow movements. ${ }^{36}$ Similarly, Muffat's Vorschläge in ex. 2.2 are in most cases shown to occupy one quarter of the value of the following note. ${ }^{37}$ Both of these blur the line between harmonic and accentuating graces.

\footnotetext{
“invariable [short] Vorschläge receive only a very small and almost imperceptible part of the value of the main note." See also Agricola, Anleitung, 102.

${ }^{32}$ Mozart, Versuch, 9/9.

${ }^{33}$ Quantz, Versuch, 8/2 and 6 (figs. 25, 9, 10).

${ }^{34}$ Donington, Interpretation, 201, for example.

${ }^{35}$ Neumann, Ornamentation in Baroque and Post-Baroque Performance (New Jersey: Princeton University Press, 1978). Neumann returns to this point throughout the chapter on one-note graces (47-199, summarized on the final page). He attributes the modern narrow view of the dominance of the on-beat execution to a disproportionate respect for the individual opinion of C.P.E. Bach, due at least in part to his proximity to his father.

${ }^{36}$ Bach, Versuch, 92. See also Agricola, Anleitung, 102.

${ }^{37}$ Muffat, F. secundum, 49.
} 


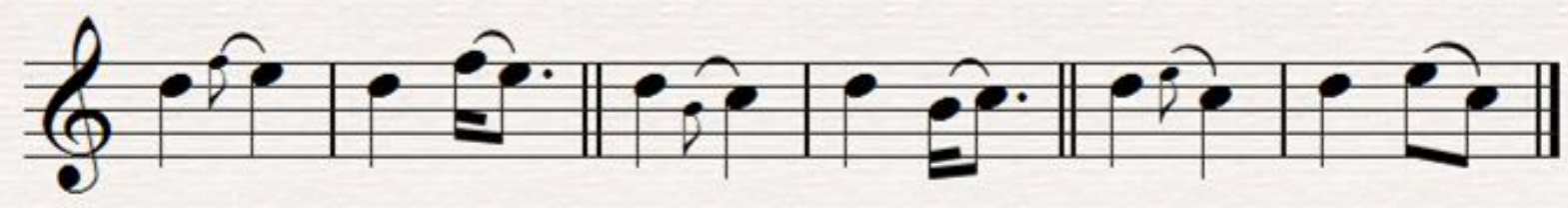

\section{Harmonic Vorschläge}

Few $18^{\text {th }}$-century writers were content to simply describe the execution of notated ornaments. The trend towards more thorough notation of ornaments and other expressive devices gained momentum throughout the century, but most performance treatises up to and including Türk's Klavierschule included detailed rules on the introduction of basic ornaments including Vorschläge. Quantz states that

[i]t is not enough to be able to play the different types of Vorschläge with their proper values when they are marked. You must also know how to add them at the appropriate places when they are not indicated. To learn this, make the following rule your guide: if a long note follows one or more short notes on the downbeat or upbeat, and remains in a consonant harmony, a Vorschlag may be placed before the long note, in order to constantly maintain the agreeability of the melody. The preceding note will show whether it must be taken from above or below. ${ }^{38}$

The last sentence of the above quotation is unusual, but Quantz does indeed advocate its literal execution in regards to harmonic Vorschläge. In examples throughout his treatise, a note approached from below receives a lower Vorschlag, and vice versa. ${ }^{39}$ Most writers allow conjunct upper Vorschläge, where otherwise appropriate, regardless of the direction of motion.

Ascending Vorschläge of more than minimal length are problematic harmonically. Most grace notes are dissonant, and dissonance should, according to the rules of the common practice period, resolve downwards. An exception can be made if the ornament is a repetition of the previous note - a rearticulated suspension. In such cases, some writers allow ascending Vorschläge even when these are far removed from their main notes. ${ }^{40}$ In ex. 2.3, Bach illustrates rules regarding the pitch of Vorschläge in relation to the preceding and following notes. Throughout Bach's treatise, small notes are given with their exact value.

\footnotetext{
${ }^{38}$ Quantz, Versuch, 8/12. The introduction of a harmonic Vorschlag on a note that is longer than those it follows also comprises Türk's first rule (Klavierschule, 3/1/5). Tartini, Traité, 5, states that the ornamented note should be longer than those it precedes: "This main note should be longer than the one that follows it, because long grace notes do not sound well with notes of equal length". The two are, of course, not mutually exclusive.

${ }^{39}$ Quantz, Versuch, chapter 8, figs. 25, 4, 11, 17, 26, chapter 13, figs. 6, 8, 25, etc.

${ }^{40}$ Muffat, F. Secundum, 50 (fig. ZZ); Mozart, Versuch, 9/15; Bach, Versuch, 87-88 (fig. 69).
} 

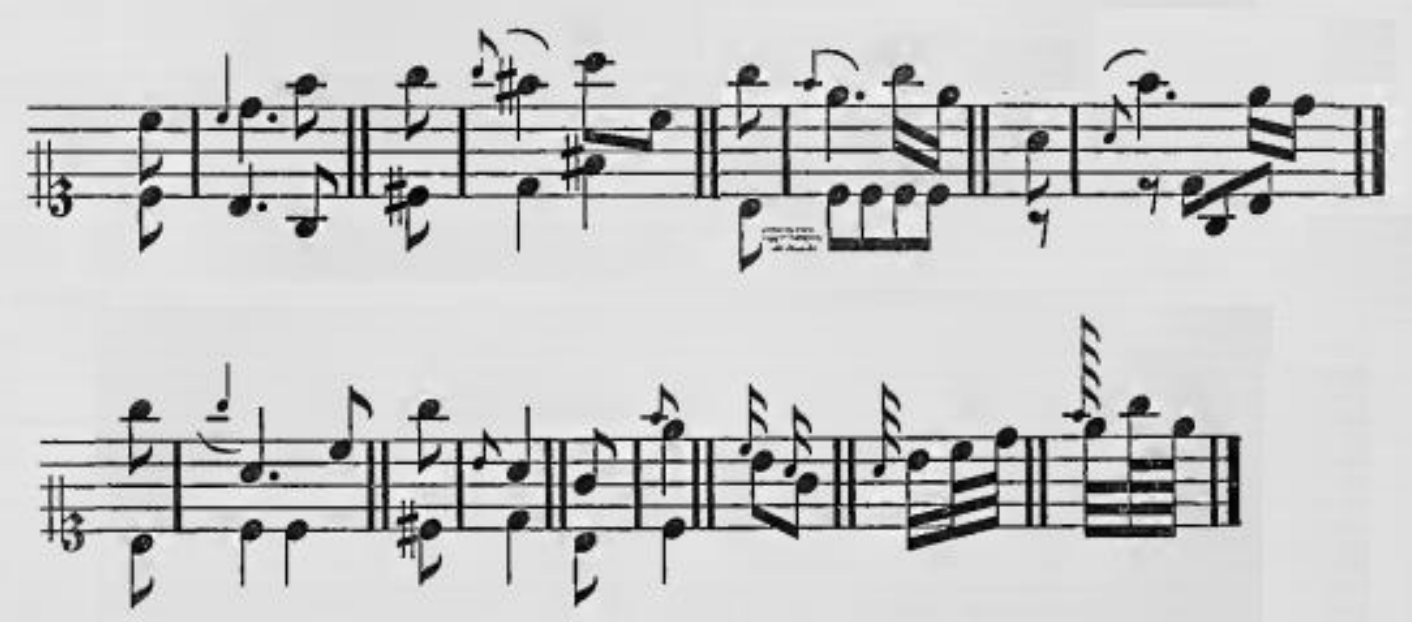

It can be seen in this example that both ascending and descending Vorschläge must either repeat the previous tone or move by step to the following. Bach's leaping examples feature sixths and sevenths, although fourths and fifths are also recommended in other sources. ${ }^{41}$

The harmonic issues of ascending Vorschläge are most obvious when these are a whole tone below the principal note. Mozart offers several solutions to this issue. Examples 2.4 and 2.5 both feature the more satisfying and generally consonant third below the main note. ${ }^{42}$ This ornament is also known as a 'slide', Schleifer or conjunct double Vorschlag, and features later in this chapter.

\section{Ex. 2.4: Mozart's suggested embellishment of rising Vorschläge}

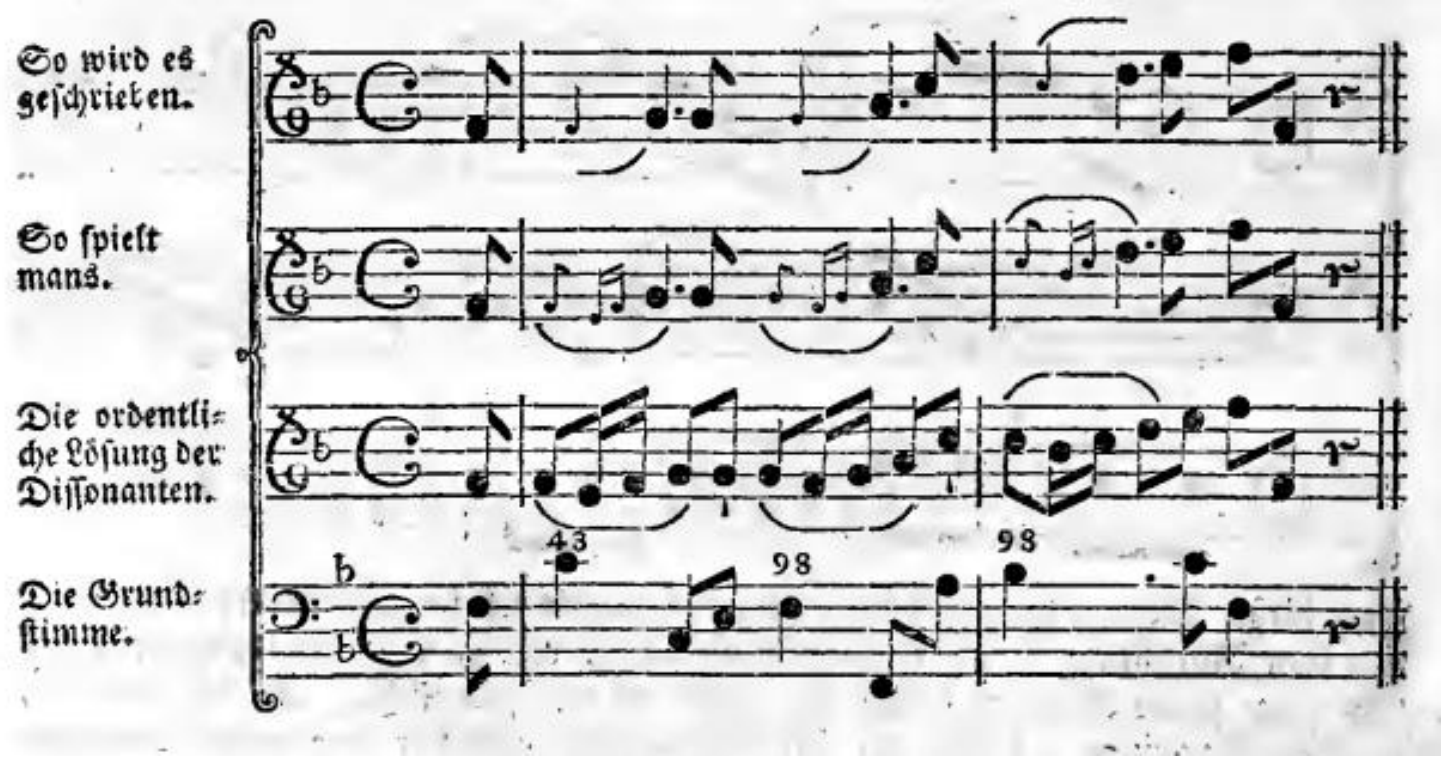

\footnotetext{
${ }^{41}$ Mattheson, Der Vollkommene Capellmeister, part 2, chapter 3, pars. $24-25$ (hereafter 2/3/24-25) and Muffat, F. Secundum, 50,55 (figs. $\mathrm{ZZ}$ and $\mathrm{Tt}$ ) recommend fourths, fifths and sixths.

${ }^{42}$ Mozart, Versuch, 9/10-11.
} 


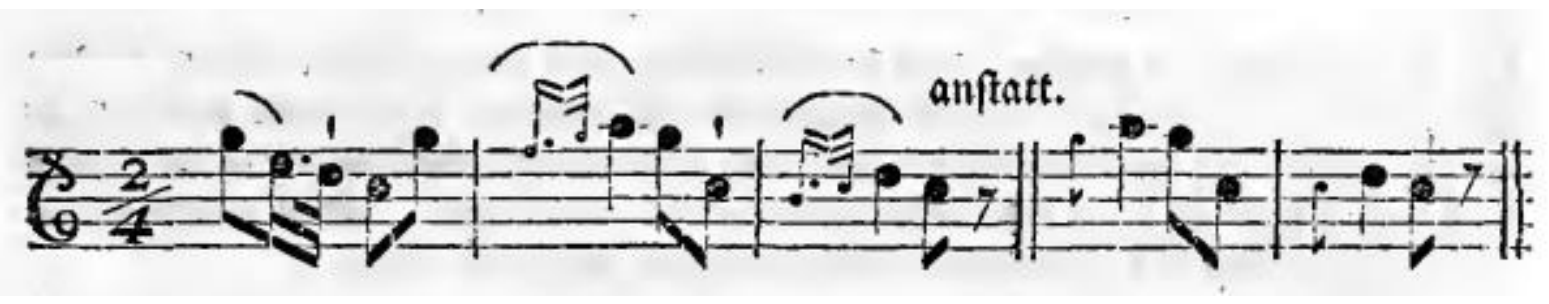

Rising Vorschläge of a semitone can be far more commonly found than those of a whole tone. Mozart attributes this to the laws of harmony and to nature itself.

Reason and hearing convince us therefore that a long Vorschlag consisting of a rising whole tone, played as it is written, rarely sounds well, but that the semitone Vorschlag always does so - because ... it is resolved according to rule. $^{43}$

In Mozart's example in ex. 2.6, the Vorschlag is chromatically raised, artificially creating an interval of a semitone. Such chromaticism can be found relatively frequently in the mid- $18^{\text {th }}$ century, but has few precedents and should not, without further investigation, be applied to earlier music.

\section{Ex. 2.6: Mozart's chromatically raised Vorschläge}

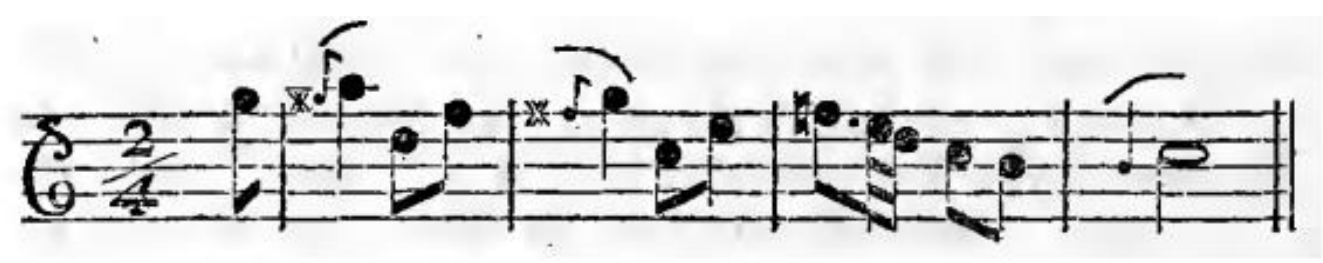

The addition of a mordent after a rising Vorschlag was so ubiquitous, at least in France, as to practically be a defined ornament in its own right. This combination is discussed further under the coming section on mordents.

The addition of a Vorschlag after a trill appears to have been a contentious issue, although an ascending Vorschlag was more commonly allowed than a descending one. Some writers allowed a Vorschlag in either direction, provided the trilled note also received its own Vorschlag. This creates a pleasing rhythmic symmetry between the two cadential notes. In Agricola's example in ex. 2.7, the first cadence is "incorrectly" embellished, while the latter three are acceptable. ${ }^{44}$ Quantz described a cadence such as the former as an offence so serious that it would cause the player to "be immediately enlisted among the musical rabble, since this error is never committed by a person of refined taste." 45

\footnotetext{
${ }^{43}$ Mozart, Versuch, 9/13-14.

${ }^{44}$ Agricola, Anleitung, 111. Agricola's views are near identical to those of Bach (Versuch, 88 and 97).

${ }^{45}$ Quantz, Versuch, 9/13, dislikes an ascending Vorschlag after a trill only slightly less than a descending one, while Mozart, Versuch, 10/12, was categorically against combining the two ornaments.
} 


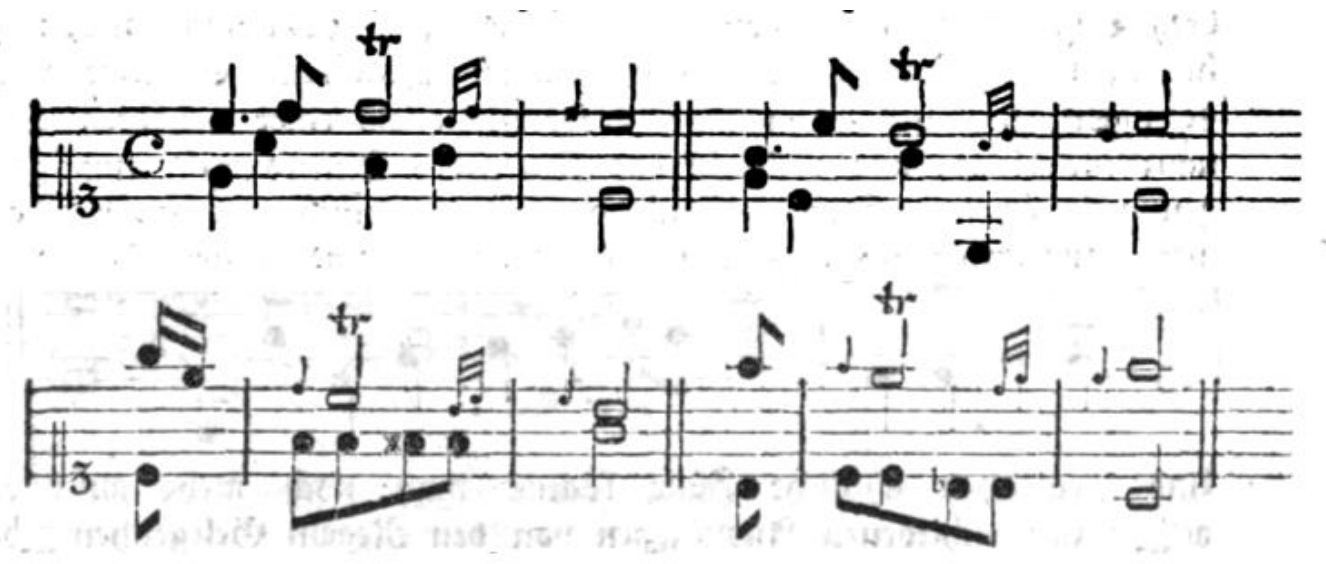

\section{Accentuating Vorschläge}

The rules concerning the introduction of accentuating Vorschläge are less strict than those for the longer variety. Agricola explains that these brief ornaments sometimes belong to the previous chord, but are at other times unrelated. He illustrates this point with the example in ex. 2.8. Although he does not draw attention to this fact, the example also demonstrates that upper accentuating Vorschläge are suitable on strong beats followed by lower and often shorter notes, whether the ornamented note is the same as (a), higher than (b), or lower than (c) the preceding. ${ }^{46}$

Ex. 2.8: Agricola's usage of accentuating Vorschläge

${ }^{46}$ Agricola, Anleitung, 99-100. 


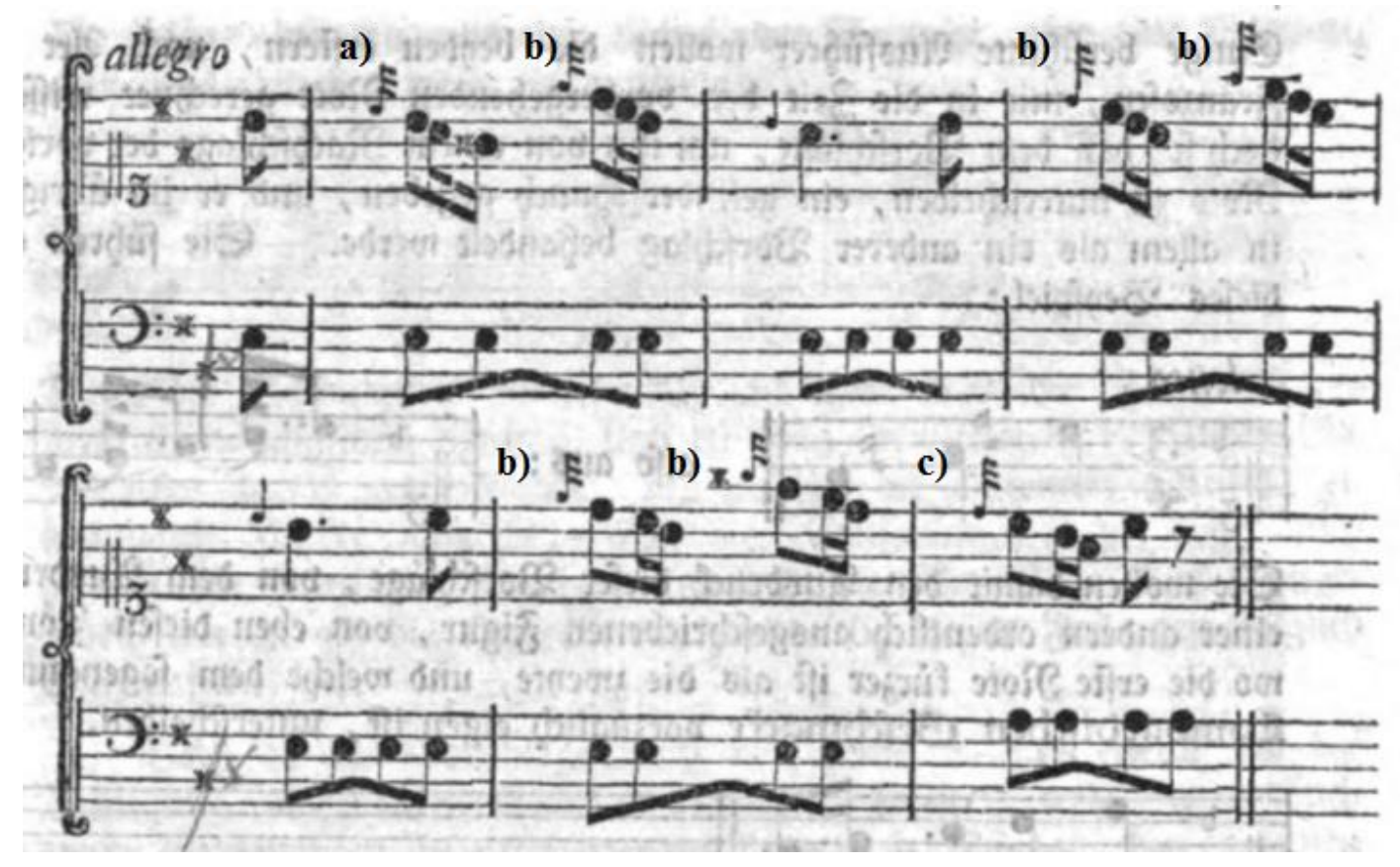

Bach recommends the addition of an accentuating Vorschlag after a conjunct ascent and before a conjunct descent - that is to say, on the highest note of a stepwise rising and falling line. ${ }^{47}$ This very common occurrence, illustrated throughout ex. 2.9 below, can also be found twice in Agricola's example above in ex. 2.8.

\section{Ex. 2.9: Bach's accentuating Vorschläge}

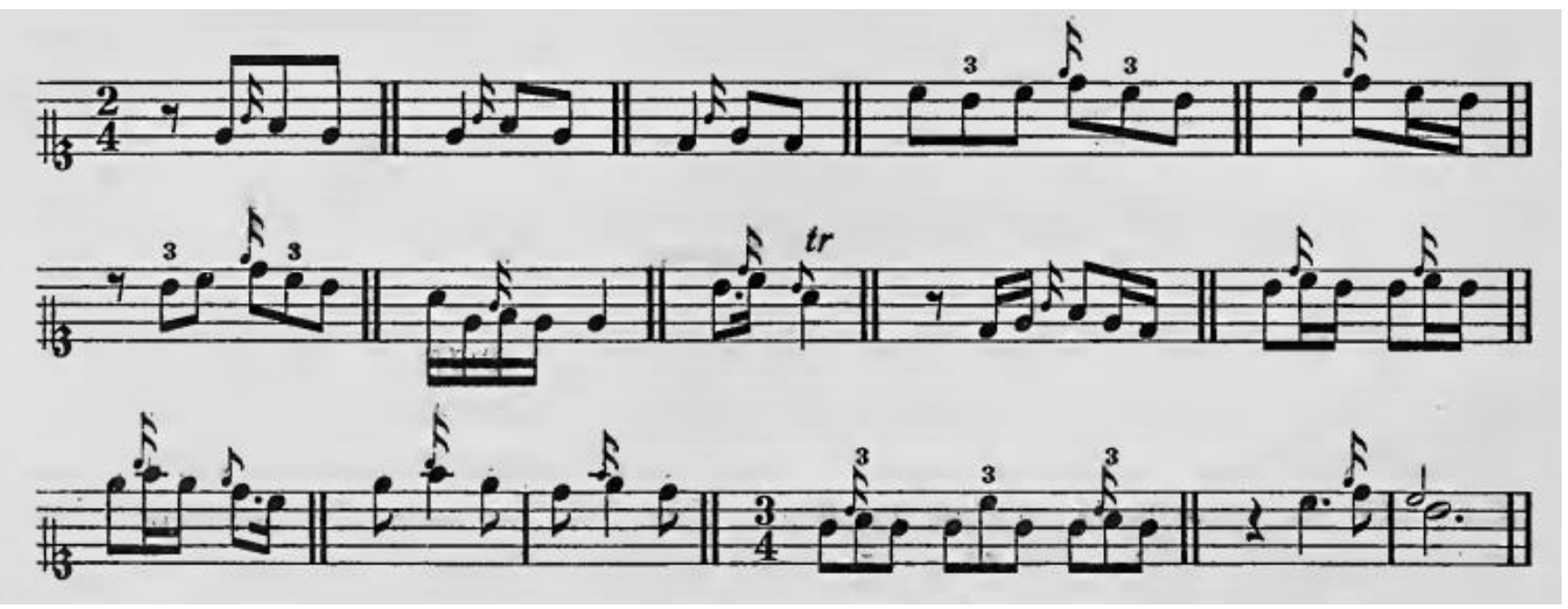

Ascending short Vorschläge (along with the more common descending variety) are often used to accent repeated notes. ${ }^{48}$ This ornament is particularly useful on instruments such as the harpsichord that must explore options other than dynamic accentuation.

The accentuating function of the short Vorschlag lends it to lively pieces. Only Tartini went so far as to prescribe short Vorschläge exclusively for "allegros, or at most those marked andante cantabile",

\footnotetext{
${ }^{47}$ Bach, Versuch, 93.

${ }^{48}$ Quantz, Versuch, 8/2; Bach, Versuch, 91 (fig. 76b); Türk, Klavierschule, 3/3/21.
} 
leaving long Vorschläge for "slow, mournful pieces". 49

\section{Connective Graces}

Single-note graces that fall between beats are of two varieties. Durchgehende (passing) Vorschläge are those that are slurred to the following, as in ex. $2.10 .^{50}$ This ornament overlaps in some instances with the accentuating Vorschlag, which may also be performed before the beat. Nachschläge are slurred to the preceding note, as in ex. 2.11. ${ }^{51}$ The placement of the slur, which throughout the $18^{\text {th }}$ century implied a slight decay in volume, has a significant effect on the rhythm and expression.

Ex. 2.10: Mozart's durchgehende Vorschläge filling in descending thirds

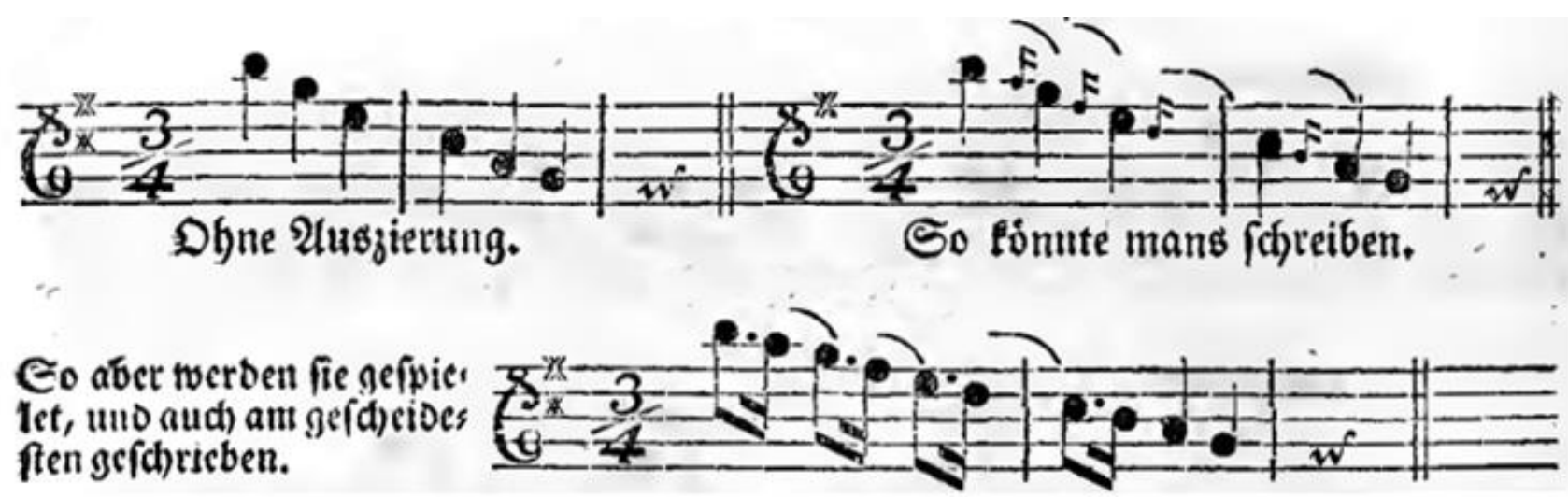

Ex. 2.11: Muffat's Nachschläge may rise or fall by step or move by leap

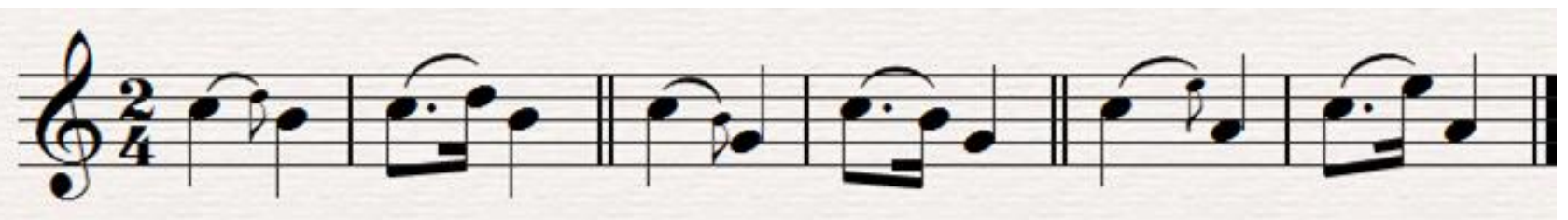

The serial examples in ex. 2.10 of the ornament known as the coule de tierce demonstrates one of the most iconic applications of single-note connective graces. Quantz advocated using such pre-beat Vorschläge wherever ambiguously notated grace notes fill in a series of descending thirds. ${ }^{52}$

\footnotetext{
${ }^{49}$ Tartini, Traité, 8.

${ }^{50}$ Mozart, Versuch, 9/17. The German text in ex. 2.10 reads "Without embellishment; One could write it so; But it is played thus, and should also be written [in large notation].

${ }^{51}$ Muffat, F. Secundum, 49 (fig. YY).

${ }^{52}$ Quantz, Versuch, 8/6: "[long on-beat Vorschläge] would be opposed to the French style of playing, to which these Vorschläge owe their origin". Agricola, Anleitung, 101, also mentioned that "some famous performers" sang the Vorschläge in the time of the preceding note.
} 
Nachschläge such as those in Muffat's ex. 2.11 above are the focus of a particularly heated passage in Bach's treatise, in which he laments that these "repulsive" Nachschläge were "exceptionably fashionable". He objected most strongly to the pre-beat rendition of notated Vorschläge, but also condemned the addition of any single-note Nachschläge. ${ }^{53}$ However, despite his influence, Bach did not successfully eradicate either the single-note Nachschlag or durchgehende Vorschlag from German musical practice. Türk, who was heavily influenced by Bach, devotes a chapter to Nachschläge. ${ }^{54}$ The example in ex. 2.12 includes varieties of the 'accent', a rising, conjunct ornament which also features as Muffat's first example in ex. 2.11 above; ascending and descending two-note Nachschläge which most commonly occur after another ornament; and the ubiquitous coulé de tierce. ${ }^{55}$

\section{Ex. 2.12: Türk's Nachschläge}

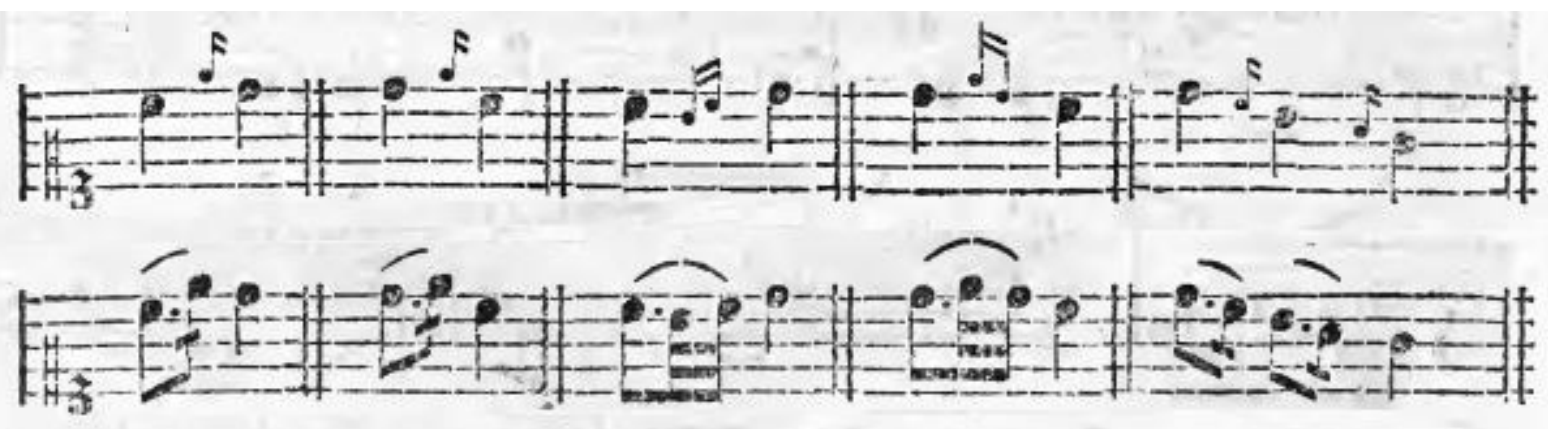

Mattheson recommends the addition of an accent before a falling leap in order to express plaintiveness or humility. He describes a performance in Hamburg in which this ornament was used as in ex. 2.13 to great expressive effect. ${ }^{56}$

\section{Ex. 2.13: Mattheson's illustration of an effective use of the 'accent'}

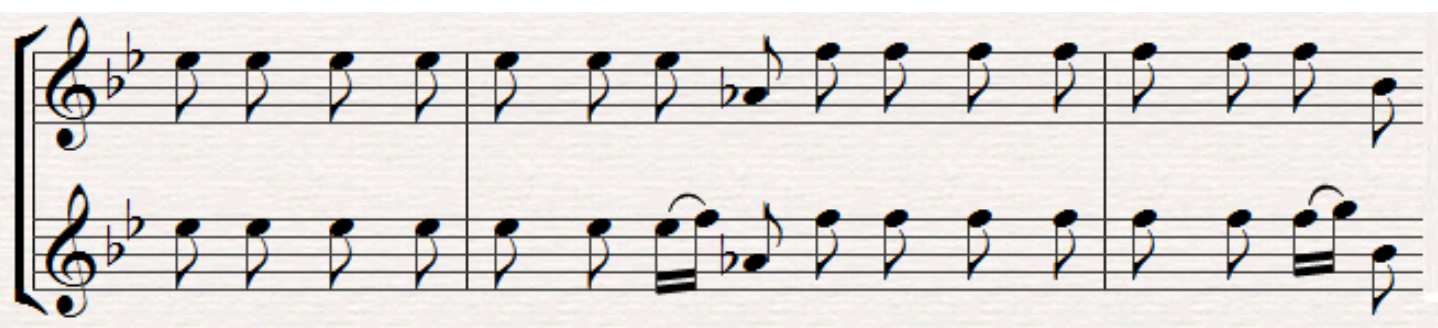

Ich will mich demSchicksal beu-gen, ich will mich demSchicksal beu-gen

\footnotetext{
${ }^{53}$ Bach, Versuch, 97-98 (fig. 88).

${ }^{54}$ Türk, Klavierschule, chapter 3, part 4. Example from par. 27. Türk explains that small notes such as those found in the top stave of ex. 2.12 can be interpreted as either Vorschläge or Nachschläge, and presents both executions. I have only reproduced the Nachschlag examples.

${ }^{55}$ The 'accent' was apparently often used to ornament each of a series of stepwise descending notes, a practice which both Bach (Versuch, 98-99) and Türk (Klavierschule, 3/4/31) considered to be in bad taste.

${ }^{56}$ Mattheson, Der Vollkommene Capellmeister, 2/3/26. This example, which translates approximately to "I will bow down to fate", represents what was sung by Madame Kaiser at the Hamburg Cathedral.
} 
Another two common patterns are mirror images of one another. Muffat advocates the use of a Nachschlag which anticipates the following pitch (ex. 2.14), while Mozart's only other example features durchgehende Vorschläge which repeat the previous note (ex. 2.15). ${ }^{57}$

\section{Ex. 2.14: Muffat's anticipations}

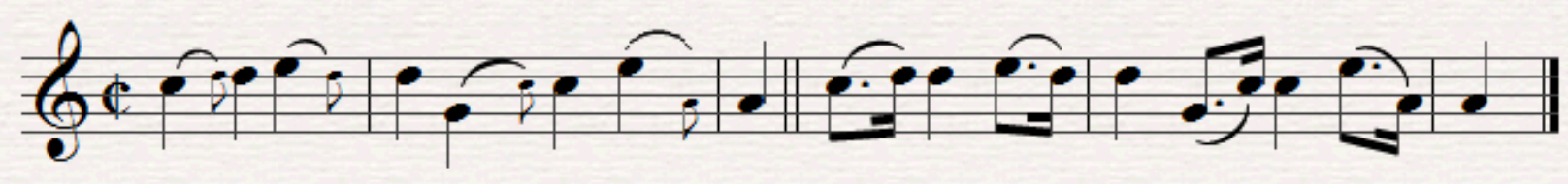

Ex. 2.15: Mozart's durchgehende Vorschläge repeating the previous note

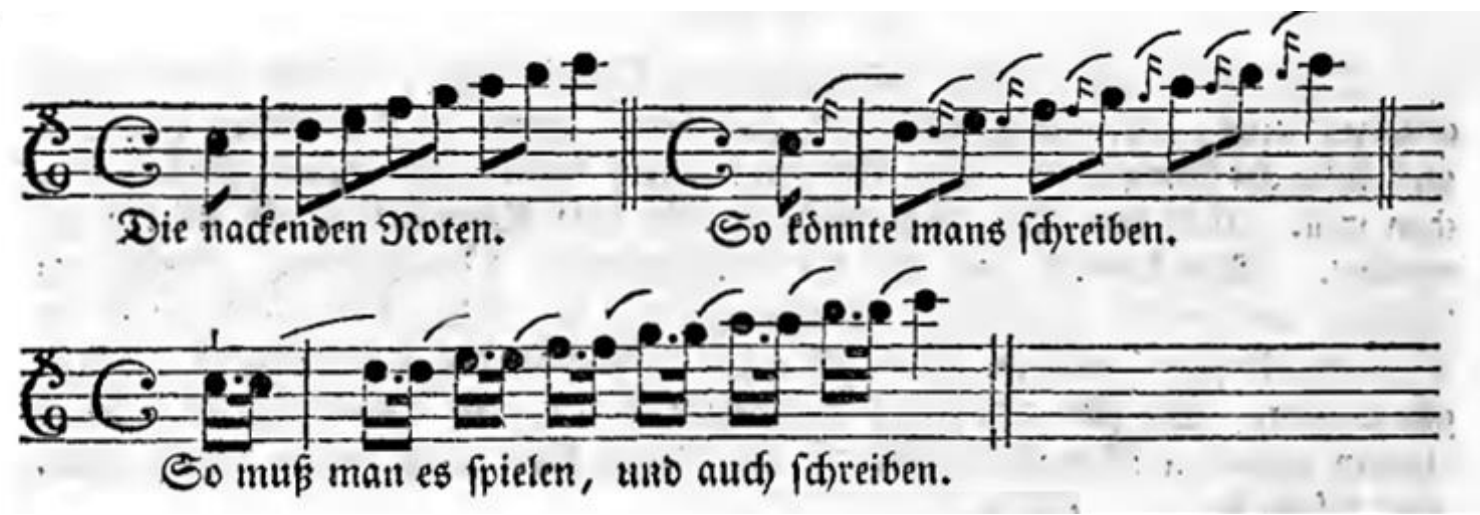

It was widely recognised that these connective graces were only very rarely notated by the composer. According to Mozart, "[t]hey are therefore such ornamentations as the violinist must know how to apply in the right place according to his own sound judgement."

\section{Two-note graces}

The two-note Nachschlag is a very common unaccented grace that strikes one note below, or occasionally above, the principal, before returning to this main note. It has been seen already in exx. $2.4,2.7$, and 2.12 , and will feature further in the coming chapter on trills.

\footnotetext{
${ }^{57}$ Muffat, F. Secundum, 50 (fig. Aa); Mozart, Versuch, 9/18. The German text in ex. 2.15 reads "The bare notes; One could write it so; One should play it so, and also write it [in large notation]".

${ }^{58}$ Mozart, Versuch, 9/16. See also Agricola, Anleitung, 113: "Double terminations are seldom written out by composers; the simple ones, never..."; Mattheson, Der Vollkommene Capellmeister, 2/3/26: "[The accent] must not be written down but is optional, like all other ornaments...".
} 
Double Vorschläge are of several varieties. One that features prominently in all three mid-century German treatises is the disjunct double Vorschlag or Anschlag. This uniquely German ornament, which may have been relatively new in the 1750 s, touches one note below the main note and then one above. The lower note may be removed by leap, if it repeats the previous note, but the upper note is always the upper neighbour. This resolves in a pleasing conjunct descent. Mozart presents this ornament as one more solution to the problem of rising Vorschläge.

\section{Ex. 2.16: Mozart's Anschläge}

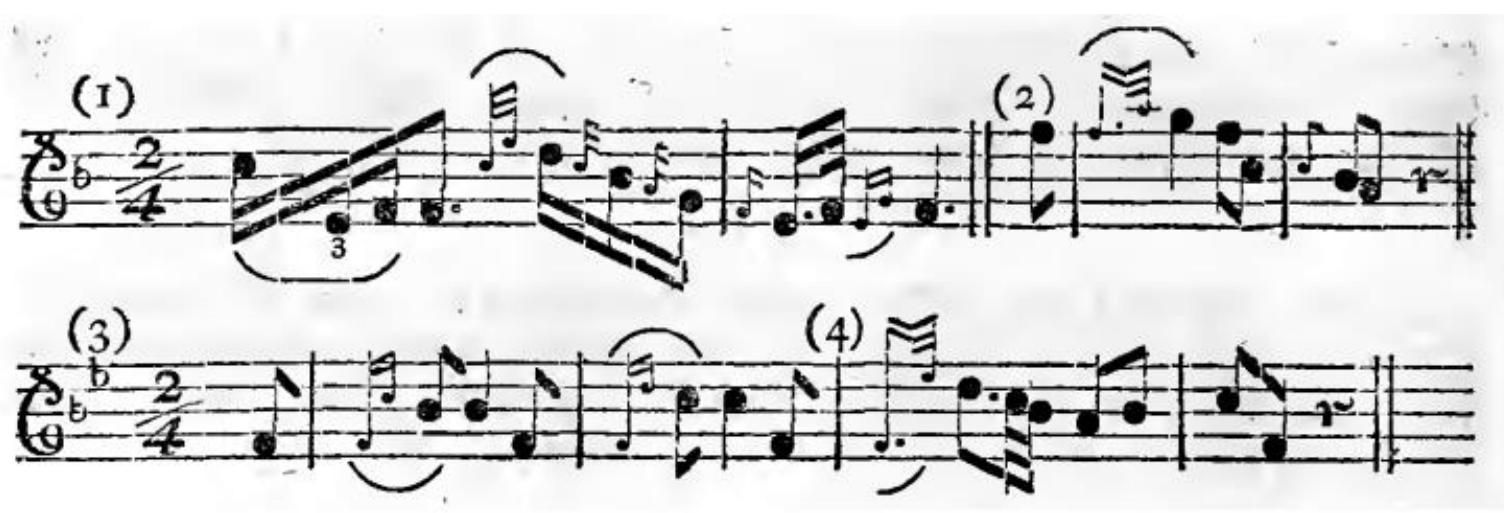

The example in ex. 2.16 above features both even and dotted Anschläge. Mozart explains that

the Anschlag of two equal notes in examples 1 and 3 is played softly and only the principal note played strongly; while in the dotted Anschlag in examples 2 and 4 , on the contrary, the dotted note is played louder, sustained longer, and the short note is slurred softly on to the principal note. ${ }^{59}$

Türk later presented Mozart's example 1 from ex. 2.16 (unidentified as such) as a poor use of Anschläge. His reasoning was that Anschläge were always used to give emphasis to the following note, and their use on weak notes was therefore inappropriate. ${ }^{60}$ This observation is certainly valid, but it appears that Mozart considered Anschläge to be gentle, connective ornaments. He also recognised an accentuating ornament consisting of the same notes which he counted as a variety of mordent:

The execution thereof is entirely different. There are dotted and undotted Anschläge, and both ... belong to melodious performance and are used interchangeably, only in slow or moderate tempo, for the filling out and binding together of melody. ... [This kind of mordent, however, is] played with the greatest rapidity; and the stress falls at all times on the principal note. ${ }^{61}$

Quantz provides a clue regarding the unusual dynamic shape of this ornament. The Anschlag, which he considers to invariably consist of the lower and upper neighbour notes, was "used by singers in extended leaps to hit the high note more surely."62

The invariable soft-loud dynamic pattern is reminiscent of Mozart and Tartini's versions of the short

\footnotetext{
${ }^{59}$ Mozart, Versuch, 9/12 (1787 edition). Regarding dotted Anschläge, see also Bach, Versuch, 135.

${ }^{60}$ Türk, Klavierschule, 4/2/15.

${ }^{61}$ Mozart, Versuch, 11/ 9 (1787 edition).

${ }^{62}$ Quantz, Versuch, 13/41.
} 
Vorschlag. Neither the violinists nor Quantz discussed the placement of the beat, but it is likely that they intended or allowed pre-beat performance. This is not the only interpretation, as can be seen from Bach's explicit and characteristic placement of the Anschlag directly on the beat. ${ }^{63}$

\section{Ex. 2.17: Bach's on-beat Anschläge}

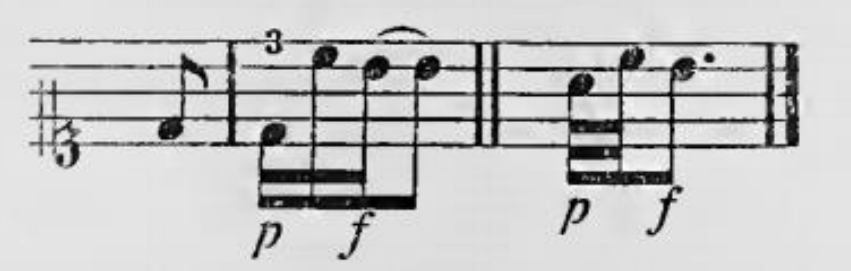

Neumann points out that Bach's recommended execution is rhythmically unstable, as a listener would most likely interpret the strong note as falling on the beat. The beat would then appear to be late, and while occasional use of "such a rendition that is at odds with the usual metric-dynamic pattern has the rubato charm of a delayed entrance ... as a routine formula repeated over and over it has the flavour of a manneristic affectation." 64

Bach clearly describes the connective nature of the Anschlag as a tool to fill out notes and to make melodies more attractive. He recommends its addition to a repeated note or a rising leap, and before a descent. It can be used to soften harsh rising intervals, such as a seventh or augmented second. ${ }^{65}$

A conjunct double Vorschlag occurs when a second Vorschlag is added on top of an existing one. This practice was condemned by Mozart, but recommended by Quantz and Bach where a descending harmonic Vorschlag repeats the previous note. ${ }^{66}$ Quantz's example of this, in which the added pre-beat grace note accentuates the existing one, can be seen above in ex. 2.1. Bach's example in ex. 2.18 below shows the addition of both long (harmonic) and short (accentuating) Vorschläge. Both of these should be performed on the beat.

\section{Ex. 2.18: Bach's long and short double Vorschläge}

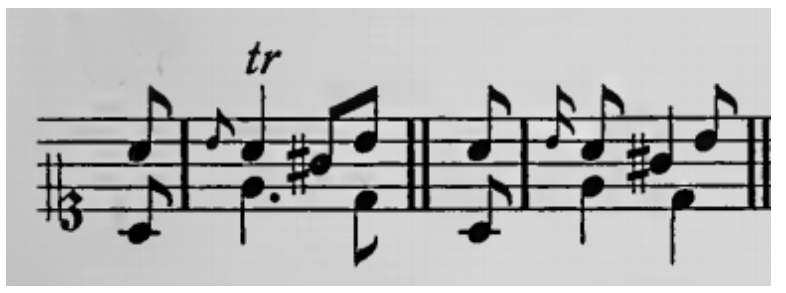

The slide or Schleifer can be seen as a variety of conjunct double Vorschlag, while also being a small tirata (an ornament which will be discussed further in the next chapter). This ornament usually occurs from below. According to Muffat, the slide is used almost exclusively on a rising third. Elsewhere, he says, the ornament is hardly used at all, although he does give an example immediately before a trill on

\footnotetext{
${ }^{63}$ Bach, Versuch, 132-33 (fig. 149).

${ }^{64}$ Neumann, Ornamentation, 489.

${ }^{65}$ Bach, Versuch, 133-34.

${ }^{66}$ Mozart, (Versuch, 9/3, 21) cites avoiding this exact abuse as the reason Vorschläge are written in small notation. Quantz, Versuch, 8/6, (figs. 9 and 10) and Bach, Versuch, 97, both show the second Vorschlag in large notation. Bach specifies that ascending Vorschläge are not eligible for either ascending or descending additions.
} 
the same note, resulting in a pattern similar to the ascending trill which features later in this chapter. ${ }^{67}$ Ex. 2.19: Muffat's slides on an ascending third and preceding a trill on the same note

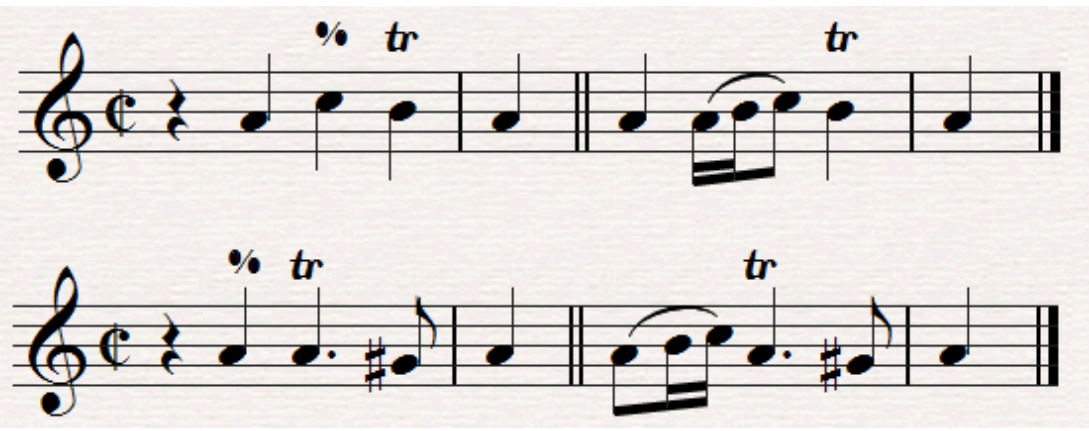

Other sources commonly apply slides to intervals ranging from a second to a sixth. Bach recommended it particularly on a fourth or fifth. Its effect, he says, is to make melodies more flowing and to evoke "pleasant feelings". 68

\section{Ex. 2.20: Bach's slides on larger intervals}

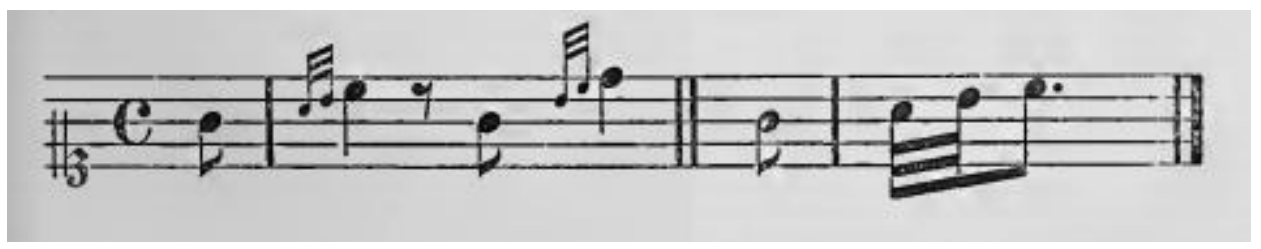

\section{Shakes}

The four varieties of ornaments in the shake family are divided by pitch. The tremolo consists of oscillations purely of intensity (volume); the vibrato of pitch oscillations of less than a semitone. ${ }^{69}$ The trill and mordent alternate the principal note with its upper and lower neighbour respectively.

\section{Tremolo and Vibrato}

On stringed instruments, pitch oscillation (vibrato) is made with the left hand, while oscillations of

\footnotetext{
${ }^{67}$ Muffat, F. Secundum, 51.

${ }^{68}$ Bach, Versuch, 136-39. See also Mozart's ex. 2.5 above. In Mattheson, Der Vollkommene Capellmeister, 2/3/46, the example given shows the slide on an ascending sixth and a series of descending thirds, while Quantz, Versuch, 13/42 (fig. 27) appears to recommend thirds and fourths.

${ }^{69}$ The term 'vibrato' is a $20^{\text {th }}$ century invention. The two most common contemporary English terms were 'close shake' and, confusingly, 'tremolo'. Mozart, Versuch, 11/1, 1787 edition, found it necessary to clarify that the oscillations were indeed of pitch.
} 
intensity (tremolo) are made with the bow. Early tremolo involved altering the speed or pressure of the bow, as opposed to the modern technique of rapidly alternating up- and down-bows. In 1627, Carlo Farina described the technique as "pulsating the hand that carries the bow in the manner of the tremulant of the organ". ${ }^{70}$ A century later, Mattheson gave a similar description, once again with reference to organ tremolo. ${ }^{71}$

Although the tremolo was apparently widely used in the $16^{\text {th }}$ and $17^{\text {th }}$ centuries, by the mid- $18^{\text {th }}$ century the violin masters Tartini, Mozart, and Geminiani only found it necessary to discuss the left-hand ornament now named vibrato. Geminiani's discussion of vibrato, among the 'ornaments of expression', focuses on how the technique may be put to expressive use.

To perform it, you must press your finger strongly upon the string of the instrument and move the wrist in and out slowly and equally, when it is long continued swelling the sound by degrees, drawing the bow nearer the bridge, and ending it very strong may express majesty, dignity etc. But making it shorter, lower and softer, it may denote affliction, fear etc. and when it is heard on short notes, it contributes only to make their sound more agreeable and for this reason it should be made use of as often as possible. ${ }^{72}$

This description is among Geminiani's most quoted passages. Many interpretations focus on the final clause, which appears to advocate extensive or even continuous use of the technique. It is, however, relevant that Geminiani's words on this matter are very similar to his less-quoted view that a (short) appoggiatura "may be added to any Note you will". 73

The more substantial treatises of Tartini and Mozart devote considerable attention to vibrato. Mozart describes a movement made "with the whole hand; which however must not move sideways but forwards towards the bridge and backwards towards the scroll". This technique is now known as wrist vibrato. The more common modern arm vibrato was impractical in the absence of a chin rest.

Mozart and Tartini both recommend a slow, an accelerating and a rapid vibrato. The illustration in ex. 2.21 is common to both treatises. Mozart states that the large strokes (' $u$ ') represent quavers and the smaller (' $x$ ') semiquavers.

Ex. 2.21: Slow, accelerating and fast vibrato in Tartini and Mozart

\footnotetext{
${ }^{70}$ Carlo Farina, preface to Cappriccio Stravagante, (Dresden, 1627).

${ }^{71}$ Mattheson, Der Vollkommene Capellmeister, 2/3/28.

${ }^{72}$ Geminiani, Art, preface, 18. In later editions, the last clause is omitted.

${ }^{73}$ Geminiani, Art, preface, 18. There is some ambiguity over whether this phrase relates only to the short appoggiatura or to all varieties.
} 


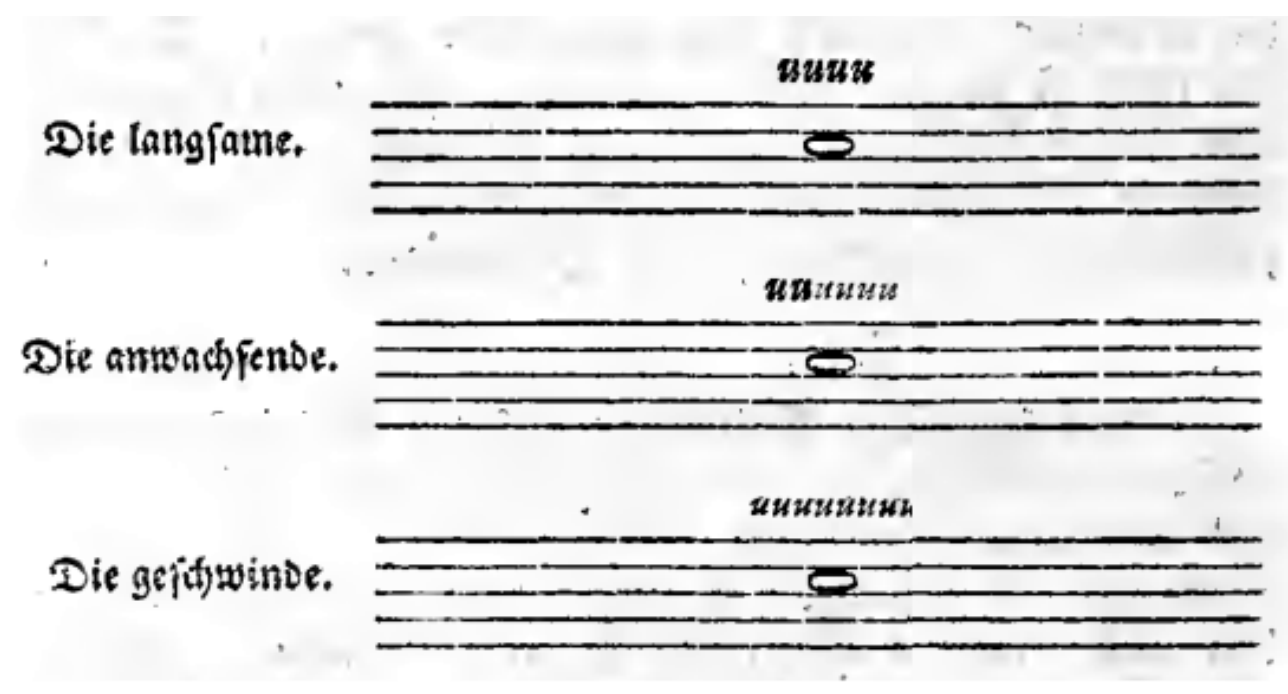

Both writers use the same examples to illustrate what is clearly a relatively slow, measured vibrato. In the case of ex. 2.22, the point of highest pitch falls on the notes marked (2), since these are on the strong beats. $^{74}$

\section{Ex. 2.22: Slow vibrato in Tartini and Mozart}

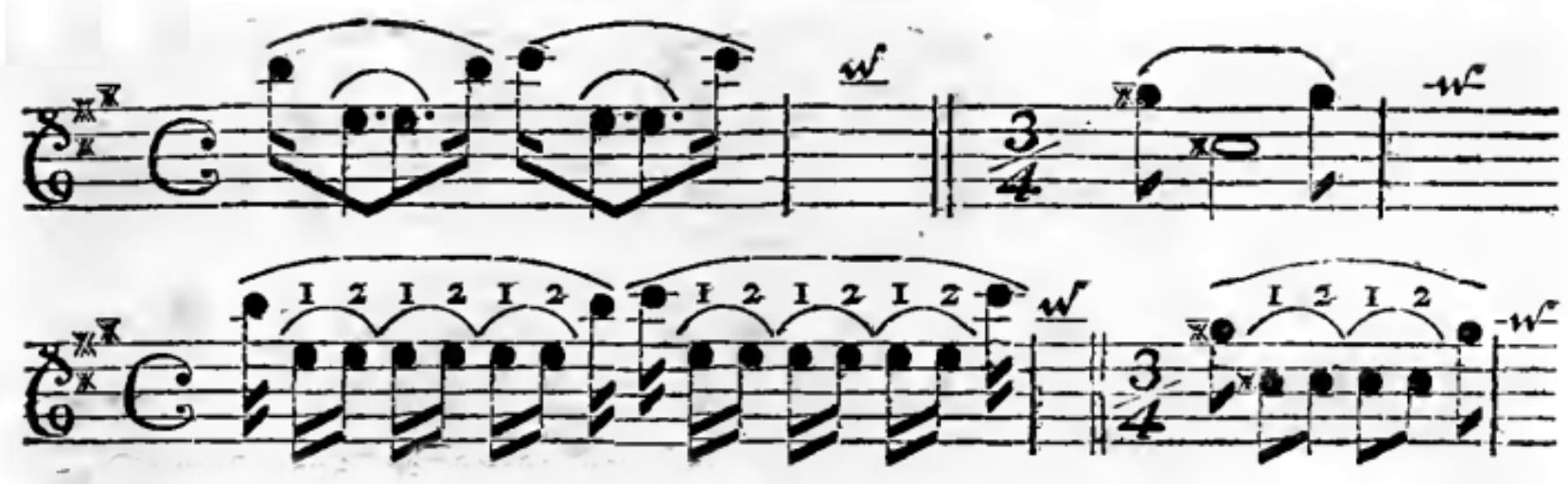

Mozart and Tartini advocate sparing use of vibrato, recommending that it be reserved for long notes. Mozart's caution against overuse indicates that it may have been used extensively by some performers:

Because the [vibrato] is not purely on one note but sounds undulating, so would it be an error if every note were played with the [vibrato]. Performers there are who tremble consistently on each note as if they had the palsy. ${ }^{75}$

The question of the desirability and extent of vibrato in Baroque performance is a particularly topical issue, as a question which confronts all performers. ${ }^{76}$ However, a straightforward answer can be found

\footnotetext{
${ }^{74}$ Mozart, Versuch, 11/5; Tartini, Traité, 16 (ex 46).

${ }^{75}$ Mozart, Versuch, 11/ 3; Tartini, Traité, 16.

${ }^{76}$ For example, in the preface to the 1961 trilingual edition of Tartini's treatise (Moeck Verlag, 43), discussion of the first four chapters, which deal with all essential ornaments, is reduced exclusively to commentary on the brief pages on vibrato. See also Neumann, 'The Vibrato Controversy', Performance Practice Review, Vol. 4, No. 1, 1991, 14-27; and Roger Hickman, 'Geminiani Unshaken', Early Music, Vol. 11, No. 1 (Jan. 1983), 73-76; among numerous other essays, books, reviews, and blog posts.
} 
in the common ground between Geminiani, Mozart and Tartini. Each of these writers classify vibrato as an ornament, and not, as is now the case, a component of basic tone production.

\section{The Trill}

The trill consists of alternation of the main note with its diatonic upper neighbour, which may lie at the interval of a tone or semitone above. Quantz describes the dominant opinion of the time in placing the trill (shake) alongside the Vorschlag as the most important of $18^{\text {th }}$-century ornaments.

Shakes add great lustre to one's playing, and, like Vorschläge, are quite indispensible. If an instrumentalist were to possess all the skill required by good taste in performance, and yet could not strike good shakes, his total art would be incomplete. $^{77}$

\section{Execution}

Like grace notes, trills are highly versatile ornaments which serve all three functions. The character of the trill depends extensively on context, and variability of the ornament was considered integral to good performance.

The three parts of any trill, identified by a number of theorists including Tartini, are the preparation (manner of beginning), the number and speed of the oscillations, and the presence or absence of a termination. ${ }^{78}$ French writers defined and named a large number of types of trills, but while fascinating, the level of detail contained in these theoretical works is unnecessary for our purposes here.

Throughout the resources surveyed, the two basic openings of a trill are a) beginning with a brief upper note, and b) beginning on a harmonic Vorschlag on the upper note. ${ }^{79}$ Mozart prescribes the former at the beginning of a phrase, in which case "the Vorschlag is hardly heard, and is in such a case naught but a strong attack on the trill." The 'prepared' trill featuring an elongated upper note is more suitable within a phrase. ${ }^{80}$ The issue also depends on line direction and the character of the piece, as the prepared trill may be more congruous in a slow, melancholy, or tender piece than a fast one, although

\footnotetext{
${ }^{77}$ Quantz, Versuch, 9/1.

${ }^{78}$ Tartini, Traité, 10-11.

${ }^{79} \mathrm{~A}$ trill which begins on the main note does not feature in the texts of Muffat or Mattheson, or in any of the mid-century treatises except Bach's (Versuch, 107), who briefly condemns "plunging directly into a trill without playing the preceding Vorschlag". Türk (Klavierschule, 4/1/34) calls a main-note trill "incorrect". Neumann, in Performance Practices of the Seventeenth and Eighteenth Centuries (New York: Schirmer Books, 1993), 397, points out that Tosi's original treatise (Opinioni, 25) does in fact explicitly describe the main-note trill as the basic form from which all other trills are derivatives - a fact commonly overlooked after both Agricola and the first English translator J. E. Galliard provided illustrations which began on the upper note. See Agricola, Anleitung, 127, and Galliard, Observations on the Florid Song (London: J. Wilcox, 1743), plate IV. Neumann makes no secret of his objective of disrupting the 'doctrine' of upper-note trills, and his methodology has come under fire from many. David Fuller, in a review of Neumann's Ornamentation, in Journal of the American Musicological Society, Vol. 33, No. 2, Summer 1980, 398, says of this section: "Even discounting the many forced and slanted arguments, the number of situations where main-note trills seem to be an authentic and desirable solution is impressive."

${ }^{80}$ Mozart, Versuch, 10/11.
} 
this is naturally not an absolute distinction.

The speed of the oscillations is likewise variable and dependent on a number of factors. A slow piece requires slower trills, as does a reverberant space, and very low notes. ${ }^{81}$ The number of oscillations is naturally closely linked to the length of the note, although it also places each individual trill in its place along the accentuating-connective spectrum. For example, very short trills such as the half-trill (ex. 2.23) and Schneller or 'snap' (ex. 2.24) are accentuating ornaments which leave an amount of the original note plain. ${ }^{82}$

\section{Ex. 2.23: The half-trill illustrated by Mozart and Bach}
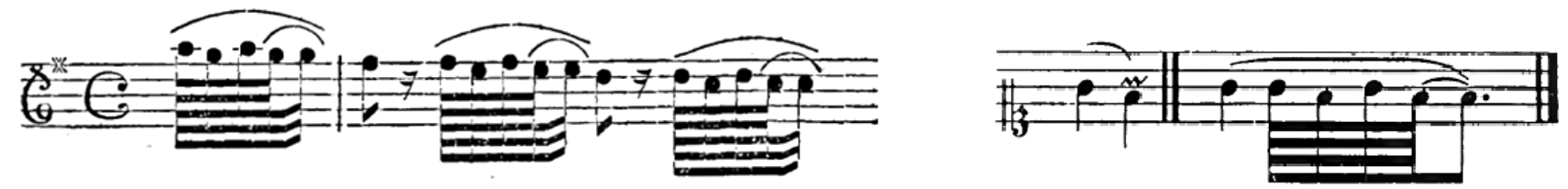

Ex. 2.24: Bach's Schneller or 'snap'

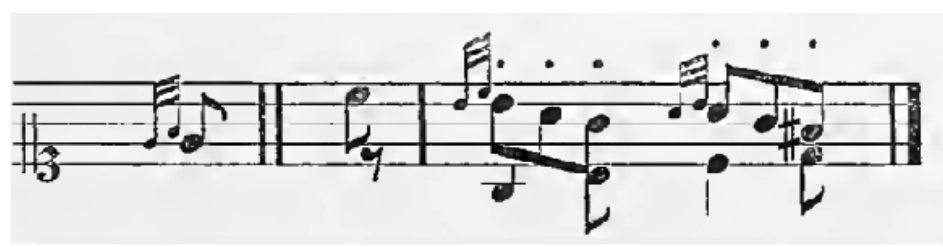

Mozart and Tartini advocate use of an accelerating trill only at cadences. The question of the evenness of the oscillations in general is one better answered in performance than theory. ${ }^{83}$

\section{Ornamentation of trills}

The addition of a two-note Nachschlag, also known as a termination or turn, to the end of any trill of moderate length was widely considered to be not only optional but compulsory. Quantz states that

[if] only a plain note is found [with a marked trill], both the Vorschlag and termination are implied, since without them the shake would be neither complete nor sufficiently brilliant. ${ }^{84}$

The least favourable context for a turn was before a stepwise descent, due to the turn's weak anticipation of the following note. In other cases, a few rapid written-out notes after the trill can also serve in pace of a turn. ${ }^{85}$

\footnotetext{
${ }^{81}$ The direction regarding tempo can be found in Mozart, Versuch, 10/7; Tartini, Traité, 10; and Quantz, Versuch, 9/2. The relevance of acoustic and pitch is mentioned by Quantz, Versuch, 9/2; and Mozart, Versuch, 10/8.

${ }^{82}$ Bach's Pralltriller or 'half-trill' from Versuch, 142 (fig. 162); Schneller or 'snap' from 110 (fig. 113).

${ }^{83}$ Tartini, Traité, 11; Mozart, Versuch, 10/7. Many treatises call for evenness of oscillation. See for example Bach, Versuch, 101; Quantz, Versuch, 9/5. However, it is possible that these should be taken as a warning against irregularity or general sloppiness, rather than against acceleration. A mechanical rendition of an ornament such as the trill is seldom effective.

${ }^{84}$ Quantz, Versuch, 9/7. See also Agricola, Anleitung, 138; Mozart, Versuch, 10/6; Bach, Versuch, 103.

${ }^{85}$ Bach, Versuch, 104.
} 


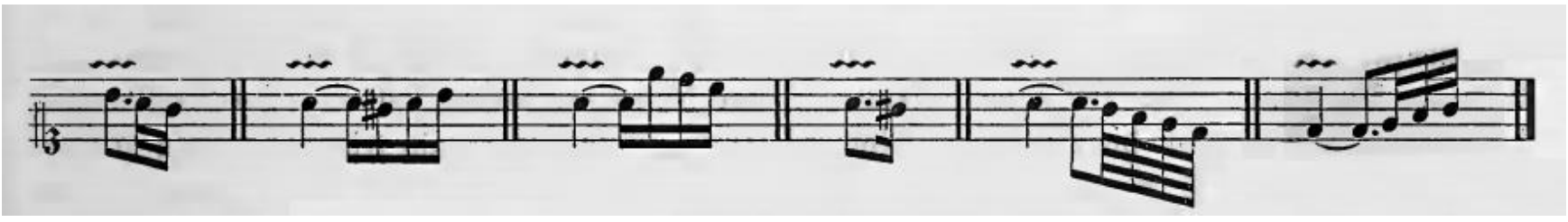

The lower neighbour note, which is a component of the ubiquitous turned ending, also features in many of the simplest and most attractive embellishments of trills.

An ascending trill starts from the lower neighbour. Bach's variety in ex. 2.26a begins unambiguously on the beat, while Mozart's in ex. $2.26 \mathrm{~b}$ may fall before. ${ }^{86}$

\section{Ex. 2.26a: Bach's ascending trill}

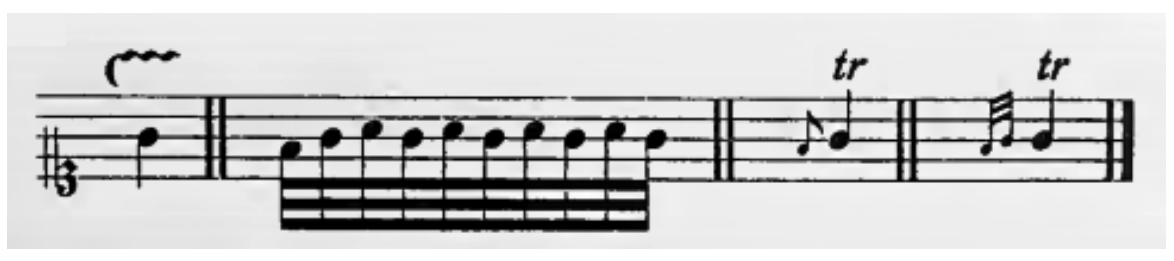

Ex. 2.26b: Mozart's ascending trill

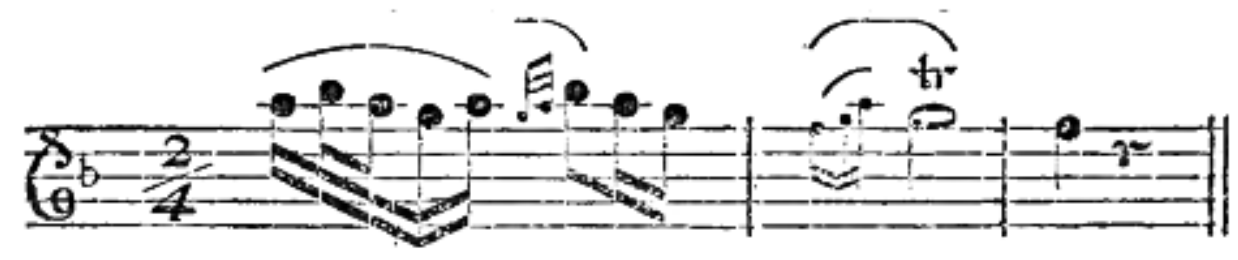

Quantz' unusual rule on the direction of Vorschläge (see 'Harmonic Vorschlag' above) also applies to the preparation of a trill. This means that a trill approached from below receives a lower Vorschlag, effectively creating another variety of ascending trill. ${ }^{87}$

\section{Ex. 2.27: Possible interpretations of Quantz's trill from below}

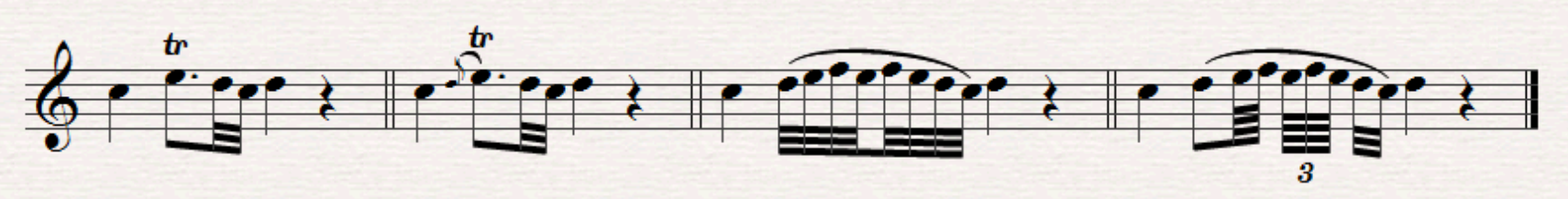

Bach, who was most descriptive of the application of this ascending trill, allows this ornament on long notes regardless of direction of motion, even if the trilled note is lower than the preceding or removed

\footnotetext{
${ }^{86}$ Mozart, Versuch, 10/5. Mozart does not discuss the placement of stress in this ornamented trill, but the pre-beat implication of short Vorschläge (9/9) and mordents (11/8) could be relevant here.

${ }^{87}$ Quantz, Versuch, 9/7-8. Quantz allows both short and long (harmonic) Vorschläge at the start of a trill. Example from Versuch, 13/22 (fig. 9).
} 
by leap. ${ }^{88}$

Bach recommends use of the less common descending trill only on "the longest notes"; on a repeated tone (a) or after a descent of a second (b) or third (c). ${ }^{89}$ As can be seen in a), the turned start of the trill does not forbid the addition of another turn at the end of the ornament.

\section{Ex. 2.28: Execution and application of Bach's descending trill}
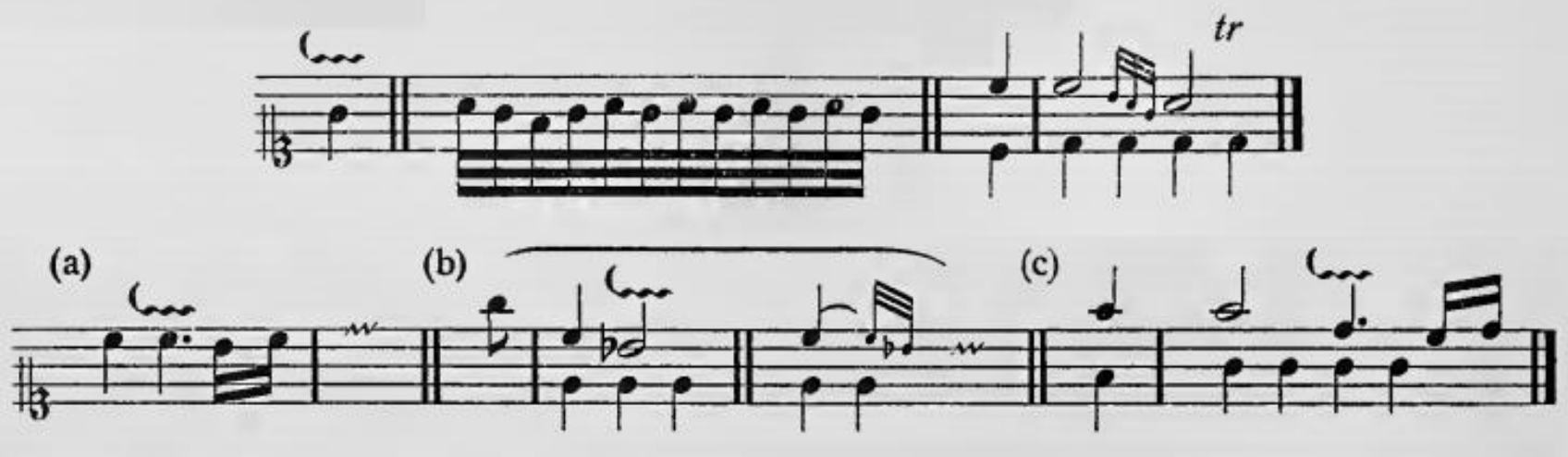

Further examples of ornamented trills involving the lower neighbour note are shown below. Agricola provides the example in ex. 2.29 for Tosi's 'double trill' which "inserts a few notes in the middle of the regular major or minor trill, so that from one trill, three are generated." "90 The arrangement of notes may indicate some degree of rhythmic freedom. Example 2.30 shows an embellished cadential trill recommended by Mozart and Tartini. ${ }^{91}$

Ex. 2.29: Agricola's 'double trill' as described by Tosi

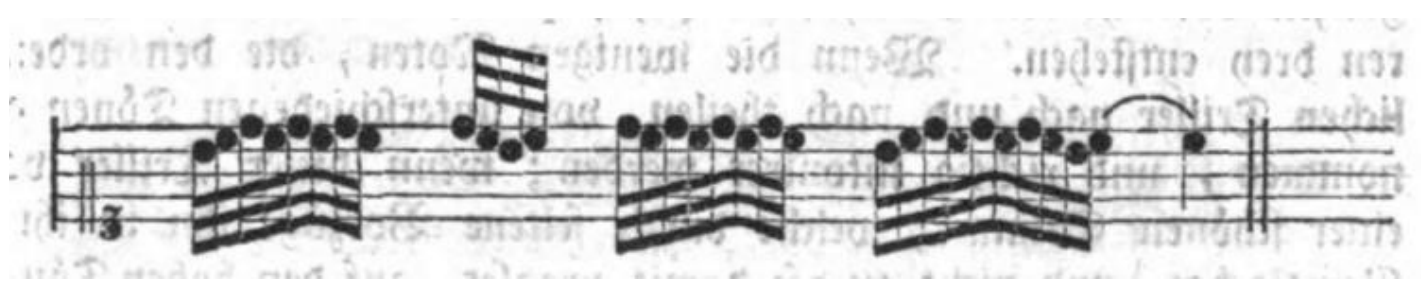

Ex. 2.30: An ornamented cadential trill in Tartini and Mozart

\footnotetext{
${ }^{88}$ Bach, Versuch, 108 (fig. 104).

${ }^{89}$ Bach, Versuch, 109 (fig 111).

${ }^{90}$ Agricola, Anleitung, 131-33.

${ }^{91}$ Mozart, Versuch, 10/6; Tartini, Traité, 11.
} 


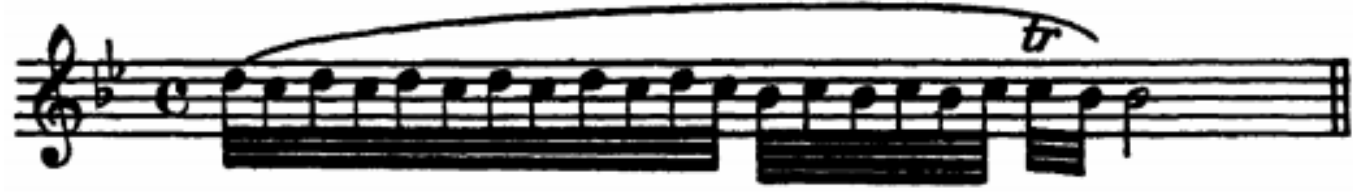

The ribattuta is a rhythmic ornamentation of the trill that is most commonly used at the end of a cadenza, or preceding a significant cadence. This ornament, which both accelerates and increases in dynamic, is itself usually followed by a standard trill on the note above. ${ }^{92}$

Ex. 2.31a: Mozart's ribattuta

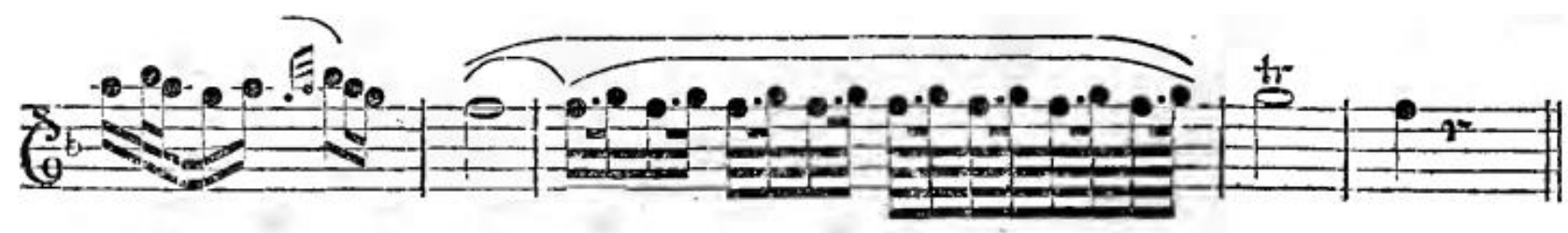

Ex. 2.31b: Bach's ribattuta

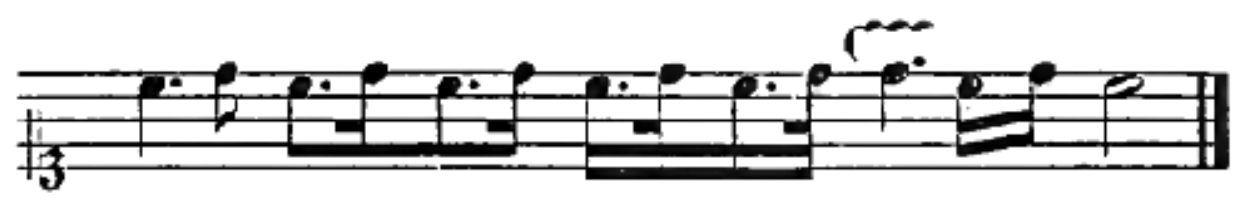

As many of the above examples illustrate, the trill's most iconic position is on the penultimate note of a cadence. The presence of these cadential trills was so ubiquitous that even without a notated symbol, a trill would be performed before internal as well as final cadences.

Tartini and Mozart recommend the two simple endings in ex. 2.32 for any descending cadence. ${ }^{93}$

\section{Ex. 2.32: Trill endings in Tartini and Mozart}

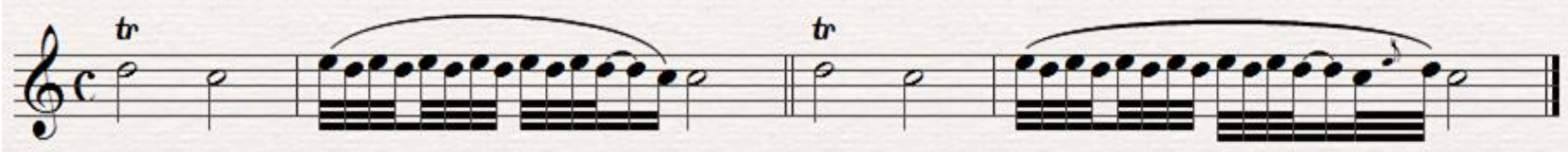

\footnotetext{
${ }^{92}$ Mozart, Versuch, 10/5 (further examples in 10/27-29 and 11/7); Bach, Versuch, 108 (fig. 105). Bach's example was reproduced by Agricola (Anleitung, 141)

${ }^{93}$ Tartini, Traité, 11. Mozart, Versuch, 10/6, omits the grace note in the second example. This he considers an ornamented close, which he recommends for internal cadences (10/13). Agricola, Anleitung, 139-40, laments the use of this three-note termination.
} 


\section{Extempore introduction of trills}

The threefold function of the trill means that there are few absolute restrictions on its placement. Bach advises that, despite its versatility, the trill is primarily a 'brilliant' ornament and must be used only with care in slow, melancholy or affetuoso pieces. $^{94}$

The treatises of Mozart and Tartini are particularly informative on the matter of introduction of trills. Short trills, they agree, can be added at many points within a melody, but generally not at the beginning of a phrase. ${ }^{95}$ The two violinists give a large number of examples, with a high degree of overlap.

A series of even descending notes can be decorated by trills on every second note, as in ex. 2.33. Although the harmony is not given, it is clear that the trilled notes include both dissonant passing notes and consonant or structural tones.

\section{Ex. 2.33: Extempore introduction of trills in Mozart and Tartini}

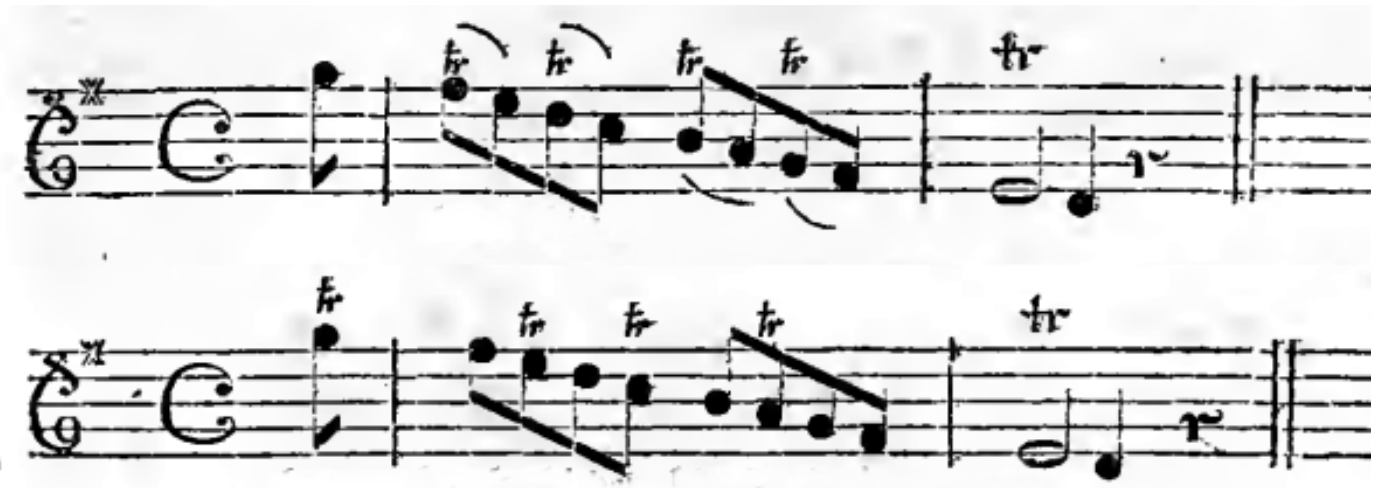

These trills, and those in the following examples, are prescribed for performance without a turn, presumably due to their brevity and the fact that a turn weakly anticipates the following note.

The trill can also ornament the common patterns shown in ex. 2.34.

\footnotetext{
${ }^{94}$ Bach, Versuch, 100.

${ }^{95}$ Tartini, Traité, 15; Mozart, Versuch, 10/15. Examples from Mozart, Versuch, 10/16-20; and Tartini, Traité, 14.
} 

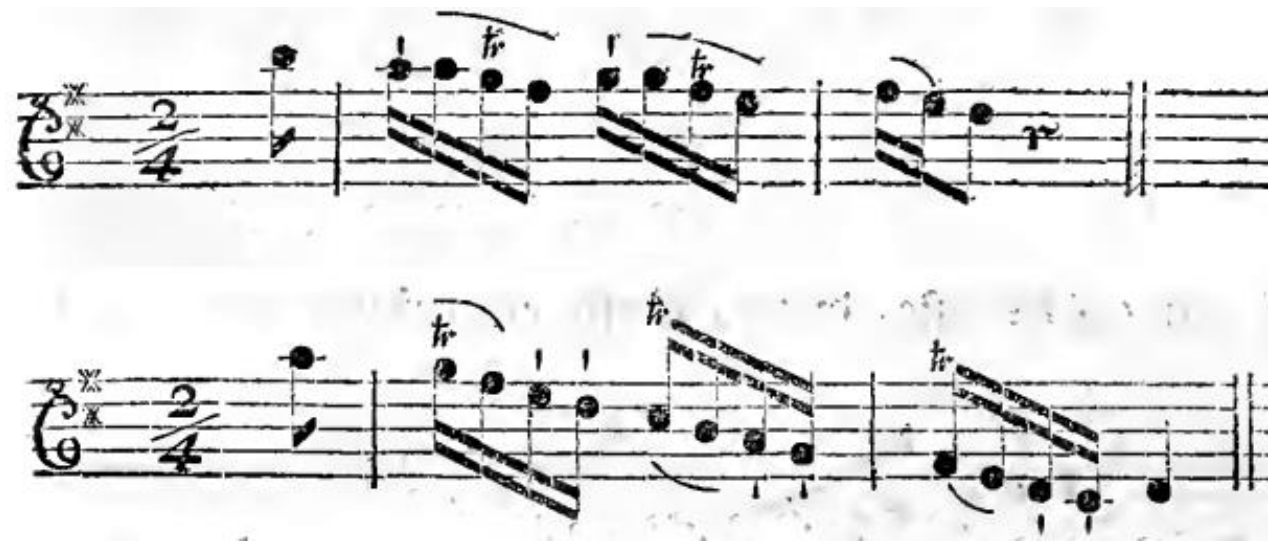

In the case of dotted notes, trills can be added to the beginning of each long note; each dot; or each short note (ex. 2.35). Tartini describes the first option as having a more melodious expression, while a trill on each short note creates a "sharper and more daring" movement. ${ }^{96}$

\section{Ex. 2.35: Introduction of trills in dotted passages in Mozart and Tartini}

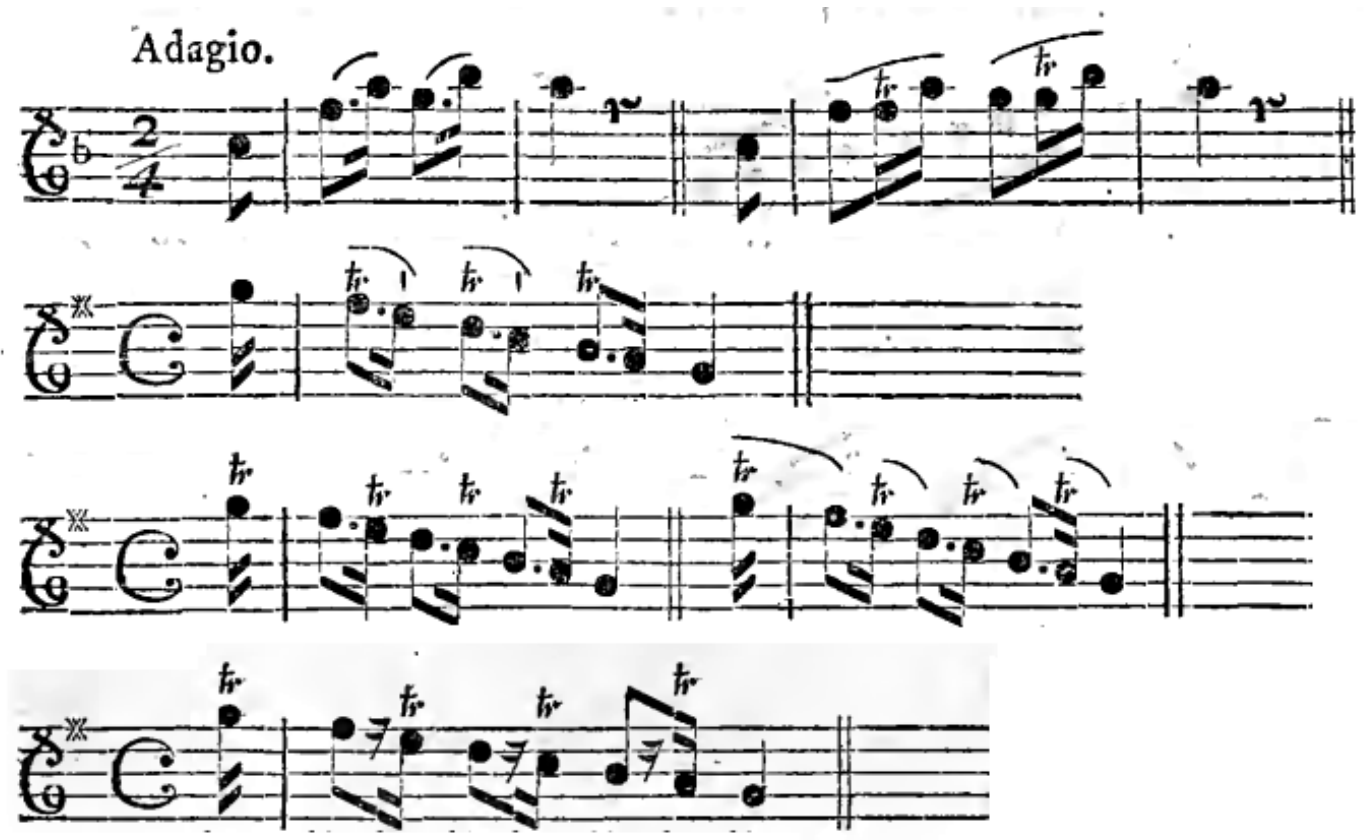

The repetitive nature of every one of these examples is significant. In each case, a repeating melodic unit is ornamented identically on each iteration. This creates a sense of unity within the phrase, but this principle should naturally not be taken to excess.

In the above cases, at most every second note receives a trill. In a stepwise ascending or descending passage, every note can be trilled in such a way that the entire line becomes a single ornament. Mattheson described this as being commonly used in 1739, despite being "probably unknown to our

${ }^{96}$ Tartini, Traité, 15. 
forefathers", and it evidently remained very popular for several decades. ${ }^{97}$

\section{Ex. 2.36: Mozart's trill chains}

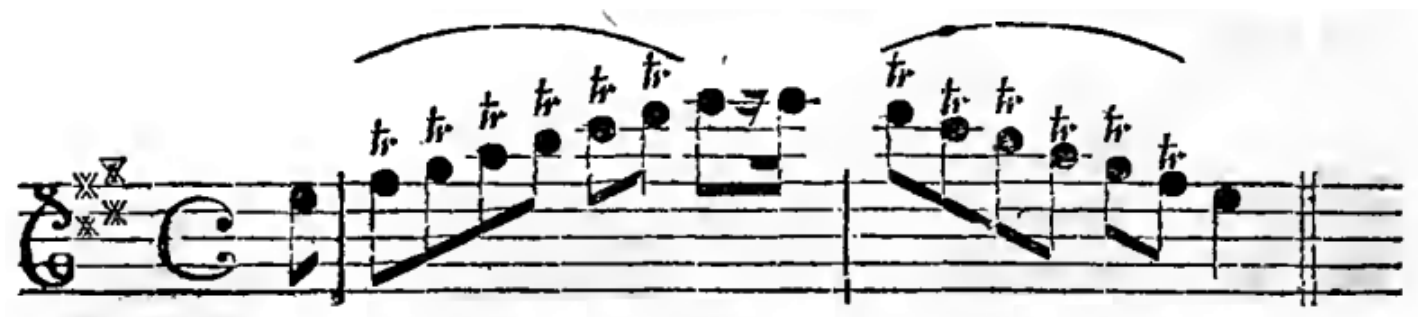

\section{The Mordent}

The most common modern interpretation of the mordent is of a very short, accented, on-beat ornament. It is widely agreed that the main note may alternate with either the diatonic or chromatic lower neighbour; that is to say, the lower accessory may be raised with an accidental. Muffat's example of the ornament in ex. 2.37 fits this nicely.

\section{Ex. 2.37: Muffat's on-beat accentuating mordents}

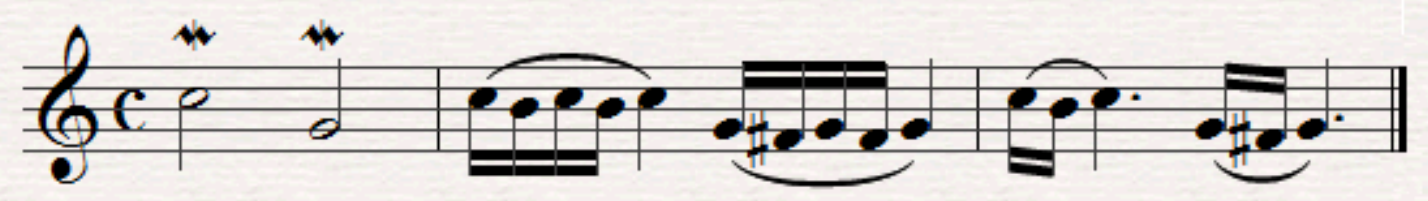

This represents one execution of the mordent, but it is not the only option and may not even be the most common in the period under question. Here I once again find it useful to categorise the various kinds of mordents as either accentuating or connective. The latter creates something of an oxymoron with the meaning of the word 'mordent', which derives from the Italian 'to bite'. I follow the precedent set by Bach in retaining 'mordent' as a convenient overarching term for all ornaments consisting of alternation between a note and its lower neighbour. ${ }^{98}$

\footnotetext{
${ }^{97}$ Mattheson, Der Vollkommene Capellmeister, 2/3/37, states that "as far as I know, they never descend but always go upwards", but by the 1750s, both ascending and descending examples appear to have been common. Example from Mozart, Versuch, 10/22-23; almost identical to that found in Tartini, Traité, 12. Tartini recommends playing such trill chains without terminations, and Mozart's fingering indicates his agreement. Agricola, Anleitung, 131, prefers "each rising trill to have its own clear termination" but also gives descending examples, and Türk, Klavierschule, 4/1/46b, agrees.

${ }^{98}$ Mozart (Versuch, 11/8-9) and Tartini (Traité, 17) follow Italian practice in counting several other short, accentuating ornaments under the name mordent, including a turn which will follow and, in Mozart's case, a variety of the Anschlag or compound Vorschlag previously discussed.
} 


\section{Accentuating mordents}

Muffat's example in ex. 2.37 above represents the on-beat, accentuating mordent which was also described by writers of Bach's school. ${ }^{99}$ However, Mozart and Tartini agree that the mordent serves best to accentuate the principal note if it is played quietly, implying pre-beat performance:

Above all, the mordent must only be used if it be desirable to give special emphasis to a note. For the stress of the tone falls on the note itself, while the mordent, on the contrary, is slurred quite softly and very quickly on to the principal note; for, otherwise, it would no longer be called a mordent. ${ }^{100}$

Due to its brevity and lack of harmonic significance, the short mordent is one of the least problematic of ornamental introductions. Muffat goes as far as to say that the ornament can be added "nearly everywhere", even on several relatively slow notes in a row. ${ }^{101}$ Bach's instructions are typically more specific:

The mordent is particularly effective in an ascent by step or by leap. It appears seldom in a descent by leap, and never on descending steps of a second. ... The mordent is the opposite of the half-trill. This latter may be used only on a step in descent, which is just where a mordent is unsuitable. ${ }^{102}$

\section{Connective mordents}

Connective mordents are of two main varieties. The first is essentially a lower-note trill of significant length, while the second was generally much shorter and served as an unaccented link between two notes.

Bach appears to consider this first variety of connective mordent as the standard form of the ornament. ${ }^{103}$ In ex. 2.38, he introduces the long (connective) and the short (accentuating) mordents, of which the former is slower and features the diatonic lower neighbour, which is chromatically raised in the latter case. This is not a categorical distinction, but as he explains later, the raised accessory makes

\footnotetext{
${ }^{99}$ Bach, Versuch, 127; Agricola, Anleitung, 133; Türk, Klavierschule, 4/1/60. Mattheson presents a mordent which is probably also on-beat (Der Vollkommene Capellmeister, 2/3/56).

${ }^{100}$ Mozart, Versuch, 11/13. See also Tartini, Traité, 17.

${ }^{101}$ Muffat, F. Secundum, 53.

${ }^{102}$ Bach, Versuch, 128, 131.

${ }^{103}$ Bach, Versuch, 128-29, 131, devotes a large part of his text on the subject to the use of the mordent as a sustaining tool, generally without any qualifier such as 'long', 'continued', or 'prolonged'. This indicates that the long variety may have been more common than the more well-known short mordent. Bach presents different symbols for long and short mordents, as seen in the example given. However, his discussion of the function and length of the ornament does not always seem to fit with his choice of symbol. I would suggest, based on Bach's text, that he used the short symbol also for mordents of medium length, which would also have some connective function. This issue is compounded by the fact that in Mitchell's English translation, the symbol for the long mordent is used only in the example above. In the other three cases where it appears in the original German, Bach's symbol for the short mordent is mistakenly substituted. To further obscure the matter, a passage (Versuch, 129) appears to have been mistranslated by Donington, (Interpretation, 266) from "[w]hen mordents serve to fill out a note" to "when mordents are continued to fill out a note", effectively weighting the entire chapter towards short, accentuating mordents.
} 
the ornament more brilliant and is therefore more suitable for the accentuating variety than the connective. $^{104}$

\section{Ex. 2.38: Bach's long and short mordents}

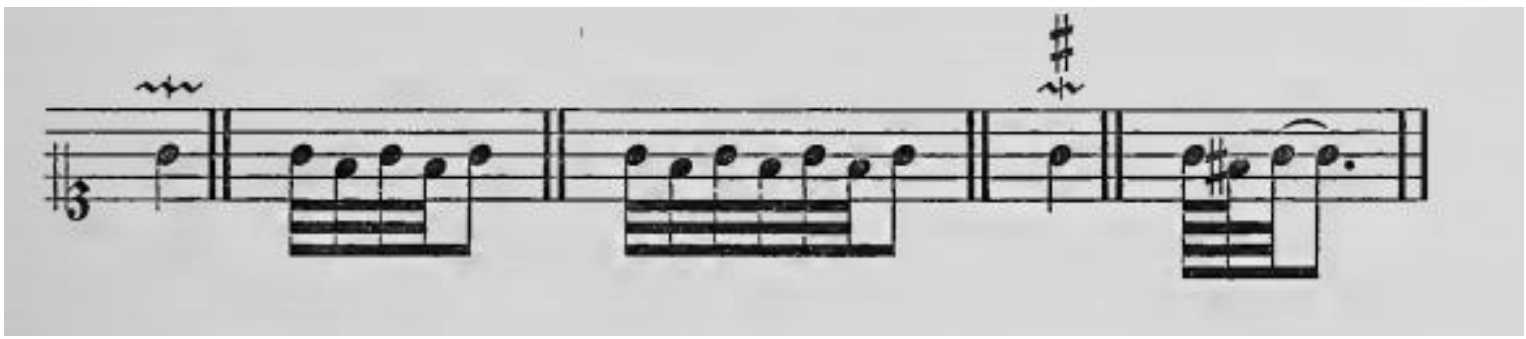

Geminiani's example of the mordent, or 'beat' in the English text, is shown in ex. 2.39.

\section{Ex. 2.39: Geminiani’s mordent}
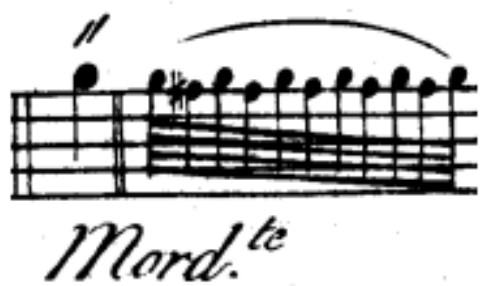

His brief written explanation typically focuses on the emotional content:

[If the mordent] be perform'd with Strength, and continued long, it expresses Fury, Anger, Resolution, etc. If it be play'd less strong and shorter, it expresses Mirth, Satisfaction, etc. But if you play it quite soft, and swell the Note, it may then denote Horror, Fear, Grief, Lamentation, etc. By making it short and swelling the Note gently, it may express Affection and Pleasure. ${ }^{105}$

Geminiani gives a range of examples of combinations of ornaments. The symbols used in ex. 2.40 are for a plain length of the note; a mordent; and a turned trill. These free flourishes resemble some of the Italian-style embellishments which feature in the next chapter.

\footnotetext{
${ }^{104}$ Bach, Versuch, 130.

${ }^{105}$ Geminiani, Art, preface, 18. Examples from exx. 18-19.
} 

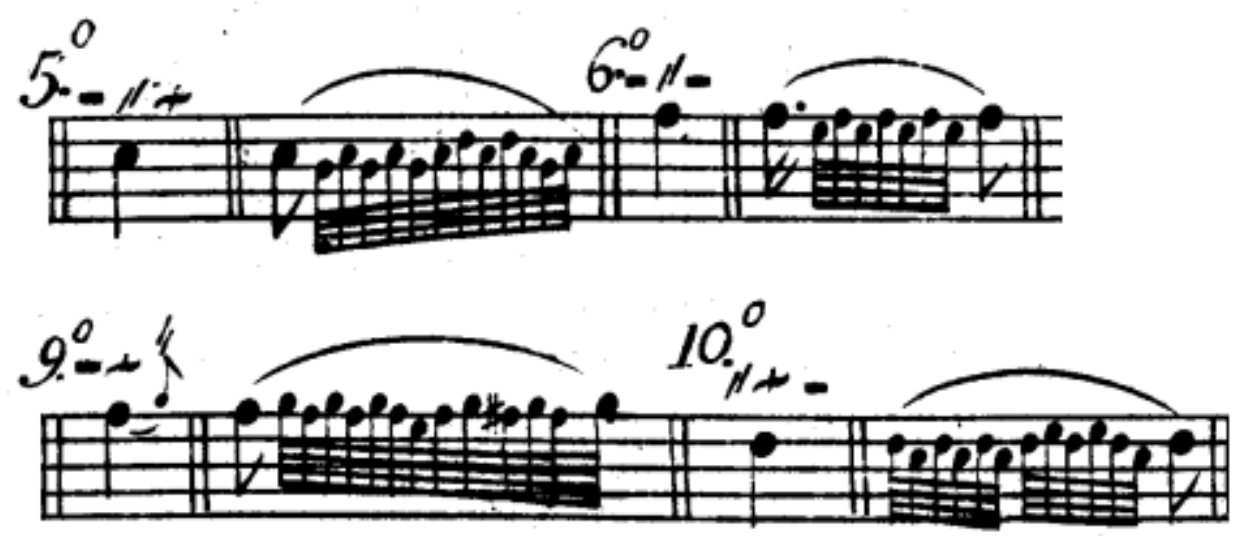

The second kind of connective mordent is most commonly found between a rising harmonic Vorschlag and its resolution. This combination is the exact inversion of a prepared trill or half-trill. The one or more oscillations are played lightly in accordance with the standard rules on the performance of harmonic Vorschläge and their resolutions. ${ }^{106}$

Mattheson echoes the French view in stating that "[i]n singing an accent is almost never made ascending where a little mordent does not appear". Geminiani and Muffat were among the writers who advocated its usage to solve the inherent harmonic issue of a rising harmonic Vorschlag. ${ }^{107}$

Like the mordent alone, this combination is most suitable in ascending passages. Muffat gives examples in both stepwise and leaping movement. ${ }^{108}$

\section{Ex. 2.41: Muffat's rising Vorschläge with mordents}
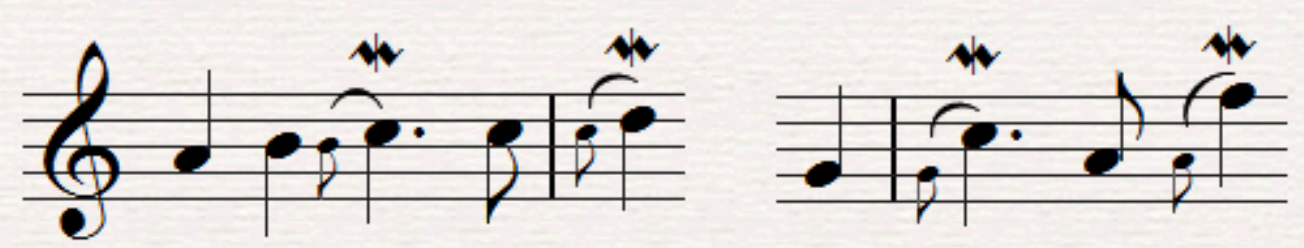

A further type of connective mordent is the French battement, a relatively long ornament that always started on the lower note. Both Mozart and Quantz mention this briefly as an alternative to the lower Vorschlag and mordent. ${ }^{109}$

\footnotetext{
${ }^{106}$ Bach, Versuch, 128.

${ }^{107}$ Mattheson, Der Vollkommene Capellmeister, 2/3/56; Geminiani, Art, preface, 18; Muffat, F. Secundum, 54.

${ }^{108}$ Muffat, F. secundum, 53, 55.

${ }^{109}$ Quantz, Versuch, 8/14-15; Mozart, Versuch, 11/16. Curiously, this is the only mention of the Vorschlag-mordent combination anywhere in Mozart's treatise, despite the large number of examples of small embellishments between the Vorschlag and its resolution, some of which are reproduced above in exx. 2.4-2.6. This likely indicates that Mozart found this compound ornament distasteful or at least considered it to be overused.
} 


\section{The Turn}

The turn is a conjunct ornament featuring the upper and lower neighbours of the principal note, most commonly in that order. The symbol in ex. 2.42 below is widely recognised today, but was in the $18^{\text {th }}$ century confined almost exclusively to keyboard music. Elsewhere the ornament was written out in small or large notation, indicated by one of the many signs for a trill, or left to the performer's discretion. ${ }^{110}$ Bach indicates that turns were frequently added by performers to the point of excess:

This lovely ornament is almost too obliging. It fits almost everywhere and consequently is often abused. ... In most cases the turn serves to add brilliance to notes. Hence, passages which must be played undecorated and sustained because of the affect are ruined by those who insert a turn because of the length of notes, in ignorance of style and touch. ${ }^{111}$

With the exception of multiple oscillations, many turns have all the components of a suffixed, uppernote trill, and can be considered honorary members of the trill family.

A general understanding of its correct use can be gained by considering the turn a normal, suffixed trill in miniature. ... It follows ... that the turn prefers an ascending to a descending following tone. ... The turn should not be applied to rapid descending notes. ${ }^{112}$

It likewise follows that the less common inverted turn is more suitable in descending passages.

It is once again possible to identify three types or families of turns corresponding to the three functions, although overlap is inevitable.

\section{Accentuating Turns}

The methods with which the schools of Bach and Tartini respectively used the turn to accentuate a note may now be familiar. Bach considers an on-beat pattern the basic form of the ornament, and prescribes the rhythmic variations shown in ex. 2.42 .

\section{Ex. 2.42: Bach's on-beat turns in adagio, moderato, and presto movements}

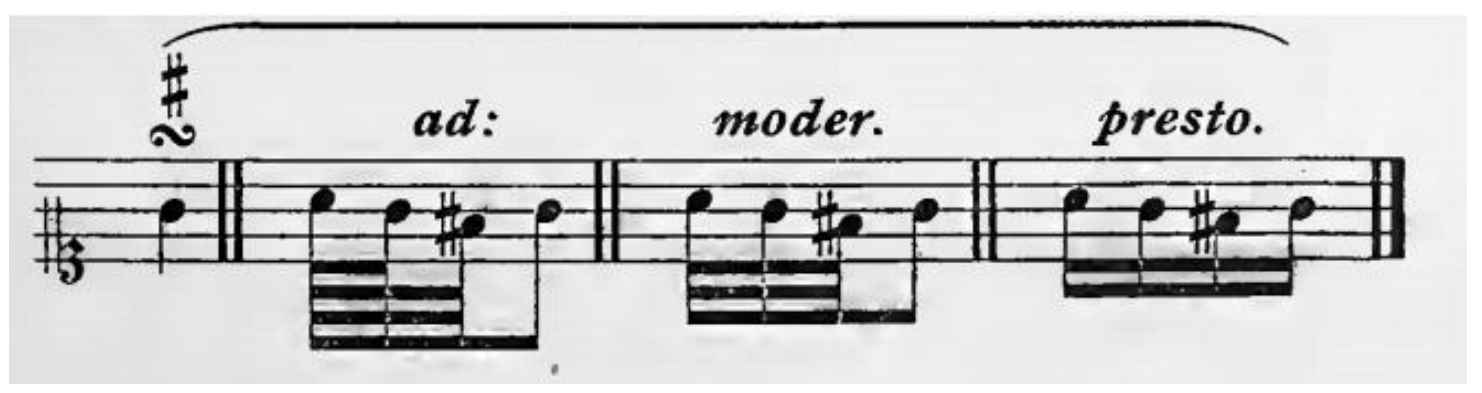

\footnotetext{
${ }^{110}$ Bach, Versuch, 117; Agricola, Anleitung, 143.

${ }^{111}$ Bach, Versuch, 114.

${ }^{112}$ Bach, Versuch, 114-15.
} 
Tartini's turn, which was adopted by Mozart, is found among the mordents. Both appear to consider it a more useful or attractive ornament than the true mordent which is played in the same manner - quiet, rapid, and slurred to the main note on which the stress falls. This type of turn has both an ascending and descending form, determined by the pitch of the preceding note. Its usage on the longer notes of unequal passages, as in the example in ex. 2.44 , is recommended. ${ }^{113}$

\section{Ex. 2.43: Pre-beat turns in Tartini and Mozart}

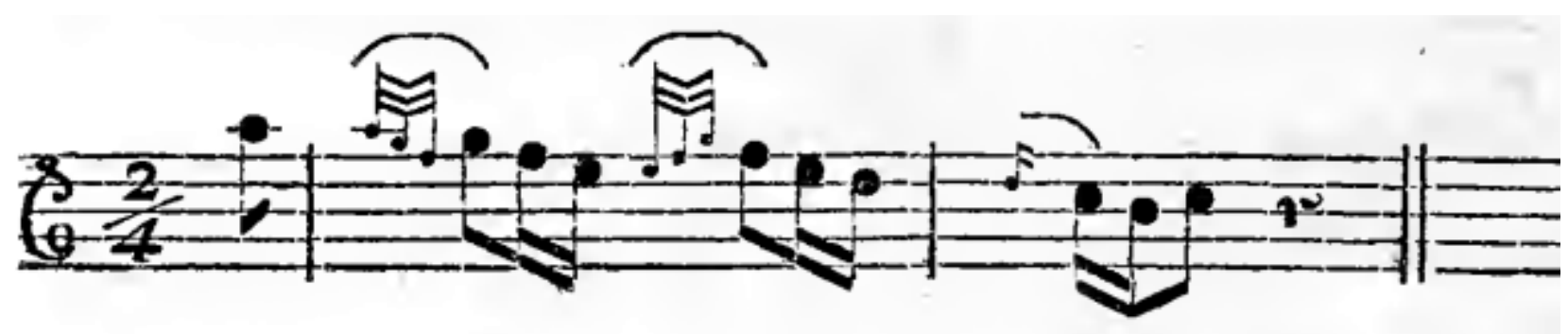

Quantz also uses the more common descending form of this ornament among his many variations on simple intervals to decorate repeated and stepwise ascending notes, the latter of which can be seen in ex. 3.7 in the next chapter. He calls for the three ornamental notes to be played quietly, with a crescendo on the main note. ${ }^{114}$

Bach's accentuating turn could also begin on a brief main note while retaining the same function. Example 2.44 shows Bach's notation for the 'snapped turn' (a), its execution (b), and its ideal use in staccato passages (c). Like the basic turn, the snapped turn should not be used before a stepwise descent. $^{115}$

\section{Ex. 2.44: Bach's 'snapped turn'}

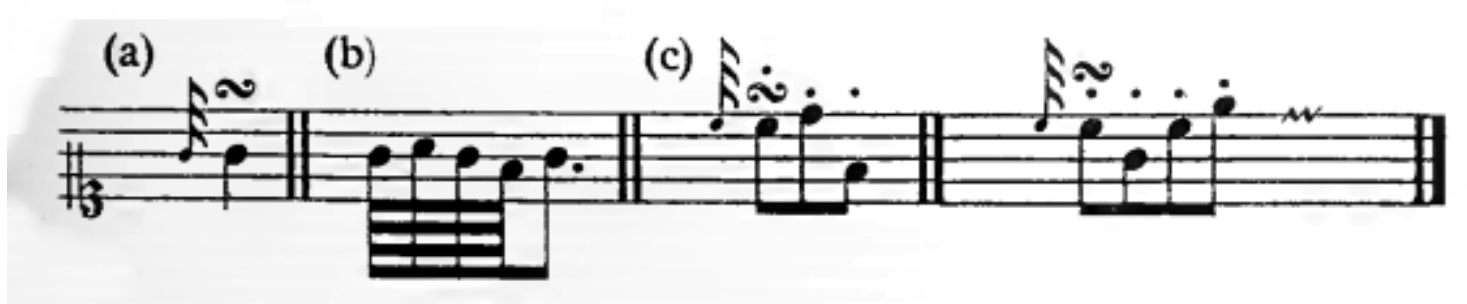

\section{$\underline{\text { Harmonic turns }}$}

All turns have some harmonic function. This becomes its primary attribute when the first note is elongated, making the ornament effectively a harmonic Vorschlag and termination. Mozart's ex. 2.45 clearly shows the components of this ornament. ${ }^{116}$

\footnotetext{
${ }^{113}$ Mozart, Versuch, 11/13; Tartini, Traité, 17.

${ }^{114}$ Quantz, Versuch, 13 (table 9, figs. 1a and 2h), commentary in 14/26.

${ }^{115}$ Bach, Versuch, 125.

${ }^{116}$ Mozart, Versuch, 9/28.
} 
Ex. 2.45: Mozart's harmonic turn constructed out of Vorschlag and turn (double Nachschlag)
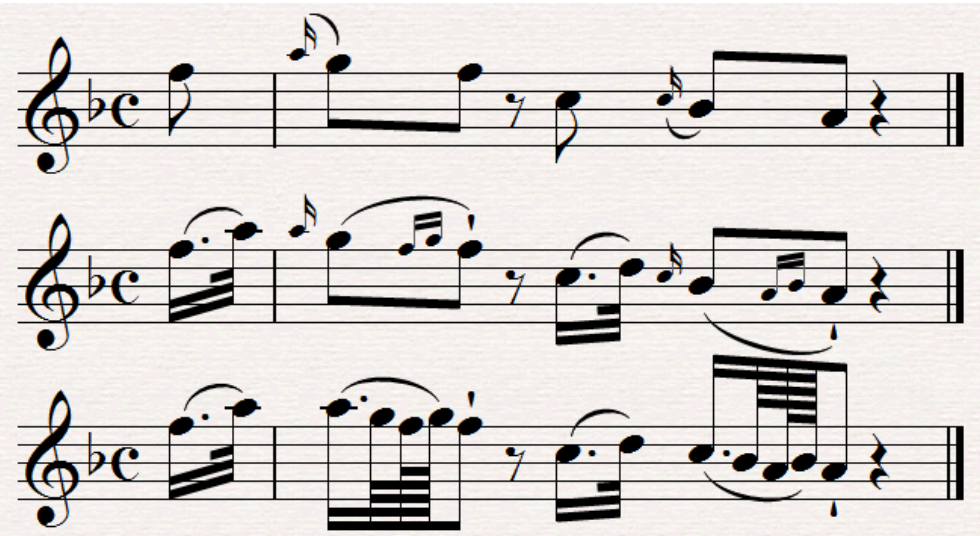

Further examples of harmonic turns can be seen below in Bach's ex. 2.46 and Tartini's ex. 2.47.

Ex. 2.46: Possible executions of Bach's turns after Vorschläge

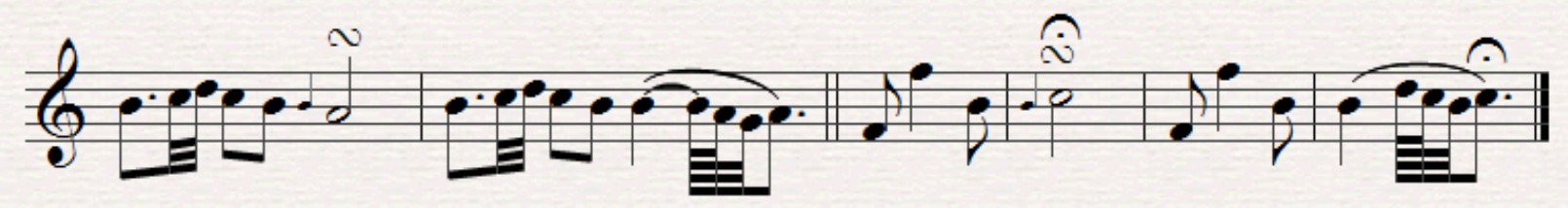

Ex. 2.47: A 'natural'figure recommended by Tartini and his provided execution
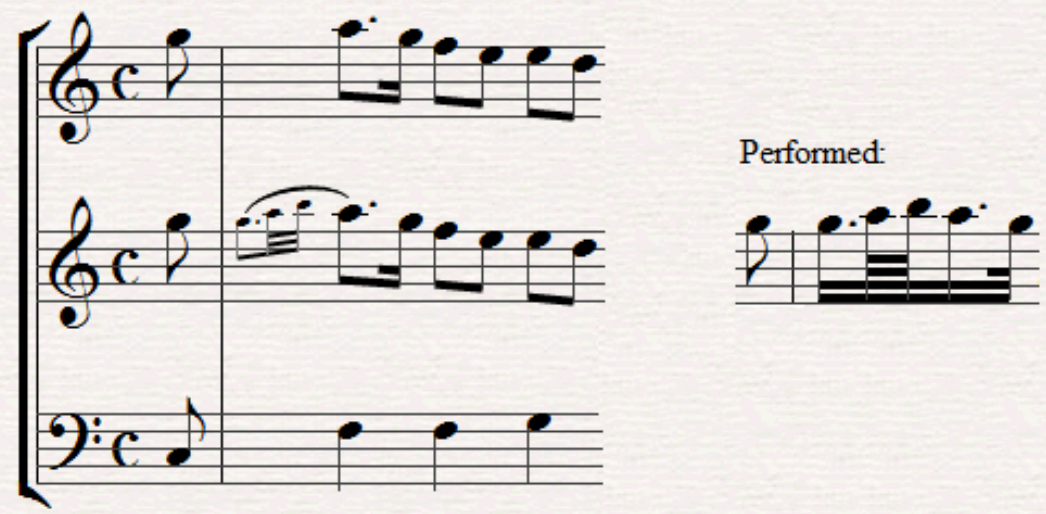

\section{Connective turns}

A turn that falls between beats, following a significant length of the main note, is a connective ornament. Bach recommends adding this type of turn to a note that is a) relatively long; b) tied; or c) dotted. 


\section{Ex. 2.48: Bach's between-beat turns}
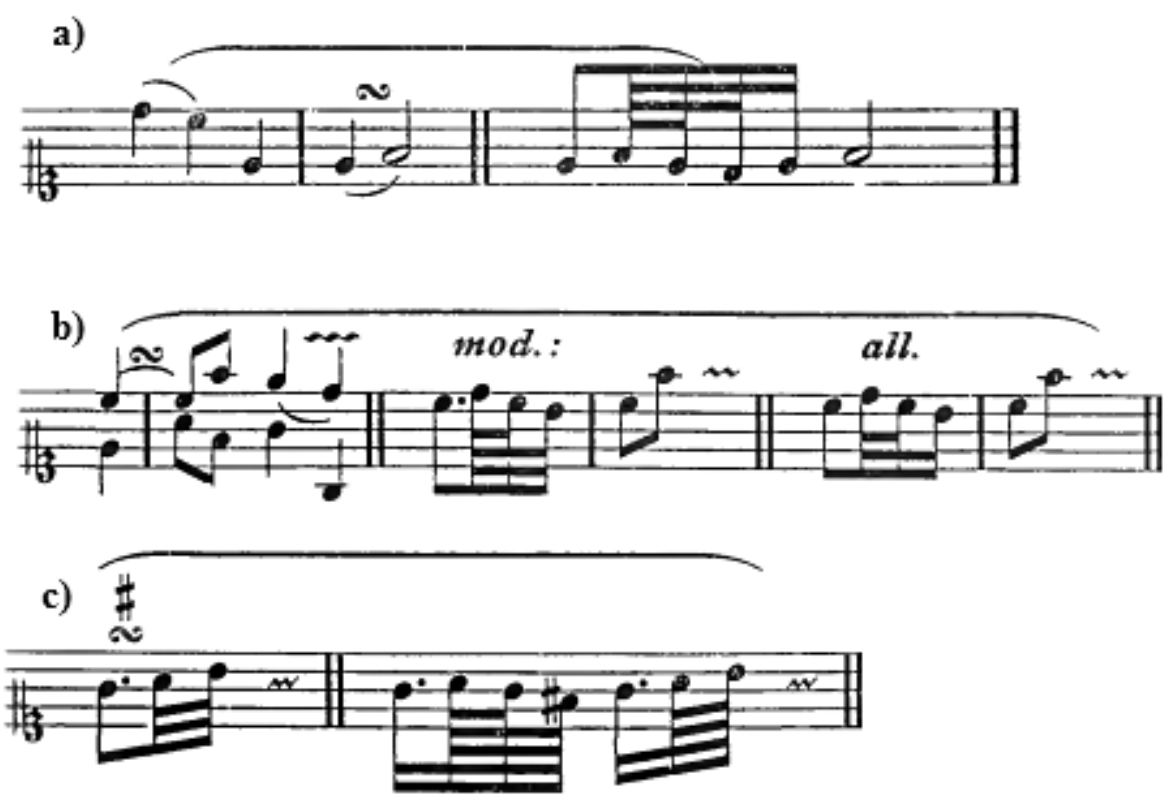

Bach's written-out examples feature rather strict rhythm. In the case of a), the turn occupies the second half of the note exactly. The resolution falls on the beat in the case of b) and on the half-beat in c).

Turns feature extensively throughout Quantz's variations on simple intervals. Example 3.7 in the following chapter shows two different connective turns and the pre-beat accentuating turn previously discussed. ${ }^{117}$

The various types of turns are just a few of the myriad possible ornaments consisting of clusters of neighbour notes. However, discussion of individual defined ornaments becomes impractical after this point. In the next chapter, I investigate non-defined or 'arbitrary' ornaments and how these can be used alongside essential ornaments to improve on the composer's original.

${ }^{117}$ Quantz, Versuch, 13/13 (fig. 2). 


\section{Extempore Variations}

\section{Diminutions}

The practice of embellishing a simple line with a large number of melodic notes was variously referred to as diminution, division, variation, or colouration; passaggi in Italian; or roulades in French. In some cases, the added notes are measured, each occupying an exact portion of the beat. Other additions featured rapid, slurred, and generally stepwise gestures that were performed freely. An example of the former can be seen in ex. 3.1, in which Muffat provides several useful diminutions for simple melodic progressions. ${ }^{118}$ The latter is shown in ex. 3.2, an excerpt from Estienne Roger's edition of Corelli's Op. 5 violin sonatas.

\section{Ex. 3.1: Muffat's measured diminutions}

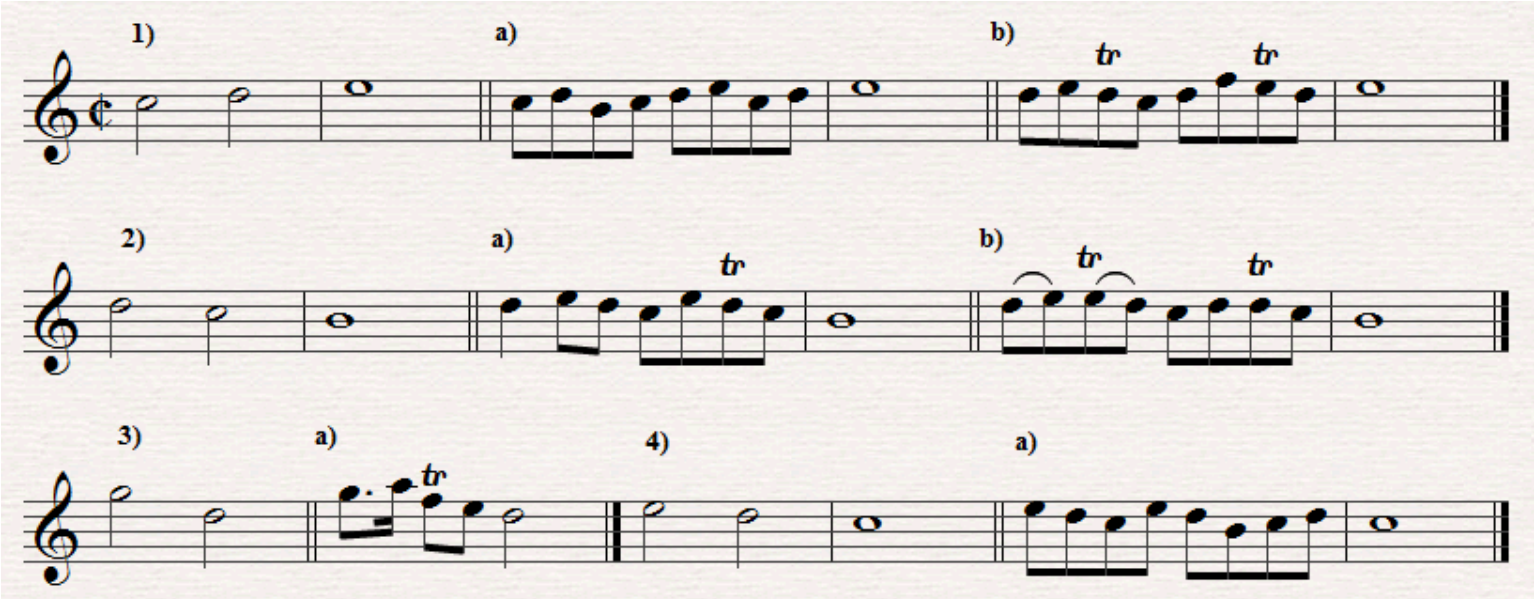

Ex. 3.2: Unmeasured diminutions in Estienne Roger's edition of Corelli's Op. 5

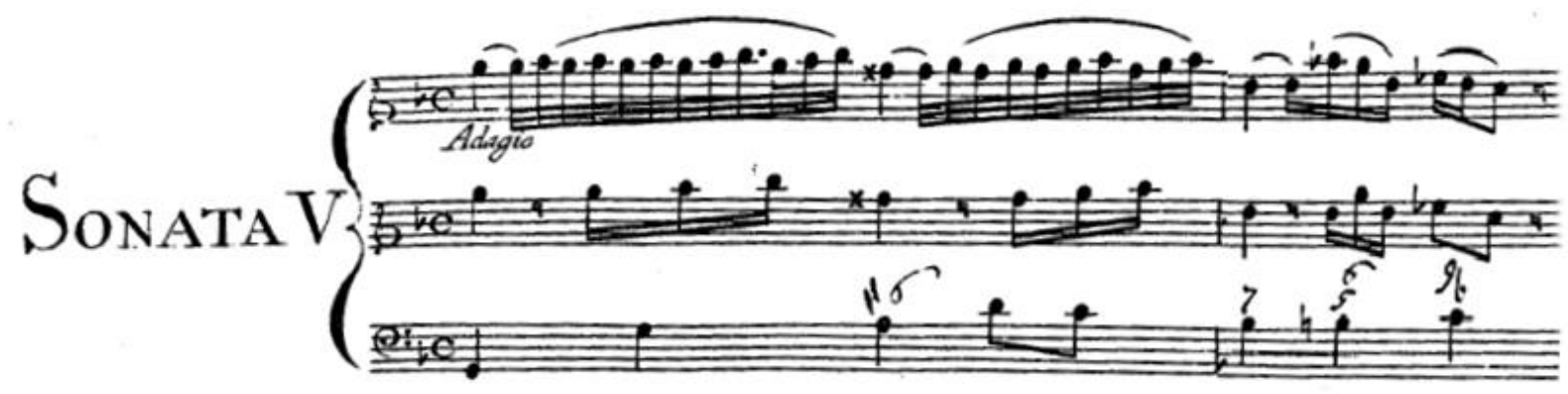

The ornamental notes in ex. 3.2 are notated with three beams, but due to their number they do not allow themselves to be literally interpreted as demisemiquavers. ${ }^{119}$ Similar unmeasured flourishes were

\footnotetext{
${ }^{118}$ Muffat, F. Secundum, 58-59 (fig. Yy).

${ }^{119}$ Bach's comment (Versuch, 157) on performing short notes after a dot could be relevant here. Such notes, he says, "are always shorter in execution than their notated length. ... when four or more short notes follow a dot they are played with dispatch, there being so many of them."
} 
commonly notated in small notes, as ex. 3.3 by William Babell shows. ${ }^{120}$

Ex. 3.3: Unmeasured flourishes in small notation in William Babell's Sonata No. 2

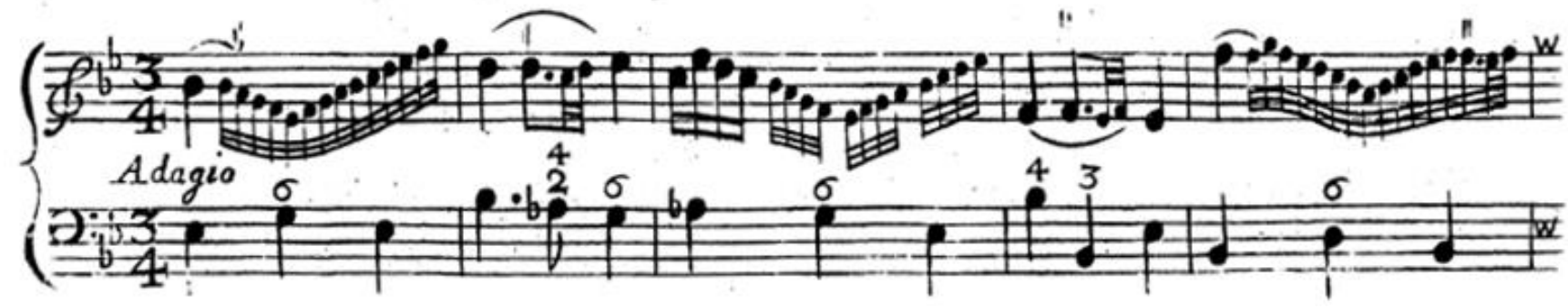

While unmeasured ornaments often featured in compositions, most treatises dealt primarily with measured diminutions. These were easier to notate and less likely to be misunderstood by the amateur musicians to which most treatises were marketed.

Four common Italian diminutions were described with a high degree of agreement by Mattheson and Mozart: the groppo, half-circle, tirata and the aforementioned ribattuta. ${ }^{121}$ Mattheson's examples of the groppo and half-circle follow in exx. 3.4 and 3.5 .

\section{Ex. 3.4: Mattheson's ascending and descending groppi}
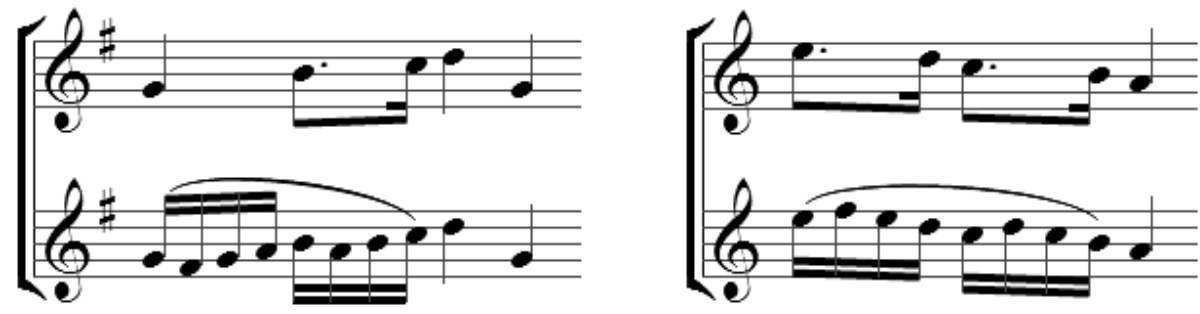

Ex. 3.5: Mattheson's descending and ascending half-circles
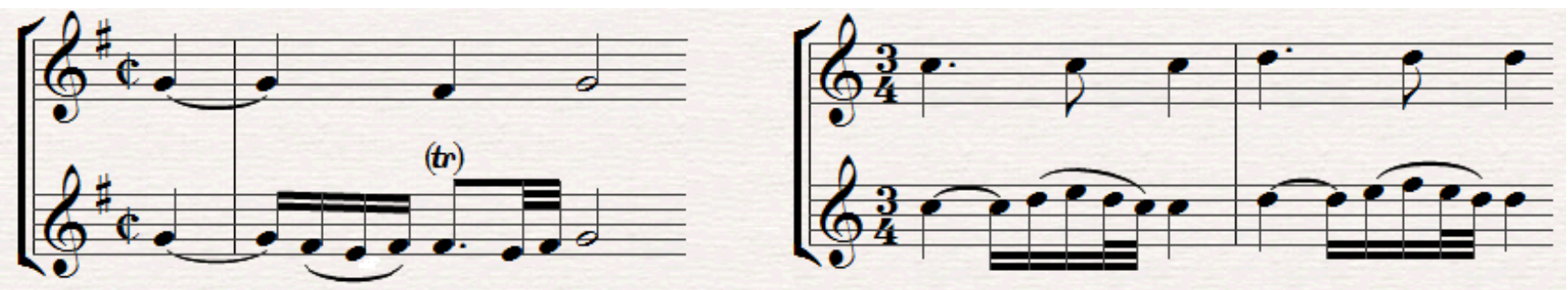

Mattheson's examples (like Mozart's illustrations of the same divisions, and Muffat's ex. 3.1 above) are presented in melody only. This was possible because the given patterns are suitable to play over any chord. This makes such formulae particularly convenient for teaching amateurs, for improvisation, and for ensemble players who have only their own part in front of them.

Such versatile diminutions, which I will refer to as 'linear' ornaments, generally fall into one of three groups. In the first are those that use the upper and/or lower neighbour, such as the groppo and Muffat's

\footnotetext{
${ }^{120}$ William Babell, 12 Solos for violin or oboe, Op. posthumous No. 1 (London: Walsh \& Hare, c. 1725).

${ }^{121}$ Mattheson, Der Vollkommene Capellmeister, 2/3/38-48; Mozart, Versuch, 11/18-19. These terms were relatively widely used, but as is to be expected, the application of names to formulae varies between theorists. The groppo or gruppo could also refer to a turn or turned trill. These three ornaments share the components of upper and lower neighbour note.
} 
example 1a. Essential ornaments such as the trill, mordent and turn also fit into this category.

The second type, including the half-circle and Muffat's examples $1 b, 2 a$ and $2 b$, utilises the range of a third above or occasionally below the principal note. A note a third above the principal is usually itself a member of the chord, or at the worst the seventh. The range of a third below, which is found in Muffat's example 4a and in the descending half-circle, is suitable provided the original melodic note is not the root of the chord. This commonly occurs in upper voices on the notes leading up to the resolution of a cadence, as seen in the examples above.

In the third category are ornaments that connect two disjunct notes, for which the Italian term tirata was commonly used in the German states. Mattheson's complaint about recent excessive use of this ornament also demonstrates the long history of the 'if I had a dollar' adage:

A short time ago people were so frightfully enamoured with this ornament that the composers writing in the most recent fashion would almost never compose an aria or symphony in which they did not use like figures frequently and explicitly; since this should rather be left to the choice of the singer or player and his discretion ... I say this much: if a tariff were to be laid to aid the church choir ... and the collection of this musical excise were charged to me, something substantial would result for the evangelical Levites. ${ }^{122}$

The Italian tirata refers either to shooting, as of an arrow, or to pulling. Mattheson denounces the latter interpretation, and slow variations of the tirata which might result from it, while Mozart allows both:

[A]s the tirata is no other than a sequence of step-wise ascending or descending notes, which are extemporised on the spur of the moment between two other notes which lie at some distance apart, there can be also a rapid [shooting] and a slow [pulling] tirata, according the whether the tempo be rapid or slow, or whether the two notes be far apart. ${ }^{123}$

After presenting straightforward stepwise ascending and descending examples of the tirata in a range of rhythms, Mozart provides several more creative examples in ex. 3.6. The first features chordal skips and an effective harmonic Vorschlag resolving onto the tonic, while the second and third examples feature chromatic motion and broken thirds respectively. ${ }^{124}$ The absence of any accompanying parts once again indicates that such embellishments can be used over any harmony.

\footnotetext{
${ }^{122}$ Mattheson, Der Vollkommene Capellmeister, 2/3/45.

${ }^{123}$ Mozart, Versuch, 11/20.

${ }^{124}$ Mozart, Versuch, 11/20-21. Chromatic ornaments were evidently rather popular in the 1750 s and possibly later, but there is little evidence for these figures in earlier decades. See also Quantz, Versuch, chapter 14, table 17, b. 7; and the excerpt from Tartini's treatise in ex. $3.8 \mathrm{~b}$ below.
} 


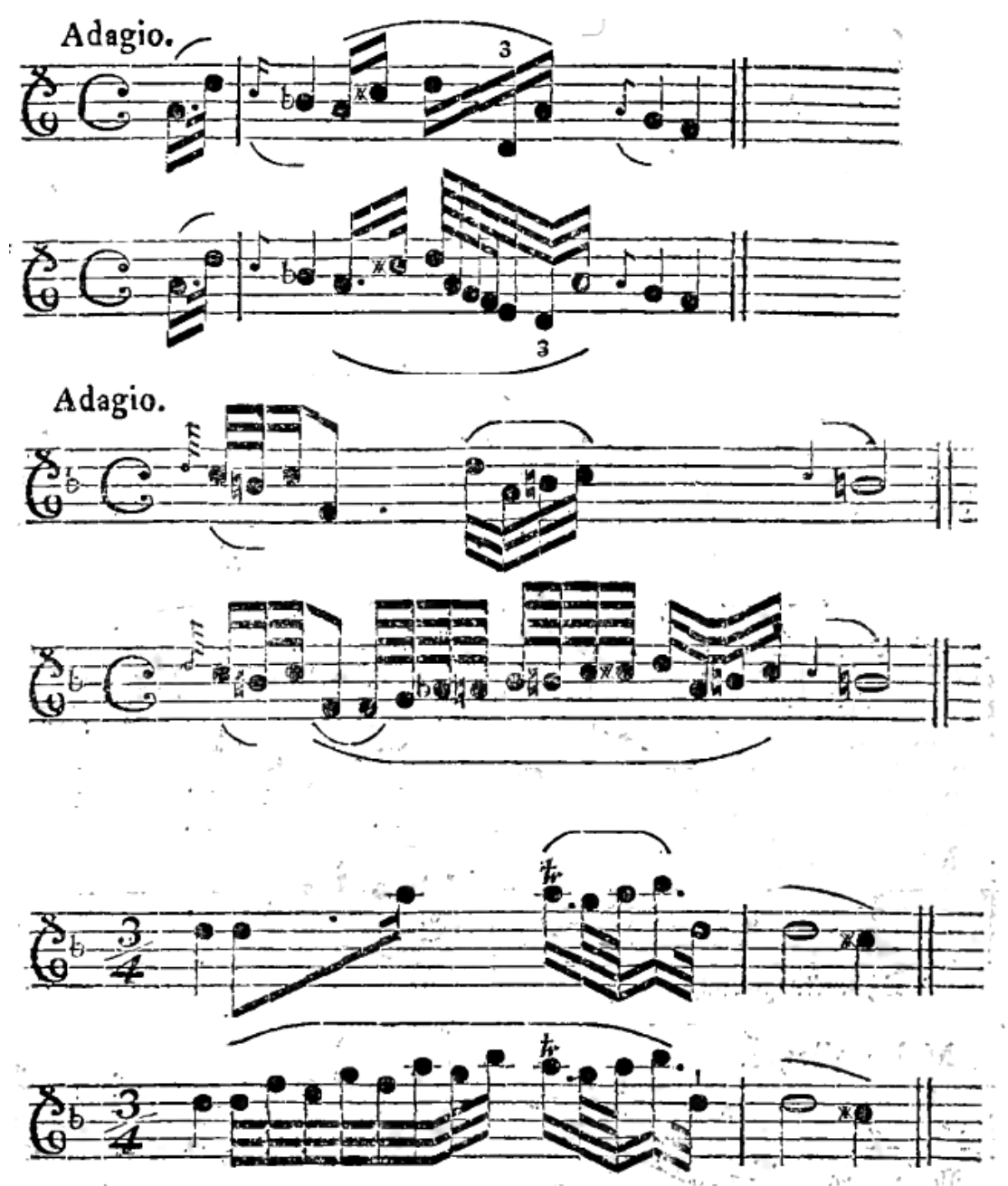

Quantz's famous variations on simple intervals are ostensibly appropriate for specific common chord progressions. The many diminutions in ex. 3.7 are prescribed for a 1-5-1 progression in C. However, analysis reveals that over half of the examples feature linear ornamentation which would be suitable in most circumstances. Examples a, f, h, and 11 use only the upper and lower neighbour notes, while b, c, $\mathrm{d}, \mathrm{k}, \mathrm{l}, \mathrm{o}, \mathrm{q}, \mathrm{r}, \mathrm{t}, \mathrm{w}$, and $\mathrm{x}$ (with octave transformation) have a range of a third above the main note. Example g combines both. ${ }^{125}$

${ }^{125}$ Quantz, Versuch, 13/13 (fig. 2). Variations m, p, and v actually ornament the progression C-D-C rather than the prescribed C-G-C. 

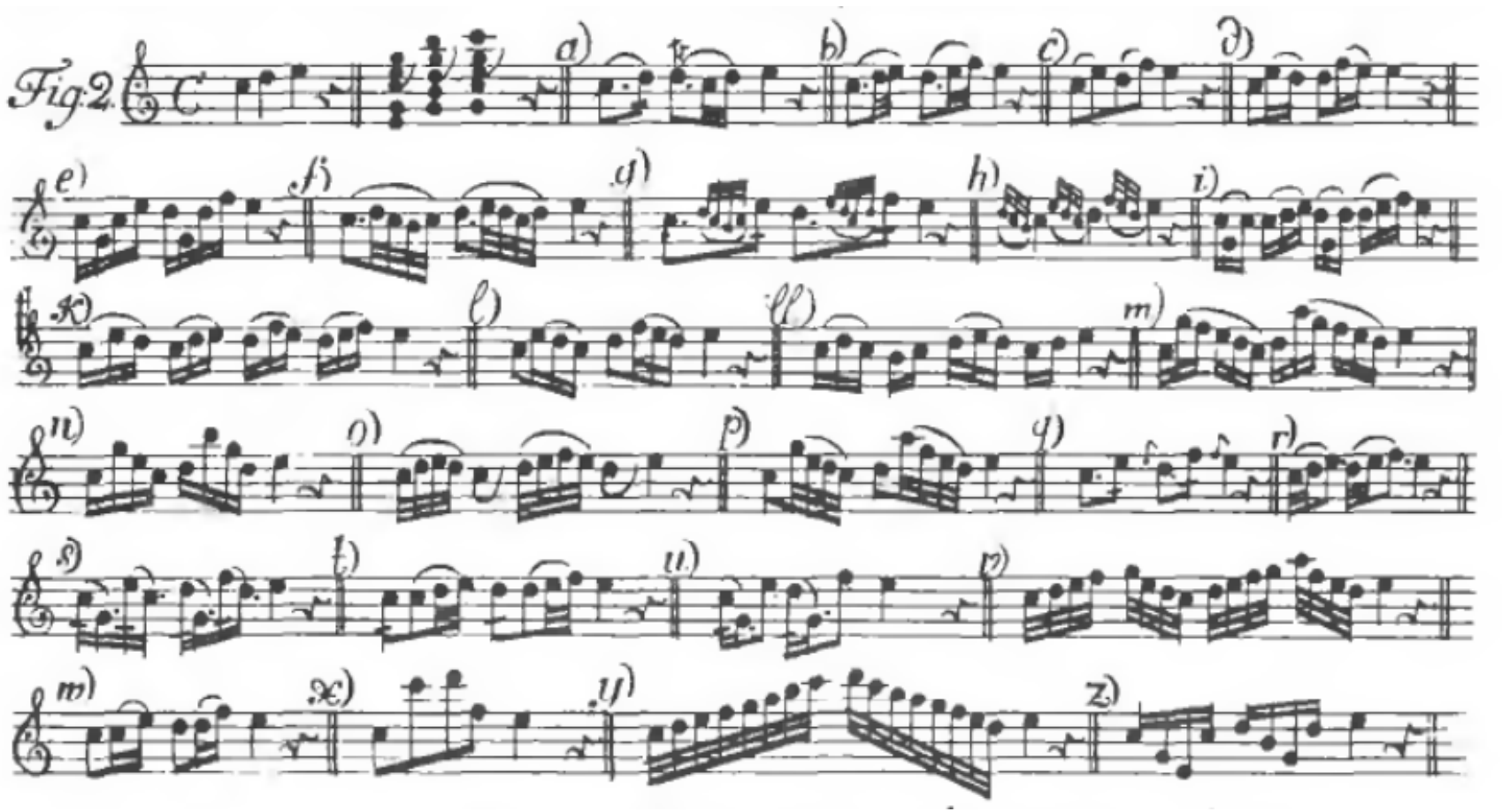

One can quickly see, based on the provided stacked chords, that in the case of the second note (D), the third above (F) is not in the chord. This is a good illustration of the universal applicability of diminutions of this category, which in this case feature the seventh of the chord. The frequent presence of the $\mathrm{F}$ can be further justified by its proximity to the following E.

Quantz's variations are reminiscent, in spirit if not in content, of the diminution treatises which were common in the $17^{\text {th }}$ century. ${ }^{126}$ However, by Quantz's own time these examples were very unusual. A rare and often overlooked analogue can be found in Tartini's treatise, in the form of close to a hundred examples of embellishments of common cadential progressions. This rhythmic variety of cadential embellishment is not the same as etymologically similar field of cadenzas, in which the accompanying voices must pause to wait for the soloist. Tartini distinguishes between the two by calling the former 'natural' and the latter 'artificial'. ${ }^{127}$

\footnotetext{
${ }^{126}$ Instrumental examples are mostly English publications, and include Christopher Simpson's The Division-Violist, or An Introduction to the Playing upon a Ground (London: William Godbid; John Playford, 1659); an unknown author's The Division Violin (London: Playford: 1684); Humphrey Salter's The Genteel Companion: being Exact Directions for the Recorder: with a Collection of the Best and Newest Grounds Extant (London, 1683). Many $17^{\text {th }}$-century German pedagogical treatises included large sections on diminution, although these are almost exclusively for the voice. Notable examples include Michael Praetorius's Syntagma Musica, part 3 (Wittenberg: Johannes Richter, 1619) and Wolfgang Caspar Printz's Anweisung der Singekunst (Guben, 1671).

${ }^{127}$ Tartini, Traité, 34. Notation of triplets and slurring varies between editions, but is only tangentially related to the purpose of this chapter.
} 


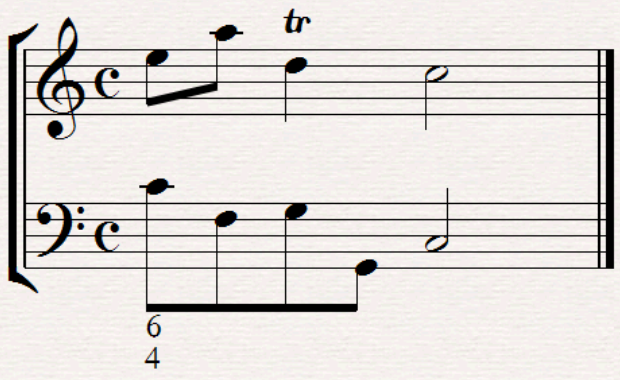

Ex. 3.8b: Tartini's embellishments for the above simple cadence
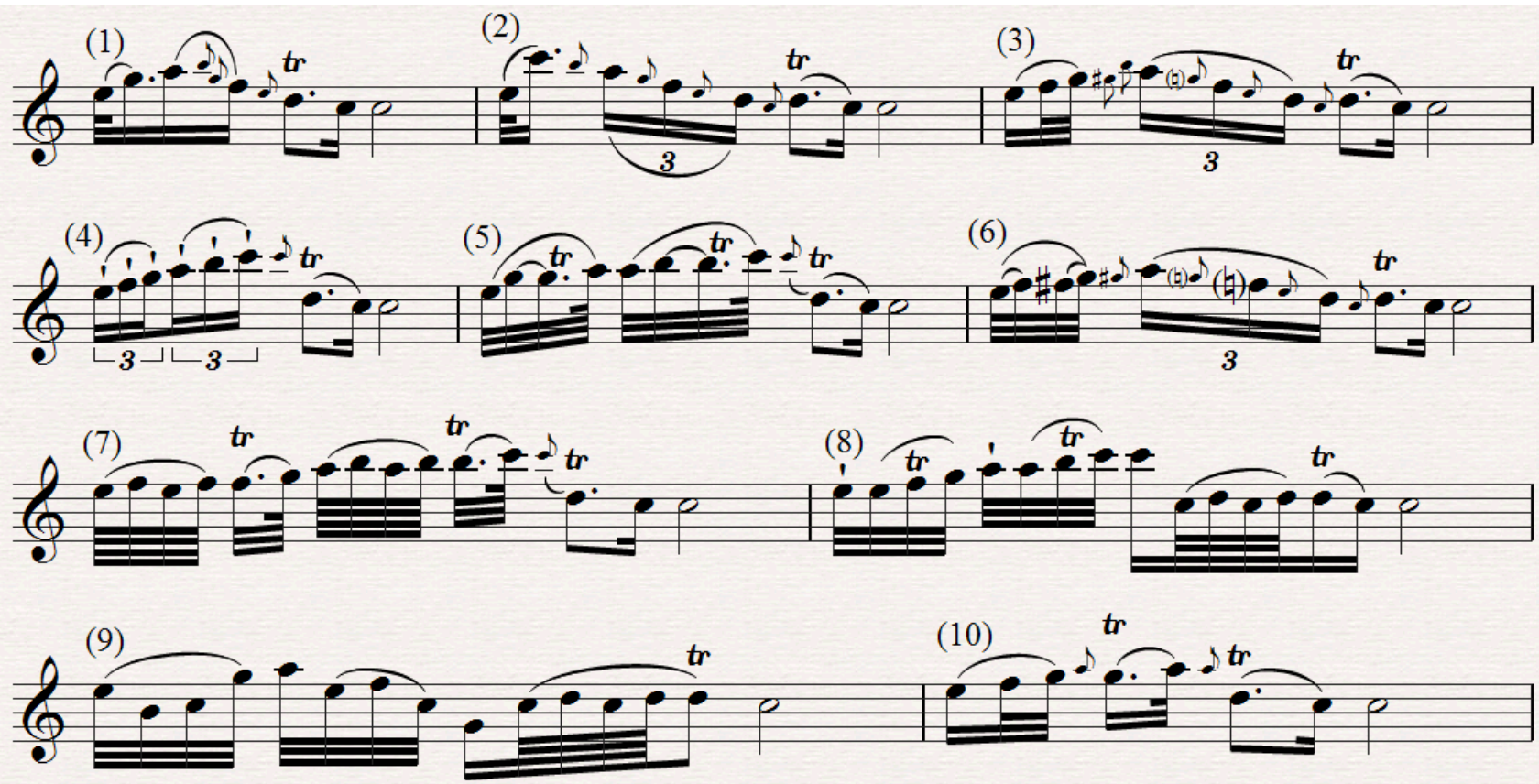

(11)

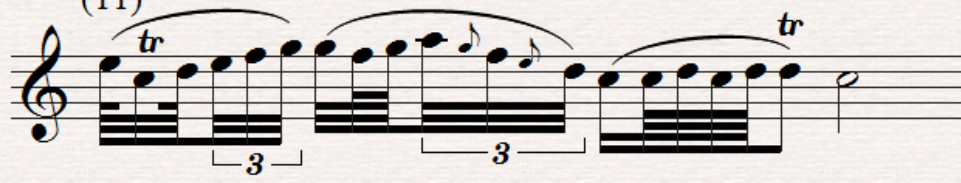

(12)

(13)

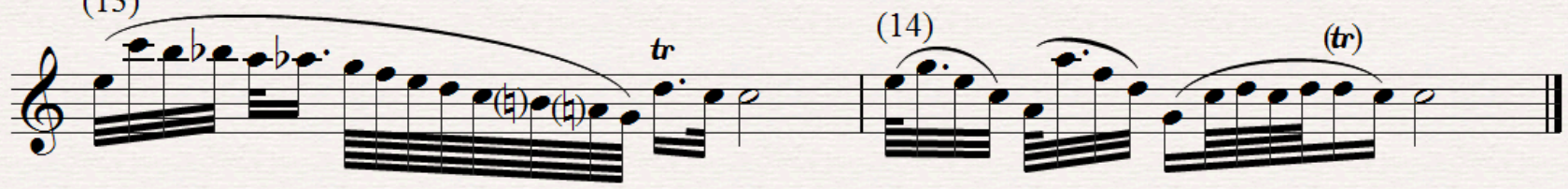

It is immediately apparent that Tartini's ornamentation is concentrated on the beat preceding the cadence itself. This is in each case only sparsely decorated, usually with no more than the compulsory trill and a Nachschlag. 
One could use components of these examples at other points within a phrase, provided the embellishment suits the melodic line. However, it is more useful to derive more general guidelines from these rare examples. Many feature rhythmic symmetry. Chromaticism and figures resembling the ribattuta or lower-note trill are also used frequently. An even more important principle illustrated here is the relationship between conjunct and disjunct motion. The large intervals at the start of examples 2 and 13 are followed by conjunct motion that fills in the interval - a generally applicable principle in composition and, by extension, ornamentation. Two exceptions to this rule are illustrated in these examples: the large leap commonly found immediately before the cadential trill; and arpeggiated passages where many chordal skips follow one another, as in examples 12, 14, and (with ornamental neighbour notes) example 9.

Muffat also provides a set of sample embellishments for cadential progressions, reproduced below in ex. 3.9. Although these examples are much simpler than Tartini's, the trend of concentrated embellishment on the beat before the cadence, followed by a simple trill and resolution, can be identified. This approach features throughout the remainder of this chapter, although the degree of embellishment varies widely.

\section{Ex. 3.9: Muffat's examples of cadential embellishment}

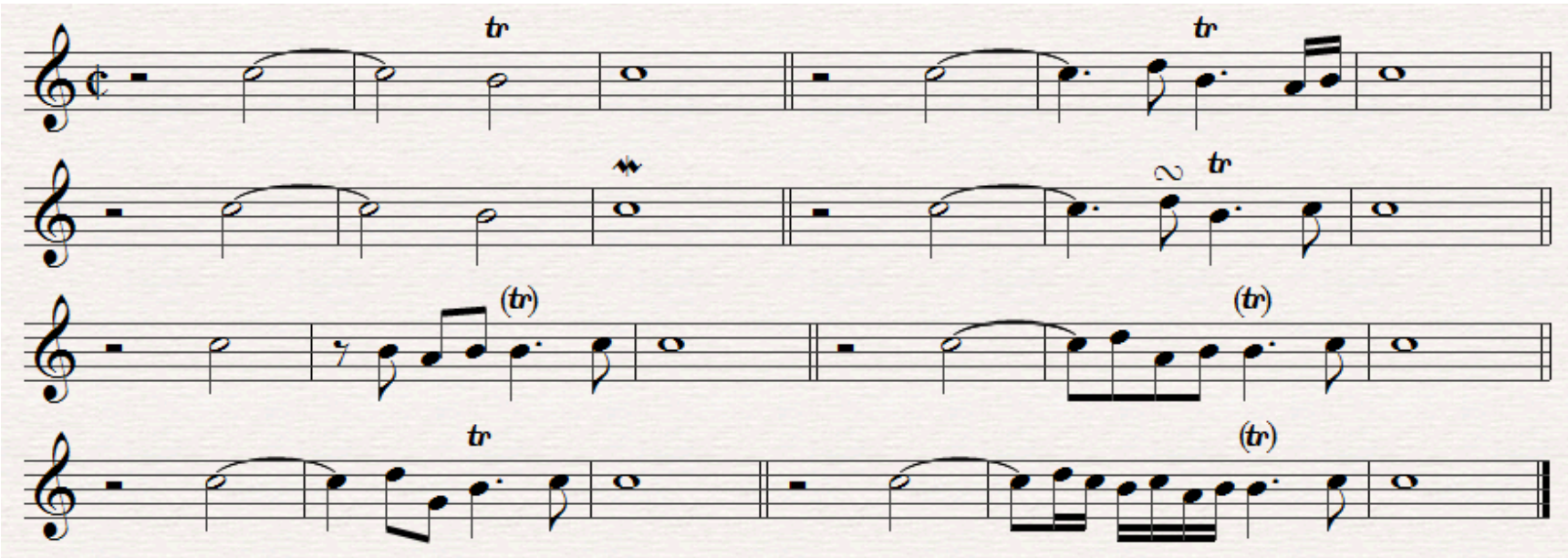

\section{Written advice on extempore variation}

In truth, one cannot complain of a lack of musical examples of diminutions. These are an excellent source of the musical motifs that form the building blocks of melodic variation. However, in order to create a pleasing elaboration of a piece or movement, the question of what ornaments or patterns are used is secondary to consideration of how these units are used.

Among the writers of his time, Quantz was the most permissive of substantial ornamentation. Before presenting his vast collection of variations, he acknowledges the almost universal existence of the culture of ornamentation:

Almost no one who devotes himself to the study of music, particularly outside France, is content to perform only the essential graces; the majority feel moved to invent variations or extempore embellishments. In itself this inclination is not 
to be condemned, but it cannot be realised without an understanding of composition, or, at least, of thorough-bass. ${ }^{128}$

Like his contemporaries, Quantz has plenty to say on the matter of poor or excessive ornamentation. Indeed, from the 1750s on, warnings against over-ornamentation outweigh practical advice on the subject. However, only two faults appear to have been universally condemned: namely, the insertion of variations of an incorrect harmony; and those of an incongruous character, such as "gay and bold variations ... in a melancholy and modest melody". ${ }^{129}$ On other issues, the opinions of theorists, performers and audiences differed.

Embellishments that were so elaborate or long that the accompanying voices were forced to wait in the manner of a cadenza were criticised in writing, but were evidently rather widespread. An example can be found in Johan Helmich Roman's version of a Corelli violin sonata. In ex. 3.10, the beat which precedes the cadence in b. 4 has 19 notes. This would be impossible to perform in time unless the overall tempo were excruciatingly slow.

\section{Ex. 3.10: Excerpt from Roman's embellishment of Corelli, Op. 5, No. 4, first movement}

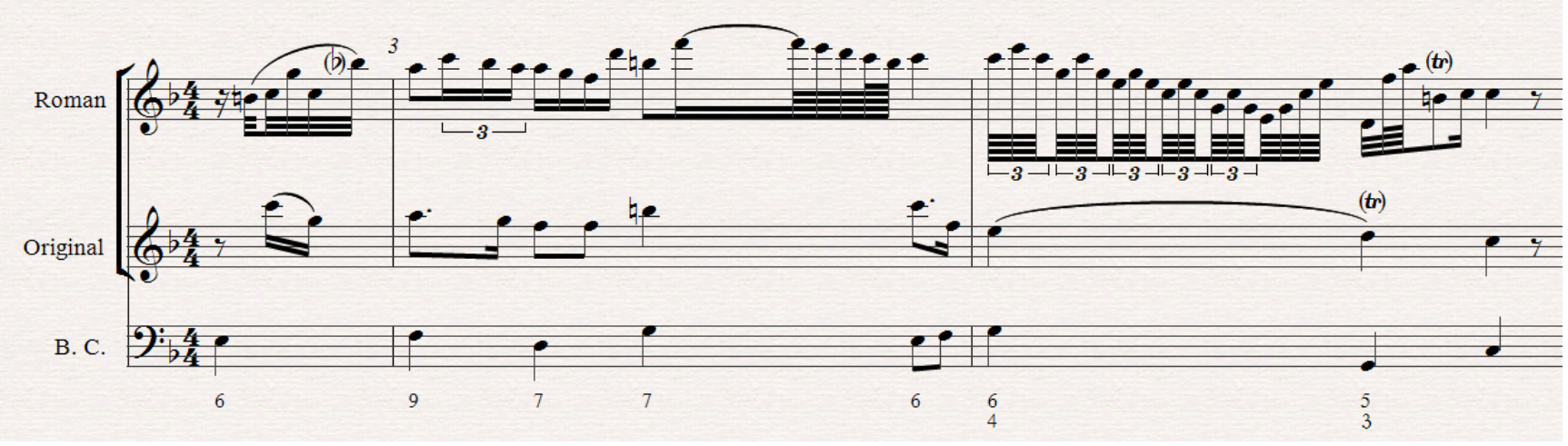

Roman's intriguing 'fantasy' on Corelli's movement would have come under fire from treatise writers on several additional points. The original notes are barely recognisable and often completely absent, and the embellishment, while creative and diverse, is consistently florid throughout the movement. Agricola may have had such treatment in mind when he issued these cautions:

A correct, pure and expressive performance of a melody, as prescribed by the composer and including the essential small ornaments, is preferable to a performance with variations that are excessive and exaggerated. Many singers are plagued with an overly zealous desire for variations, which they use ad nauseam. Nothing, however, is more insufferable that their not singing the simple prescribed melody at all, but singing [instead] monotonous, perhaps memorised variations twice [i.e., the first and second times of an aria's A section]. By doing this, they cancel out the actual purpose of the variations: namely, to provide variety by means of the alternation of the simple with the more complex. ${ }^{130}$

\footnotetext{
${ }^{128}$ Quantz, Versuch, 13/2.

${ }^{129}$ Quantz, Versuch, 13/8.

${ }^{130}$ Agricola, Anleitung, 235. See also Quantz, Versuch, 13/7: "the principal notes, on which the variations are made, are not
} 
The only true laws imposed upon the performer are those of aesthetics. Seen from this angle, it is quite possible to forgive variations that obscure or replace the original notes, when the result is pleasing. On the same grounds, contrast between simplicity and complexity should not lightly be sacrificed, as this technique almost invariably results in a more engaging performance. Quantz prescribes a specific approach to achieving such contrast:

Variations must be undertaken only after the plain air has already been heard, otherwise the listener cannot know if variations are actually present. ... If [the theme] returns frequently, a few notes may be added the first time, and still more the second, forming either running passage-work, or passage-work broken through the harmony [stepwise or arpeggiated divisions]. The third time you must again desist and add almost nothing, in order to maintain the constant attention of the listeners. ${ }^{131}$

Quantz provides a sample embellishment of a simple adagio, the opening of which can be seen in ex. 3.11. Many small ornaments are used, including the trill, turn, Anschlag (disjunct double Vorschlag), and harmonic and connective Vorschläge, in addition to diminutions in a wide range of rhythms. However, since he warns that his example is "overloaded with graces", more detailed analysis of his usage of small and large ornaments would be uninformative. ${ }^{132}$

\section{Ex. 3.11: Quantz's sample ornamented adagio}

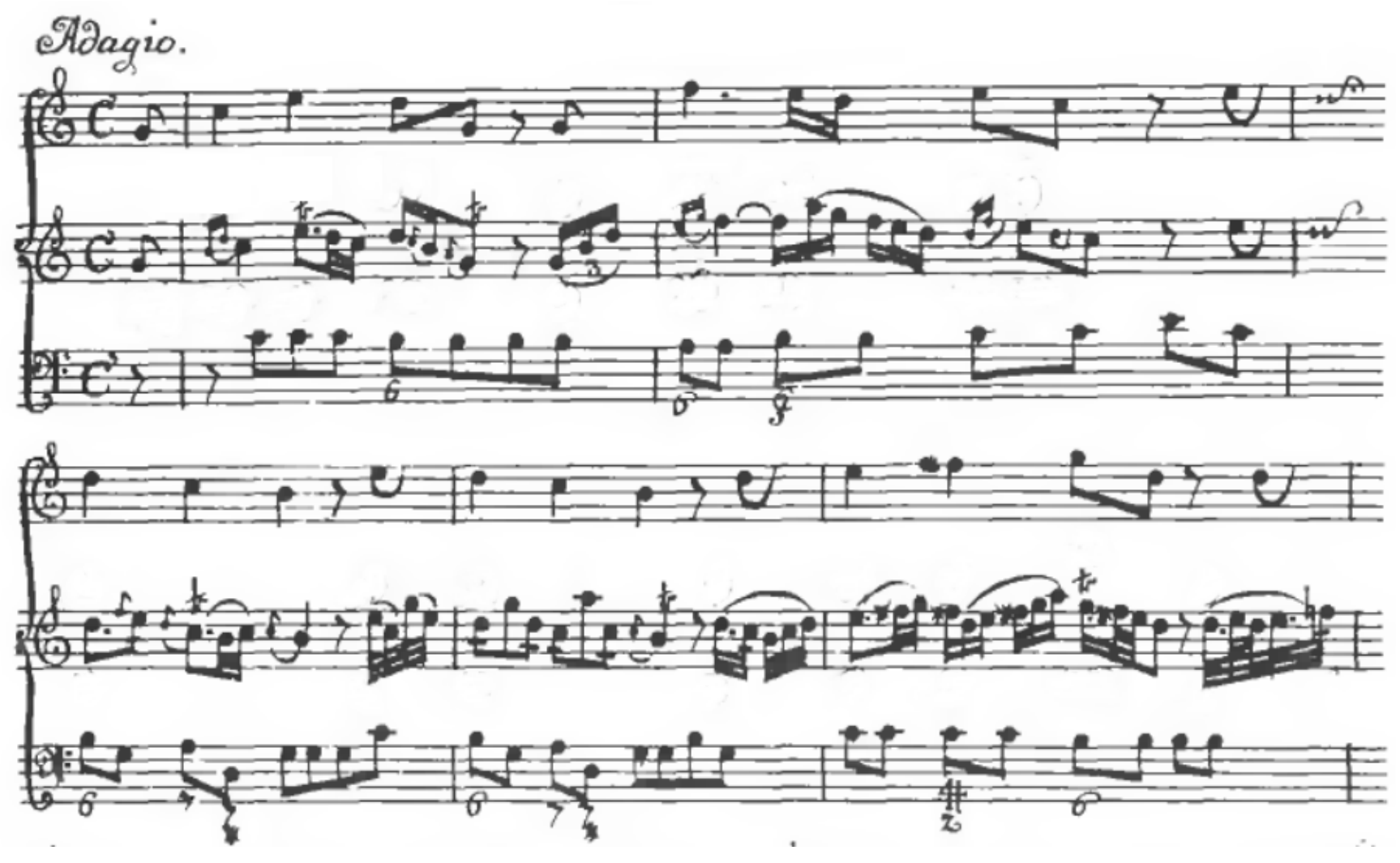

obscured ... usually the first note of the variation must be the same as the plain [original] note ... another note may be chosen from the harmony of the bass, but the principal note must then be heard immediately after it".

${ }^{131}$ Quantz, Versuch, 13/9, 14/14.

${ }^{132}$ Quantz, Versuch, 14/24 (table 17). 


\section{Musical examples of extempore variation}

The first few decades of the $18^{\text {th }}$ century produced several published examples of instrumental ornamentation that were intended for performance and imitation. To some degree, this trend may have been inspired by the unprecedented popularity of Arcangelo Corelli's Op. 5. This set of twelve sonatas for accompanied violin was first published in Rome in 1700 and formed the backbone of the solo violin repertoire throughout Europe until well into the $19^{\text {th }}$ century. Example 3.12 shows the typical simplicity of the adagios.

\section{Ex. 3.12: Corelli Op. 5, No. 3, first edition: opening}

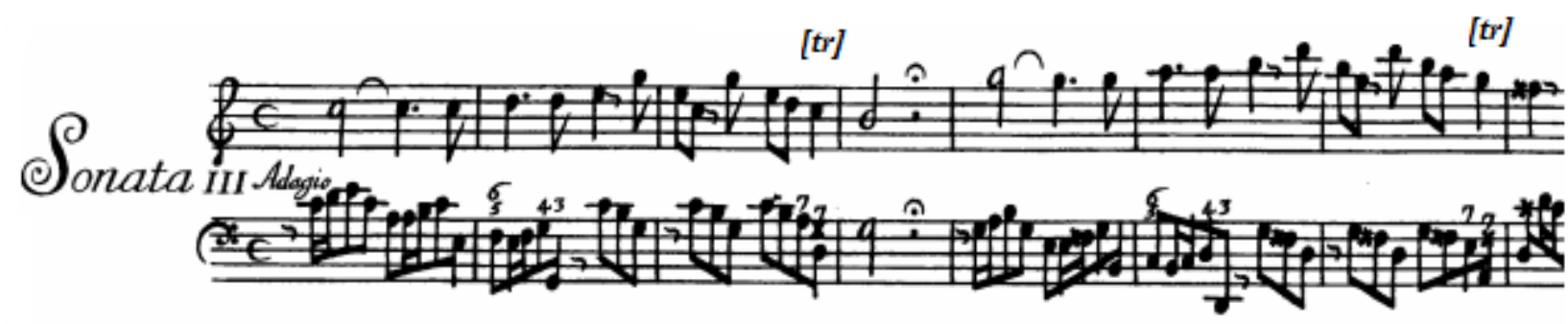

Performers of any century will agree that slow movements present a particular challenge. Charles Burney identifies embellishment as one of the tools available to a performer to create an engaging piece out of such a skeletal movement:

An adagio in a song or [instrumental] solo is, generally[,] little more than an outline left to the performer[']s abilities to colour: and the performer who is not enabled to interest an audience by the tone of his voice or instrument, and by taste and expression, should never be trusted with slow notes, in the performance of which the smallest defects are so easily discovered; and if not highly embellished, they soon excite languor and disgust in the hearers. The talent of executing an adagio well, in which performers of great powers of execution often fail, is a merit of the highest class which a musician can possess. $^{133}$

While Italian violinists were comfortable with the practice of creating their own embellishments, those native to other European countries evidently required some assistance. Within a decade, the first two ornamented versions appeared, which share the distinction of being published during the composer's lifetime. The first, an arrangement for recorder, consisted of just two of Corelli's sonatas tacked on to a 1707 London publication of unrelated recorder works. The embellished line was composed by an unnamed "eminent master" and was printed in place of, rather than in addition to, the original melody. ${ }^{134}$ The first violin embellishment was published in 1710 by Estienne Roger, a significant printer based in Amsterdam. This edition provided an ornamented line on a separate stave for the twelve slow movements of the first six sonatas. Roger claimed publicly that Corelli himself had composed this ornamented version, announcing shortly before the edition's release that he was "presently engraving the ornaments of the adagios of these sonatas, which Mr. Corelli himself has been

\footnotetext{
${ }^{133}$ Abraham Rees, The new Cyclopedia, or, Universal Dictionary of the Arts and Sciences (London: Longman, 1802-20), Vol. 1 (1802). 'Adagio' entry written by Charles Burney.

${ }^{134}$ Christopher Pez, A second Collection of Sonatas for two Flutes and a Bass (London: Walsh \& Hare, 1707). The inclusion of the Corelli sonatas, and their eminent ornamentation, was advertised in the Post Man, April 12-15, 1707.
} 
good enough to compose completely afresh, as he plays them. These will be true violin lessons for all amateurs." 135

Dispute over the authenticity of the graces began almost immediately with Roger North and continues to this day. ${ }^{136}$ However, the question is not strictly relevant - regardless of true authorship, the 1710 edition represents a contemporary and popular example of ornamental practice. It was extensively copied and republished across Europe, and remained worthy of mention in Quantz's treatise nearly half a century later. ${ }^{137}$ For the sake of convenience, I will follow the example set by Neal Zaslaw among others in referring to this version as Corelli's. ${ }^{138}$

The opening of the third sonata, seen above in ex. 3.12, follows in these two earliest embellished versions.

\section{Ex. 3.13: Corelli Op. 5, No. 3: opening}
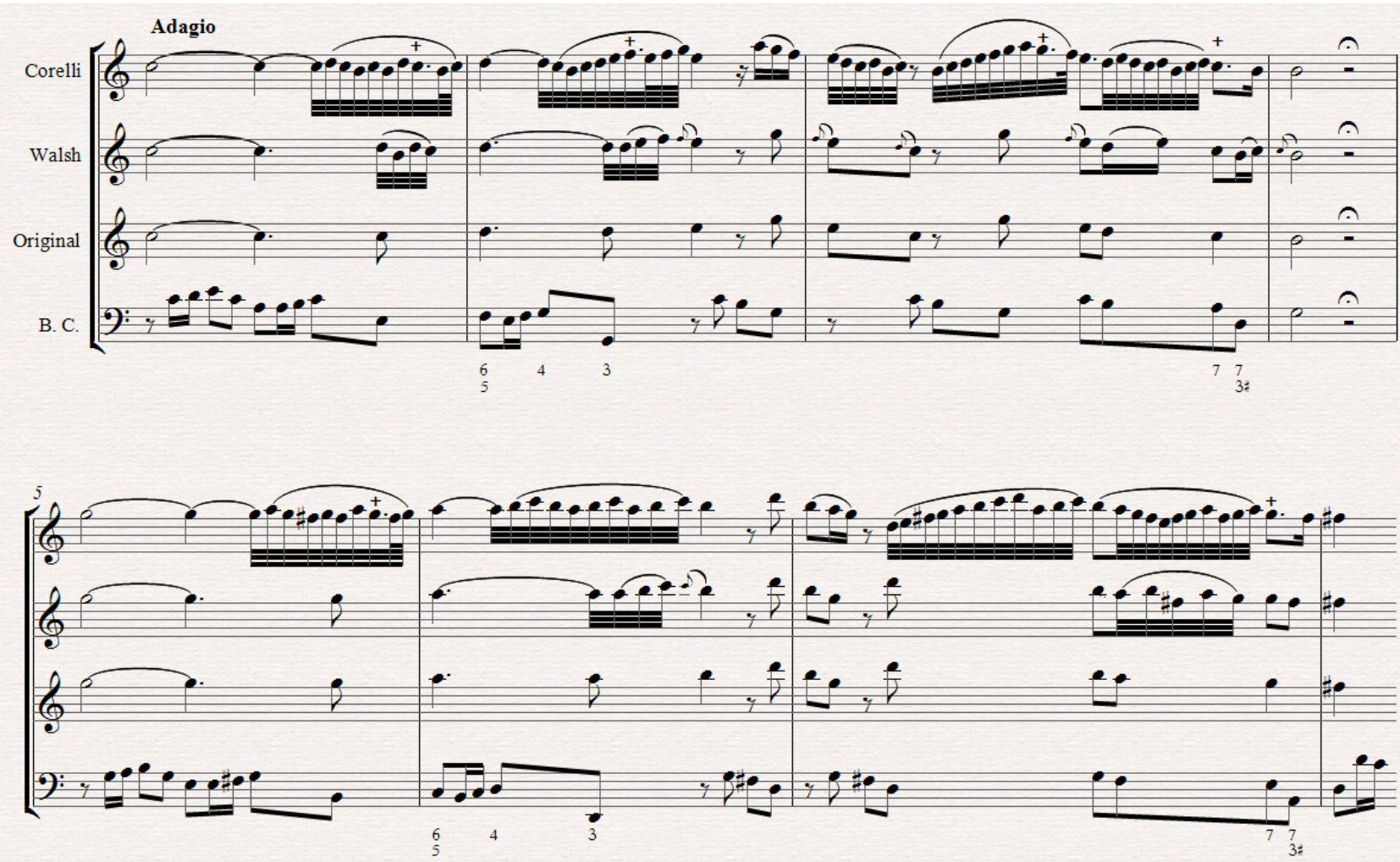

It can be immediately seen that Corelli's version is far more florid than Walsh's restrained opening.

${ }^{135}$ F. Lesure, 'Estienne Roger et Pierre Mortier: un épisode de la guerre des contrefaçons à Amsterdam', Revue de musicologie (1956), Vol. 38, 41-42, trans. Neal Zaslaw in 'Ornaments for Corelli's Violin Sonatas Op. 5', Early Music, Vol. 24, No 1, February 1996, 109.

${ }^{136}$ Roger North on Music: Being a Selection from his Essays written during the years c. 1695-1728, ed. John Wilson (London: Novello, 1959), 161: "[s]ome presumer hath published a continuall course of this sort of stuff [rapid graces, which are ineffective at a distance] in score with Corelly's solos ... Upon the bare view of the print any one would wonder how so much vermin could creep into the works of such a master." Nicholas Cook, in 'At the borders of Musical identity: Schenker, Corelli, and the Graces', Music Analysis, Vol. 18, No. 2 (July 1999), 179-80, names Pincherle, Boyden, Stowell, and Rangel-Ribiero alongside Zaslaw who champion Corelli's authorship. Donington, Bukofzer and Neumann believe that the edition is a forgery; "mainly, it appears, because they do not consider them good enough to be Corelli's" (Cook, 180).

${ }^{137}$ Quantz, Versuch, 15/2.

${ }^{138}$ Zaslaw discusses the reasons for his belief in 'Ornaments for Corelli’s Violin Sonatas', 102-04. 
While the edition attributed to Corelli represents either genuine or imitation Italian practice, Walsh's "eminent master" was catering to the tastes of the London public, and elected to increase note density gradually over the course of the movement.

Despite the rather different scale of the embellishment, some comparisons can be made. In both cases, the longest notes of the original are left plain, and rapid notes are used to lead towards the following strong beat. In this excerpt and throughout both editions, more notes are typically used immediately before cadences, but the cadences themselves are treated very simply.

The excerpt in ex. 3.13 above is a four-bar phrase which is then repeated immediately in the dominant. The embellished versions both acknowledge this repetition with some identical and some new material (see Corelli bb. 1 and 5, Walsh bb. 2 and 6).

Nicholas Cook draws attention to a point later in the same movement where Roger's ornamentation not only highlights but creates structure that was "at best implicit" in the original. The downbeat of b. 13 features a cadence in the relative minor, A. Compare the next bar (see ex. 3.14) with the opening of the same movement (ex. 3.13 above). ${ }^{139}$

\section{Ex. 3.14: Corelli Op. 5, No. 3: middle of first movement}

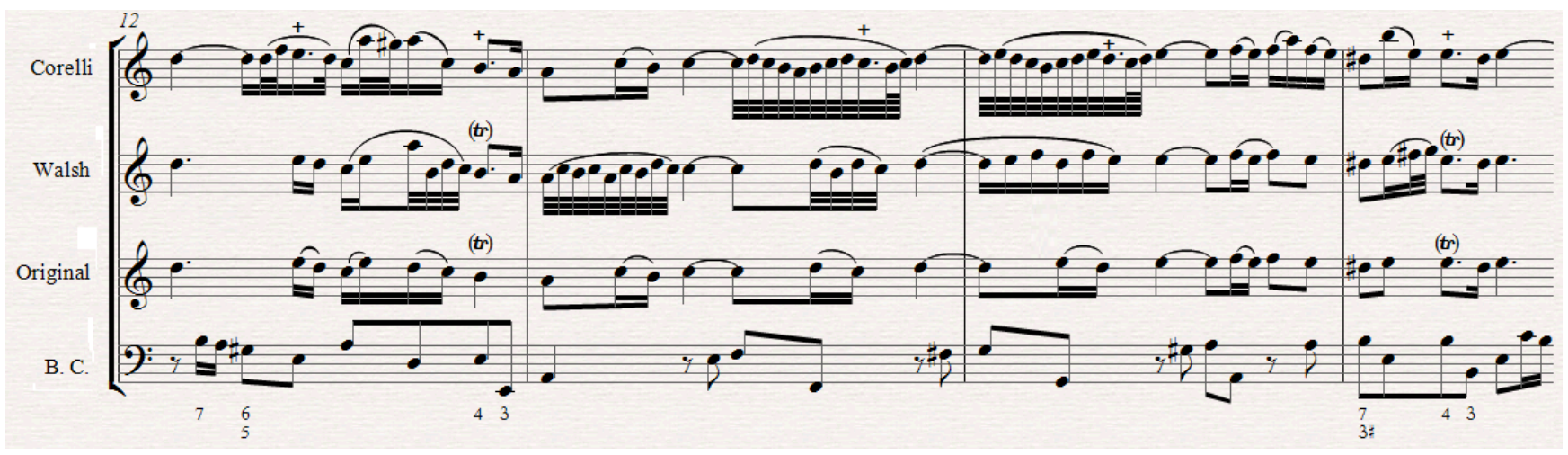

The original melody of both sections is similar only in featuring the melodic progression C-D-E. Corelli's version uses this vague similarity as a basis for identical embellishment that, although it lasts only one bar, is enough to give the impression of a recapitulation of the opening material. This takes place almost exactly in the middle of the movement, and evokes the familiarity of binary form.

Walsh's ornaments in ex. 3.14 bear no resemblance to the opening of the movement - as can only be expected. However, the notes also do not appear to react to the rising sequence present in the original. In general, Cook's observation that the "graces tend to elaborate each figure as it comes, almost one note at a time" is very accurate. ${ }^{140}$

In Corelli's version, such examples of ornamental liberty - for the most noble of ends - are not isolated. A similar case of structural use of embellishment can be seen in ex. 3.15, in which identical embellishment is added to two very different cadences. The distinctive rising trill-like figure is first used in the middle of the movement, then again to herald the end.

\footnotetext{
${ }^{139}$ Cook, 'Schenker, Corelli, and the Graces', 185. There is, apparently, a mistake in b. 14 of Roger's edition. This has an extra tied crotchet on the downbeat, resulting in five beats in this bar. Omitting this crotchet was the only sensible interpretation, which also increases the resemblance to the opening.

${ }^{140}$ Cook, 'Schenker, Corelli, and the Graces', 185.
} 

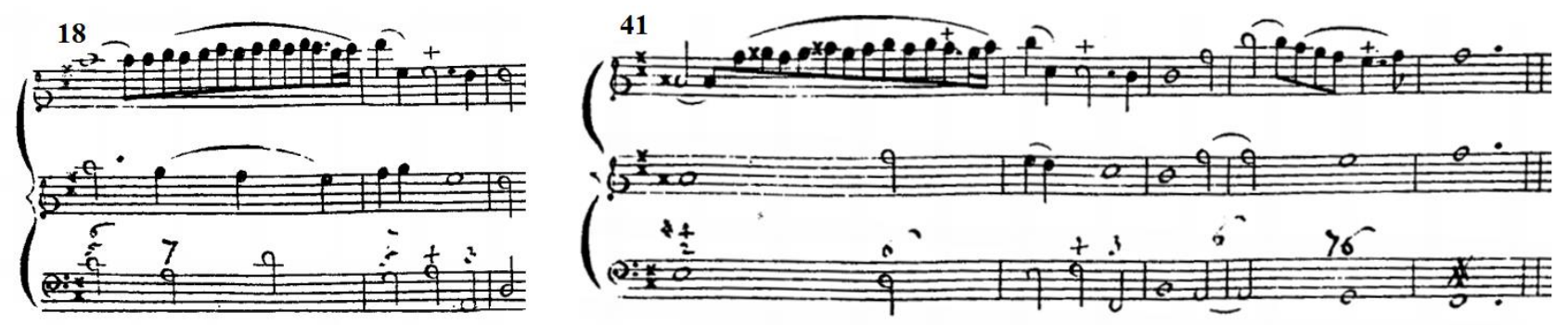

The note density of the two editions is more similar in the fourth sonata, in which the recorder arrangement features many more of the sweeping flourishes that were equated with Italian ornamental virtuosity. Example 3.16 presents sections where gestures from the original melody are repeated in the continuo part.

\section{Ex. 3.16: Interplay between parts in Corelli Op. 5, No. 4, first movement}

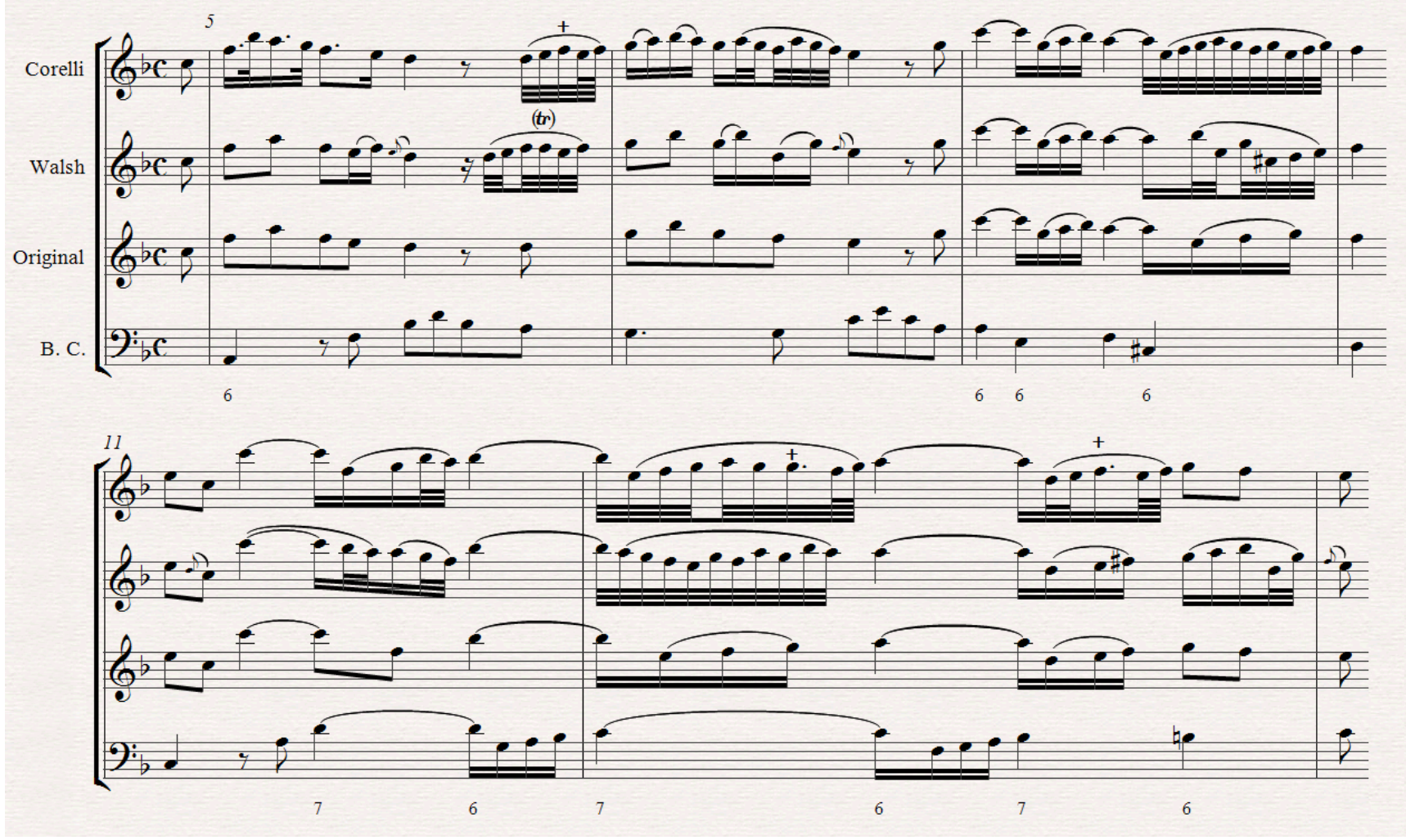

Evidently, the exchange of melodic material between players did not constitute an imperative for completely unornamented performance, although it may have inspired some restraint in this case. A skilled continuo player could mimic some of the soloist's extemporisations, although this theory is complicated by interpretations of the commonly prescribed accompaniment of 'violone o cimbalo'. ${ }^{141}$

${ }^{141}$ There is ongoing discussion over whether the ideal accompaniment for such sonatas consisted of both a keyboard and a bass stringed instrument, or either one alone. See for example Peter Walls, History, Imagination and the Performance of Music (UK: Boydell Press, 2003), 30-43. 
Corelli's longer flourishes feature three characteristic endings. Four examples in ex. 3.13 above finish with a short, terminated trill. A further four in the same excerpt finish by falling a third or fourth before rising three notes, arriving immediately above the next note. These two rising figures lead towards and accentuate the following note, and can be found throughout the above examples and the set of sonatas as a whole. The third formula, which features in ex. 3.17 below, is a 'curved' falling relaxation that anticipates the following note with both upper and lower neighbour notes.

\section{Ex. 3.17: 'Curved' endings in Corelli Op. 5, No. 5, third movement}

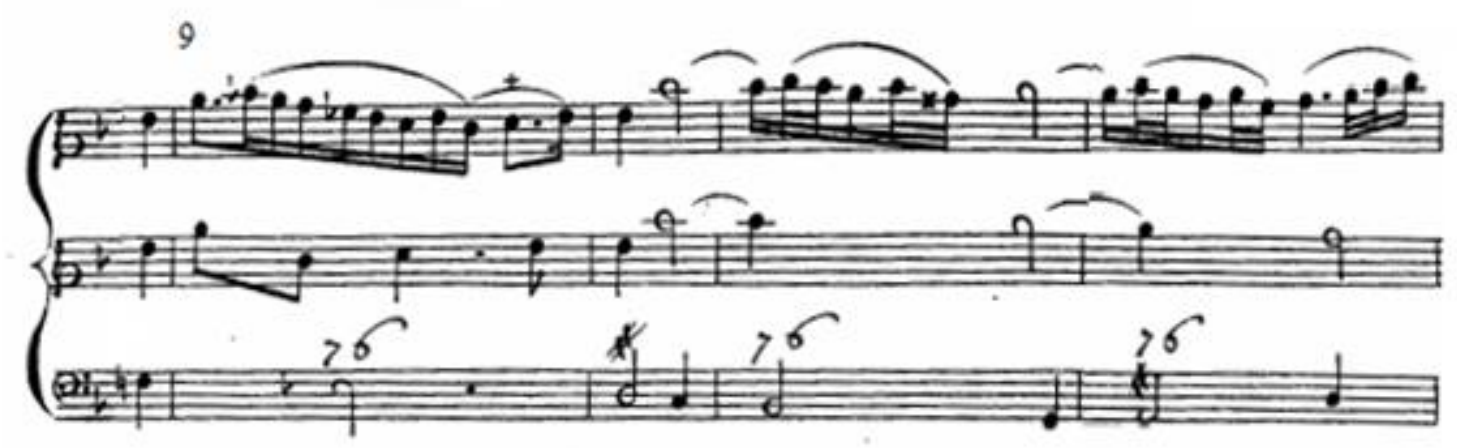

No such patterns can be found in Walsh's flourishes, which appear to be very nearly all unique. Where Corelli's ornaments consist almost exclusively of conjunct motion, Walsh's edition embraces broken thirds and leaps among scale passages. Most of Corelli's very few leaps and arpeggiated segments occur immediately before cadences, and the same trend can be identified in Walsh. ${ }^{142}$ In general, conjunct motion is more often congruous in a slow and melancholy or tender movement. The strategic placement of occasional leaps to herald cadences is another way in which the ornamentation accentuates the structure of the original movement.

England appears to have been among the countries most receptive to ornamented instrumental works in the early $18^{\text {th }}$ century. However, most of the published examples, like Walsh's recorder arrangement of Corelli, gave only the ornamented line. It would be relatively difficult, although not impossible, for the performer to use these ornamented editions to create a new and substantially different embellished version of the piece. This implies that there was a sizeable number of English amateurs who favoured fully composed works, relying less on their own ornamental input.

This is not to say that no English musicians of the early $18^{\text {th }}$ century varied and ornamented pieces. William Babell, whose works featured briefly above in ex. 3.3, was best known for his heavily ornamented and technically demanding arrangements of popular arias, many by Handel. The twelve Solos for violin or oboe, published after his death in 1723, show the influence of the mixed style. The unmeasured flourishes found throughout this set of sonatas are immediately reminiscent of the Italianstyle Corelli arrangements; however, Babell also makes extensive use of characteristically French unaccented grace notes.

Ex. 3.18: William Babell's Sonata No. 2 from Op. Posthumous No. 1

\footnotetext{
${ }^{142}$ See for example ex. 3.14 , b. 12 in both editions, b. 15 in Corelli; and ex. 3.16, b. 12 in Walsh. In ex. 3.16, the ornament on beat 4 of b. 12 in the Walsh edition appears to be embellishing a $\mathrm{G}$ minor chord rather than the prescribed $\mathrm{G}$ major.
} 


\section{Sonata}

II

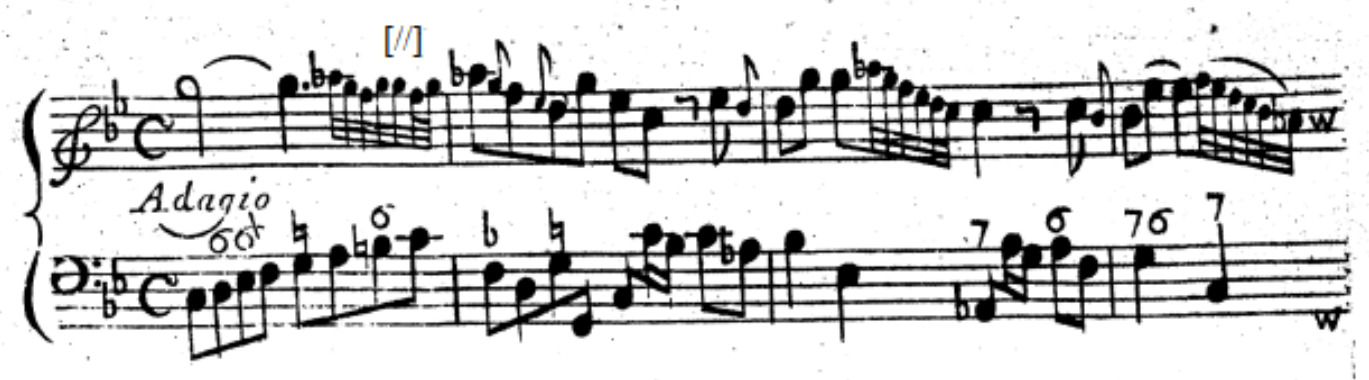

Babell's flourishes frequently use two of the three characteristic endings found in Roger's arrangement of Corelli. The terminated trill can be seen above in the last bar of ex. 3.3, and the falling 'curved' ending features in the excerpt in ex. 3.19 below.

Ex. 3.19: 'Curved' endings in Babell's Sonata No. 1

Sonata I

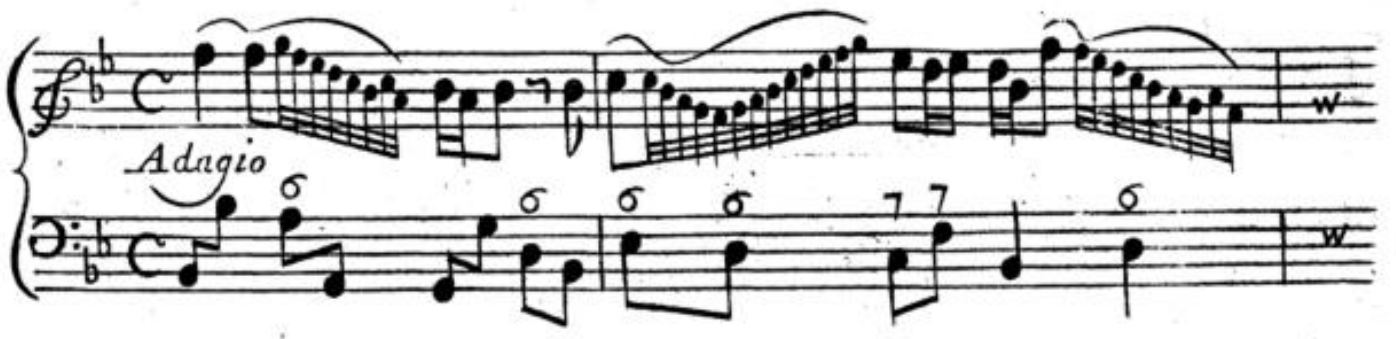

Geminiani's 1739 reworking of his own Op. 1 violin sonatas, first published two decades previously, further demonstrates the English popularity of more explicit prescription of ornaments. The French orientation of the ornaments in ex. 3.20 is clear.

Ex. 3.20: Geminiani's alterations to his Op. 1, No. 1
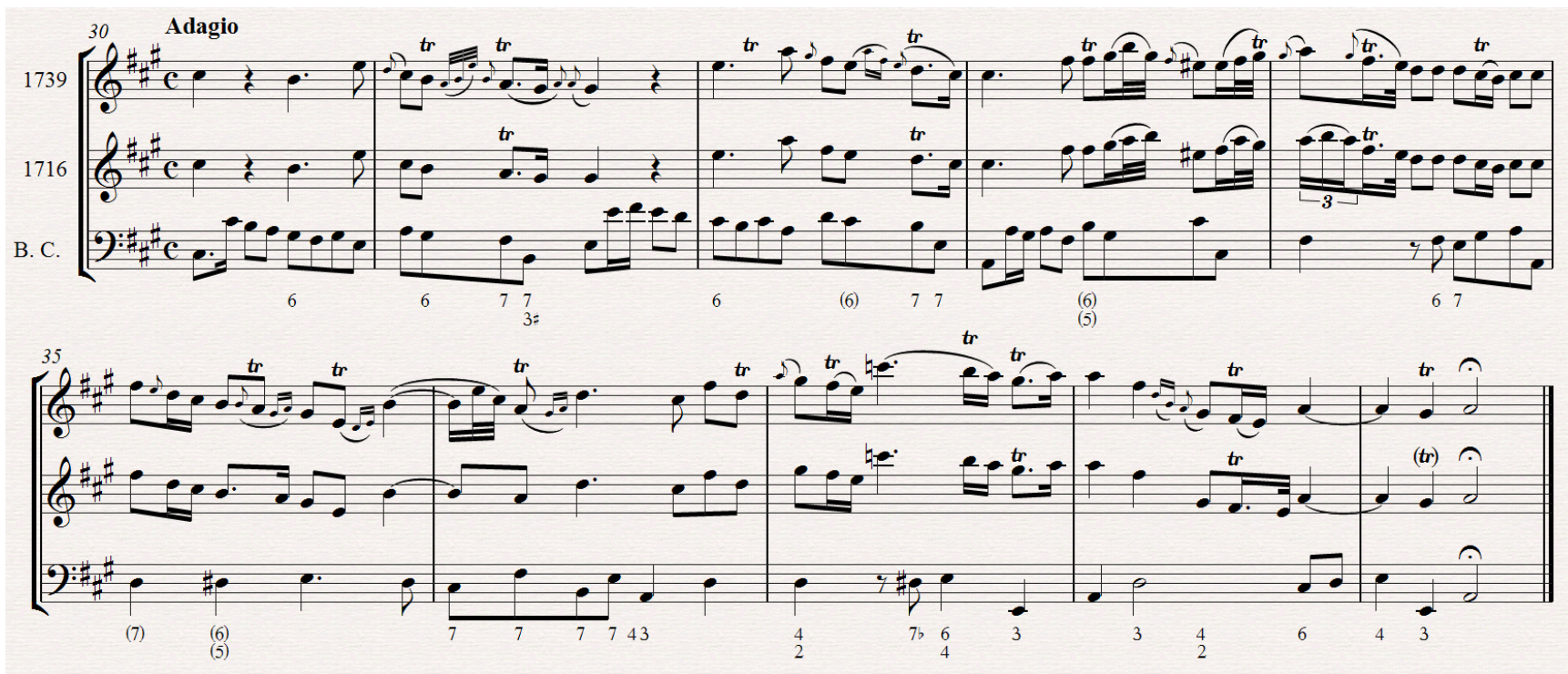
Unlike these English examples, Telemann's twelve Methodical Sonatas of 1728 and 1732 for violin or flute are not performers' editions but pedagogical resources. ${ }^{143}$ One slow movement from each sonata features an embellished line printed below the original melody. As in Corelli's sonatas, the movements are not repeated, so the ornamented line must take the place of the original melody. Other slow movements also invite ornamentation, as do the repeats of many fast movements. The set is also valuable for several written-out cadenzas.

The ornamented movements are in a variety of tempos and characters, allowing the composer to demonstrate many different techniques and approaches to ornamentation. Example 3.21 shows the opening bars of the first sonata. These bars demonstrate both 'linear' ornamentation and more harmonically significant figures consisting of arpeggios or featuring other notes of the chord.

\section{Ex. 3.21: Telemann Methodical Sonata No. 1: first movement}

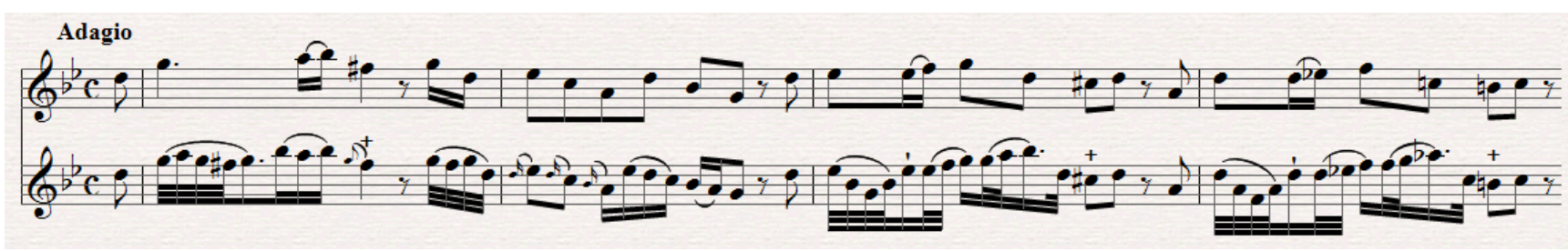

The sequence in bb. 3-4 is ornamented identically, even including details of articulation. However, the recapitulation of the opening melody a few bars later (see ex. 3.22) is given new, although not completely unrelated, ornamentation.

\section{Ex. 3.22: Telemann Methodical Sonata No. 1: recapitulation of first movement}

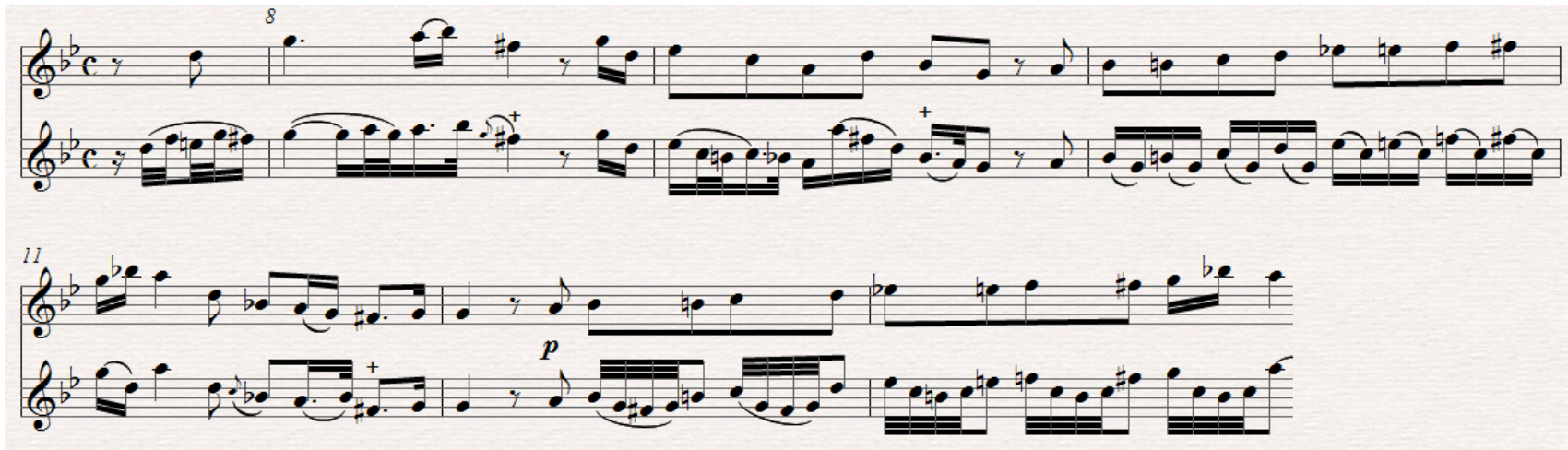

The second half of the excerpt in ex. 3.22 above features a rising chromatic line which is repeated twice. The second instance is more elaborately embellished.

The first four sonatas follow this format in the treatment of repeated material. Melodies that are repeated immediately are ornamented identically, while those that are repeated in different parts of the movement, such as the recapitulation of the opening theme which occurs in every case, are treated differently. Repeated figures such as the chromatic line in ex. 3.22, which have less melodic

\footnotetext{
${ }^{143}$ G.P. Telemann, Sonate Metodiche à Violino Solo ò Flauto Traverso da Giorgio Filippo Telemann (Hamburg: 1728) and Continuation des Sonates Methodiques, à Flûte traverse ou â Violon ... Composées par George Philippe Telemann (Hamburg: 1732). While the languages of these title pages might appear to indicate that the sets are composed in the Italian and the French manner respectively, both are in fact representative of the mixed style in which Telemann excelled.
} 
significance, are generally treated differently, commonly increasing in complexity on the second iteration. By following this structure conspicuously at the beginning of the work, Telemann appears to be recommending it as a starting point. Later sonatas are less formally structured and demonstrate a range of alternative approaches.

In typical galant style, the original melodies are generally periodic and constructed out of units which are repeated and varied. The same repetition of rhythmic or melodic ideas is also evident in the ornamentation. However, if the same melodic fragment appears more than twice in the original melody, it would be unattractive to ornament these identically every time. Telemann demonstrates this in the second sonata. The similarity between the first and second halves of ex. 3.23 is enough to lend a sense of congruity to the movement, but the differences are sufficient to keep the listener's interest. This excerpt is also a good illustration of Telemann's approach to the introduction of triplets, which are used liberally in some movements and are completely absent in others.

\section{Ex. 3.23: Telemann Methodical Sonata No. 2: treatment of repetition}

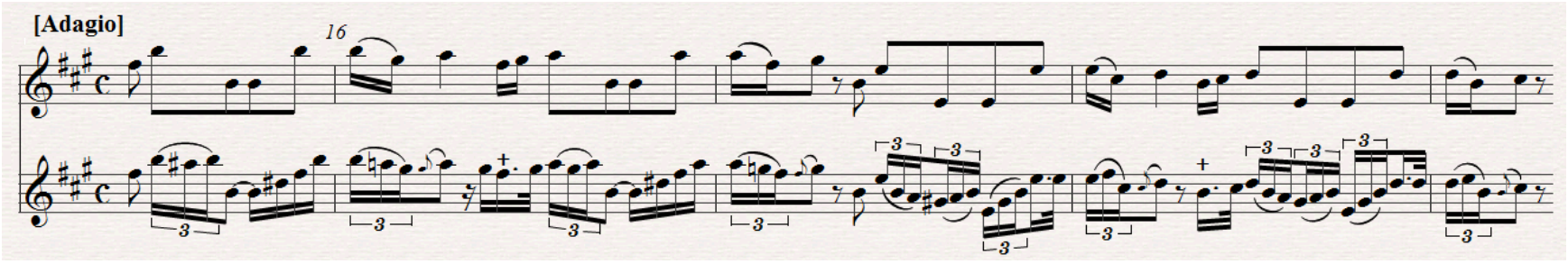

Syncopations are a feature of several movements. These are ornamented in a variety of creative ways while retaining the essence of asymmetric rhythm. Example 3.24 demonstrates several of these. In bb. 8-9, the rhythm is diminished, resulting in twice as many syncopations of shorter value. Those in b. 7 and on the first beat of b. 11 are transformed into equal semiquavers, but the accentuation of the second semiquaver is retained due to the slur. Syncopated rhythms are also added in bb. 10-11 where they were absent from the original melody.

\section{Ex. 3.24: Syncopations in Telemann Methodical Sonata No. 9, first movement}
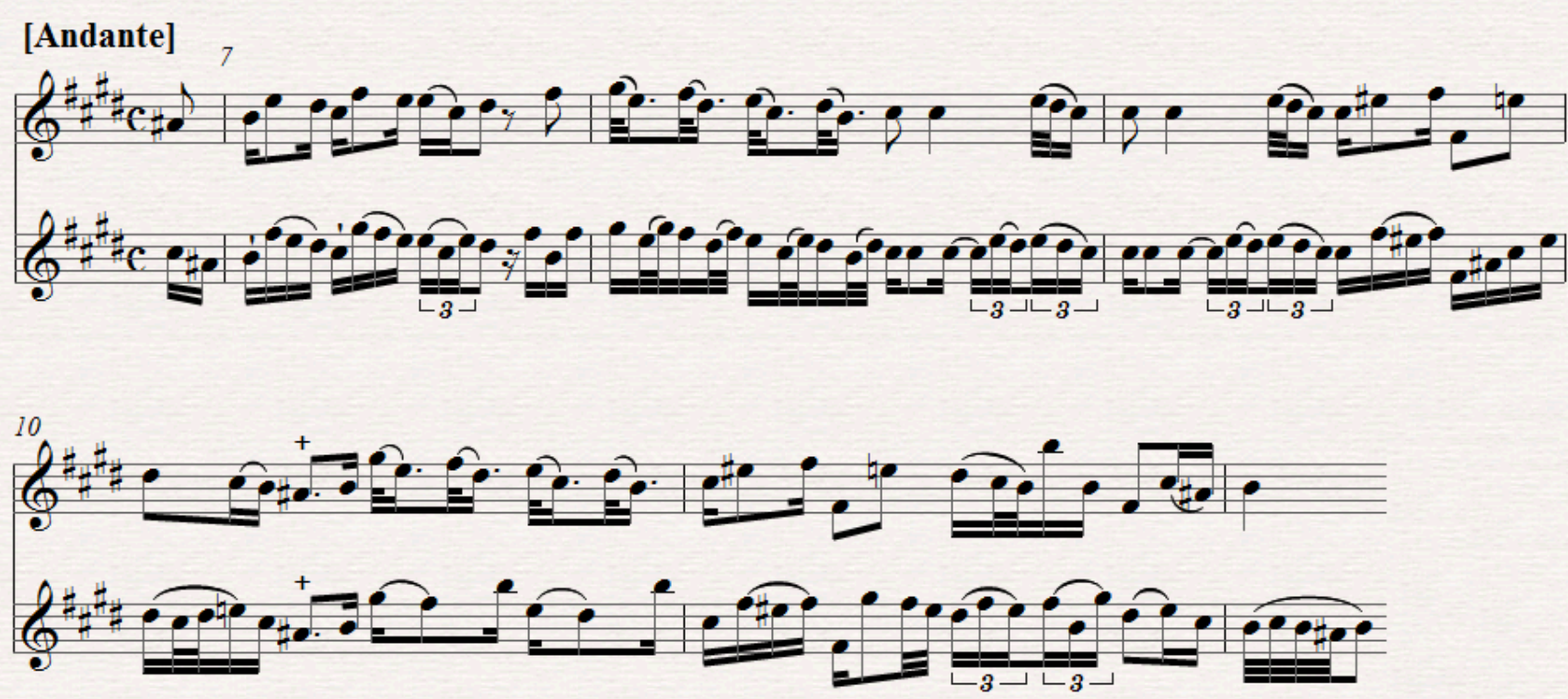
Example 3.25 shows the opening bars of Sonata No. 11. The syncopation in the first bar begins at the same time in the embellishment, but is shortened slightly to allow space for more notes to follow. In the second bar, the slur and rest serve to accentuate the second, fourth and sixth quavers, effectively creating a more rapid syncopated rhythm.

\section{Ex. 3.25: Telemann Methodical Sonata No. 11: opening}

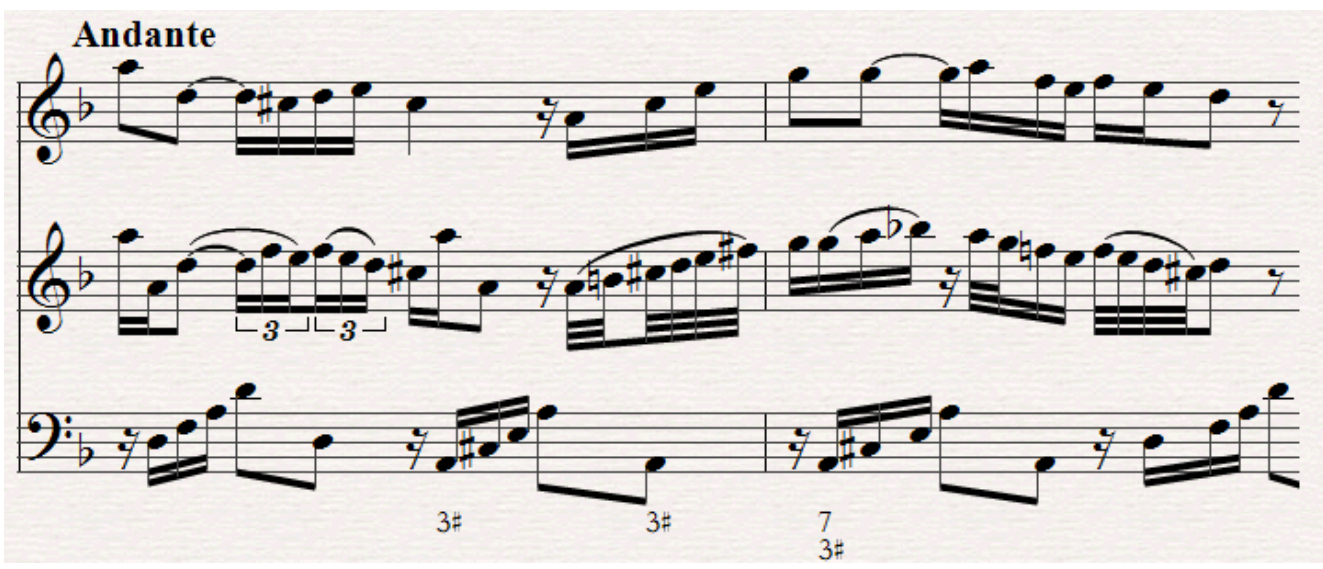

This excerpt is also notable for the interplay between parts. Throughout much of the movement, the bass repeats a distinctive arpeggiated chord. The same figure also features in the original melodic line at the end of the first bar, but this is obscured by the embellishment (see ex. 3.25 above). Two later instances of this figure in the original violin part are also obscured in different ways. Example 3.26 below shows how Telemann compensates for this near the end of the piece by bringing in a similar rhythm in imitation of the bass.

\section{Ex. 3.26: Imitation between parts in Telemann Methodical Sonata No. 11}

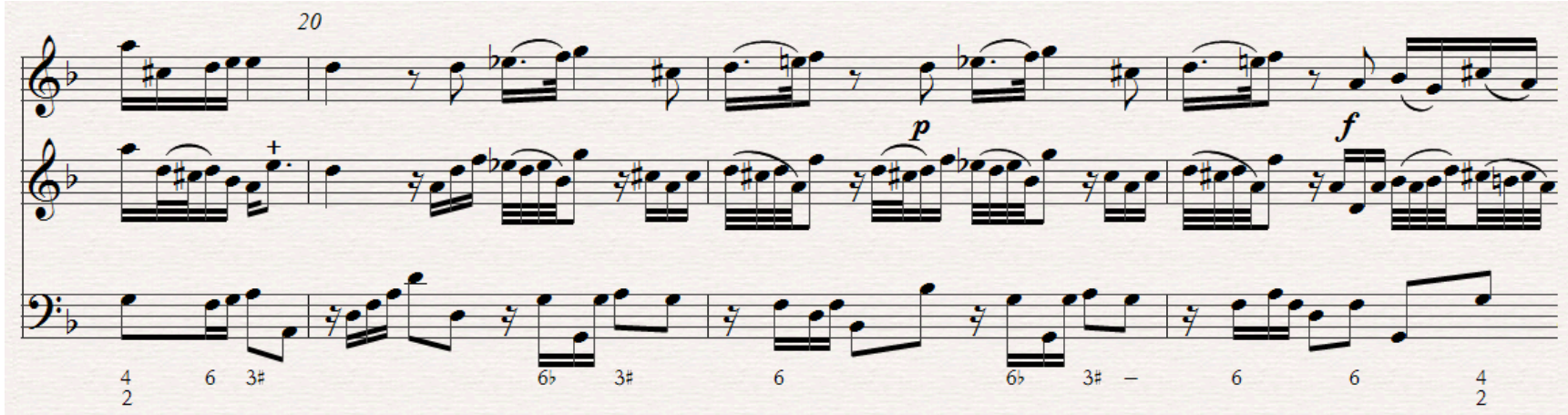

In this excerpt, as in most of these movements - and indeed, throughout most contemporary examples of ornamentation - the added figures frequently reach outside the range of the original intervals. Provided any notes which are highlighted by the line direction are chord tones, or fall immediately by step to a consonant note, the ear is not offended by this.

Telemann's ornamented movements are in a variety of slow tempos besides the traditional adagio and andante examples above. Example 3.27 shows a section of the largo from Sonata No. 10. A large part of the plain melody of this movement is constructed out of falling conjunct lines, and the 
ornamentation can be seen as a study in the treatment of such descending scales. The line in b. 16 is enlivened rhythmically. Bar 17 illustrates the technique of first reducing the melodic line to its essential components and then embellishing these, ignoring any passing or harmonically insignificant notes. In b. 20, Telemann adds descending figures referencing the material of the original melody, and b. 21 features a unique arpeggiated transformation.

\section{Ex. 3.27: Telemann Methodical Sonata No. 10: first movement}

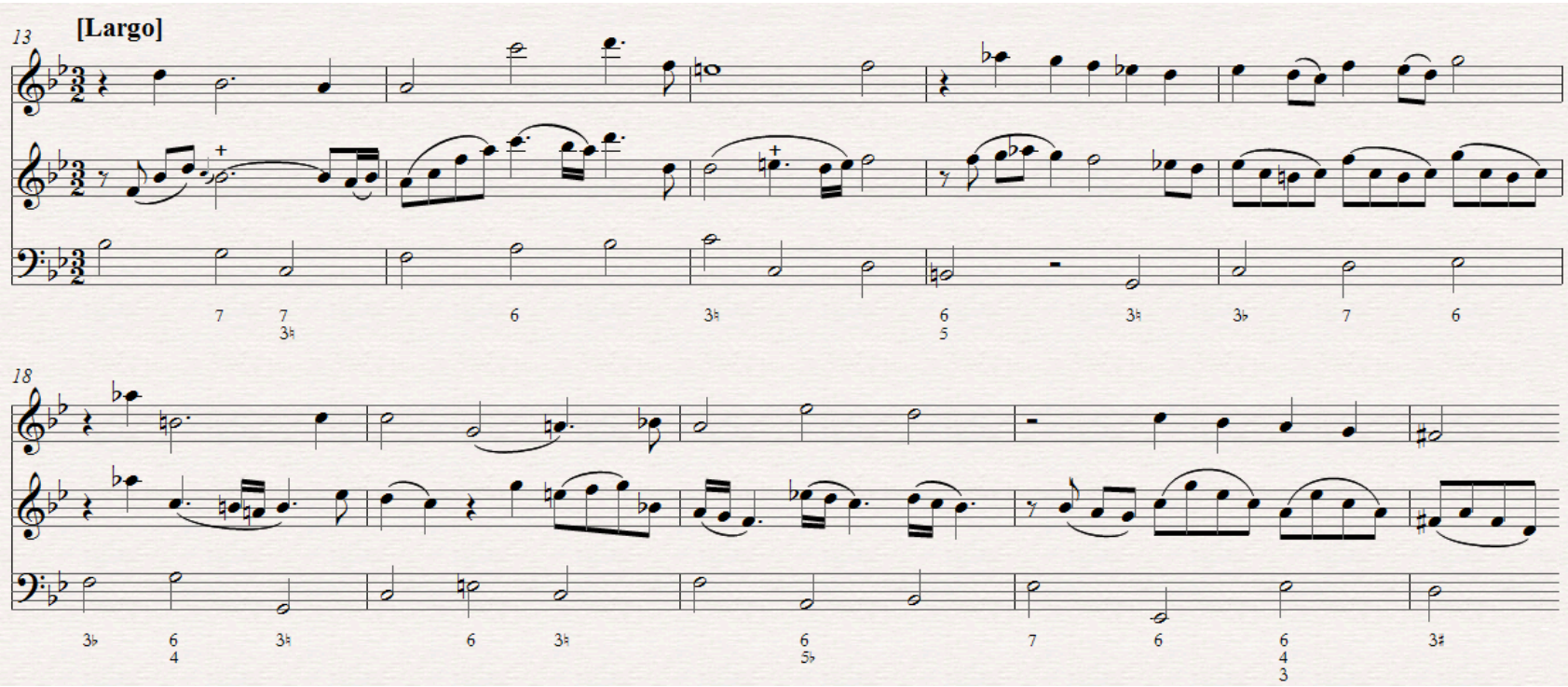

Chromaticism features in the original melody of several of the ornamented slow movements. Telemann does not add chromatic figures in his embellishment, but his treatment of existing chromaticism often results in some very unusual intervals. The excerpt in ex. 3.28 features an augmented second and several different tritones.

\section{Ex. 3.28: Ornamentation of chromaticism in Telemann Methodical Sonata No. 8}

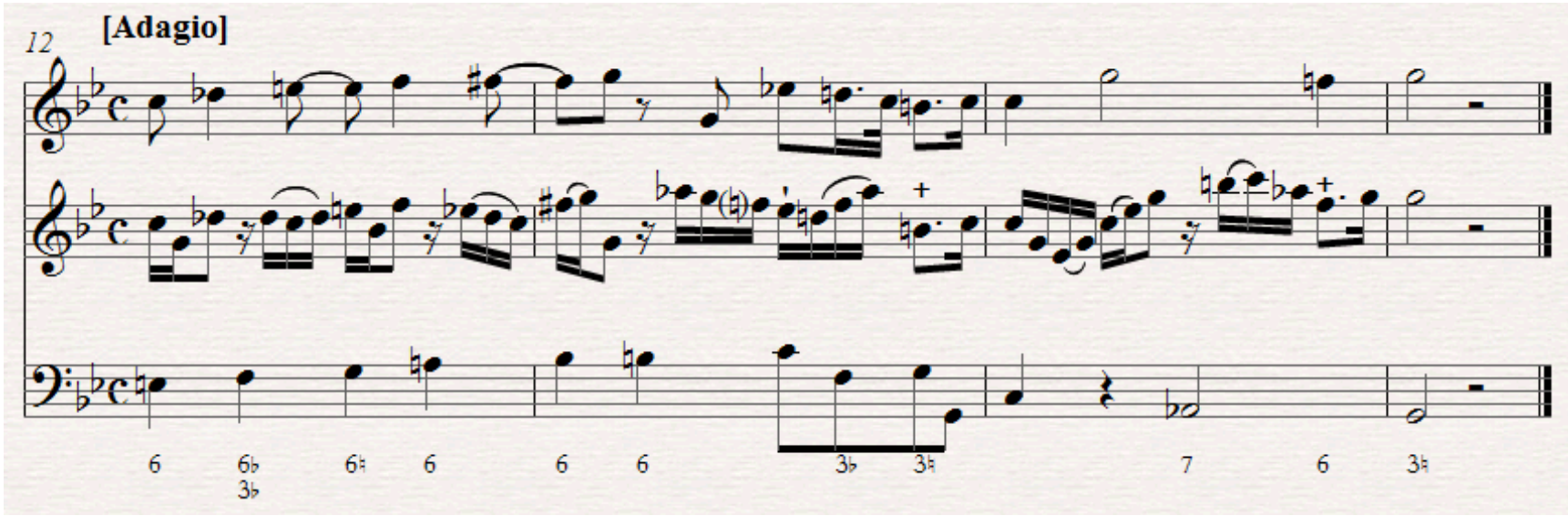

The introduction of such 'stretched' intervals and chromatically altered notes which pull the melodic line up or down greatly increases the range of expression available to the performer.

The embellishment of the Siciliana of Sonata No. 7 is the most conspicuously French of the set, and is written in the characteristically French key of B minor. Rather than the measured divisions from which 
most of Telemann's ornamentation is constructed, this Siciliana is mainly decorated with short, defined ornaments.

\section{Ex. 3.29: French-style ornamentation in Telemann Methodical Sonata No. 7}

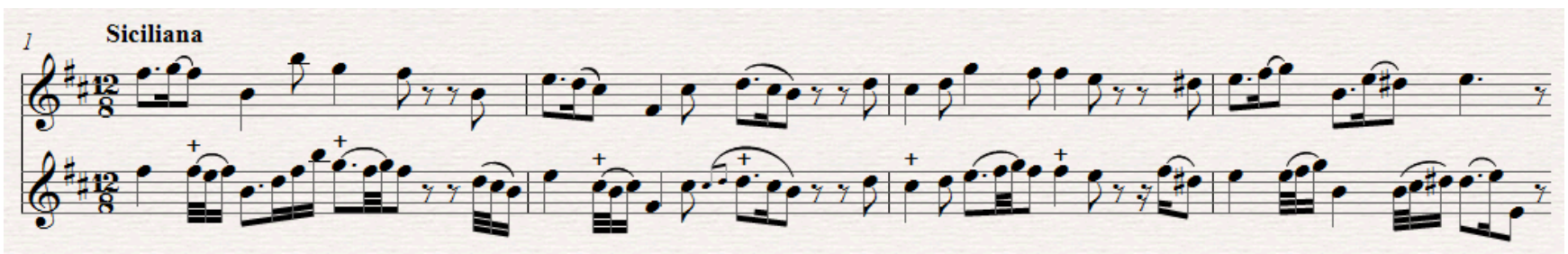

Many of these ornaments are elaborations of trills and mordents, rising three-note 'slides' as seen in b. 4 , or the falling counterpart seen in the upbeat to the second bar. The combination of trill and mordent, which features in the first and second bars, is used throughout the movement. This notation literally indicates a trilled turn or short, suffixed trill, although due to the speed a simple turn may be intended. ${ }^{144}$ All of these very rapid ornaments frequently occur on the third part of the beat (the third, sixth, ninth and twelfth quavers), accentuating this offbeat and giving the melody a light, lifted character.

\section{Towards a performance guide}

The very 'methodical' nature of Telemann's sonatas gives the ornamented versions the appearance of exercises in composition rather than examples of improvisation. Indeed, the impression that melodic ornamentation must be improvisation in an absolute sense may be in part to blame for the avoidance of this field by the majority of modern classically-trained musicians. Considering the importance of harmonic accuracy, a degree of planning likely remained part of the practice of extempore variation even for the most skilled and creative of $18^{\text {th }}$-century performers. Contemporary writers do not appear to have had any problem with pre-planned ornamentation, provided this was performed spontaneously as if improvised. ${ }^{145}$

Components of the diminutions discussed at the beginning of this chapter can be frequently found within examples of embellishment such as those presented above. The use and adaptation of these stock phrases, and in particular of those with minimal harmonic significance termed 'linear' ornaments, is the most straightforward starting point for a modern musician with interest in the art of embellishment.

\footnotetext{
${ }^{144}$ See discussion of the limited usage of the turn symbol under "The Turn" in the previous chapter.

${ }^{145}$ For example, Agricola laments the use of "monotonous, perhaps memorised variations" (Anleitung, 235).
} 


\section{Discussion and Conclusion}

\section{The role of the performer}

Of the many substantial changes to Western musical culture over the last three centuries, the most relevant to my topic is the shift in the roles of composer and performer. Ernest T. Ferand describes improvisation as the more or less complete overlap of these roles:

The very beginnings of musical practice can scarcely be imagined in any form other than that of instantaneous musical expression - of improvisation. ... The exclusively or predominantly improvisatory nature of early musical practice also resulted from the circumstances that the strict division into groups of creative musicians (composers), performing musicians (singers, players), and passive listeners (the public) - a division accepted as a matter of course in our modern Western musical life - was unknown in the early stages of musical development. Inventor and performer of a tune were usually the same person ... who on repeated performances of his 'composition' constantly made changes to it. $^{146}$

The overlap between performer and composer first became less than absolute with the oral tradition of folk songs, and of reusable melodic fragments such as the maqams of Arabic music. These fragments allowed the creation of new and varied tunes from a stock collection of motives learnt by rote, similar to a jazz player reading from a 'fake book'. Later, the advent and refinement of musical notation allowed even greater separation and, by extension, specialisation. However, the overlap remained a vital part of music-making in all ages and in all styles, with the singular exception of modern Western art music in the classical tradition.

It is an unavoidable consequence of the variability of our voices and instruments, and the incomplete nature of even very detailed musical notation, that every performance is an interpretation. However, the current climate of 'classical' performance favours a style in which the range of expression must be within the scope of the printed text, avoiding any infringement upon the composer's role. As a result, modern virtuosi are extremely proficient at using subtle expressive devices such as dynamics, articulation, and tone colour, including use of vibrato.

This limitation of the performer's role is, in the context both of history and of modern non-classical music, both extreme and unique. To address this modern condition of the classical tradition, it is necessary to understand the causes of this bias against ornamentation and other manifestations of performer / composer overlap. In $18^{\text {th }}$-century music, this overlap is also illustrated in the realisation of figured bass, and improvised or prepared cadenzas and preludes. The former two are now often prescribed by editors, while the latter is almost an extinct genre. ${ }^{147}$

Two major causes of the current approach to musical performance have been well-documented. First, the development of a performance style designed to record well, favouring technical perfection and the

\footnotetext{
${ }^{146}$ Ernest T. Ferand, Improvisation in Nine Centuries of Western Music (Köln: Arno Volk Verlag, 1961), 5.

${ }^{147}$ I do not presume to say that no modern performers employ ornamentation and the other 'overlap' skills listed, since many excellent musicians do so. However, these are very much the minority and only the realization of figured bass is becoming an expected skill for students of classical music.
} 
ability to withstand endless repetition, has been explored by Robert Phillip. The extension of this style to live performance has significantly changed audience expectations of classical music. ${ }^{148}$ Second, the modernist view of 'The Work' as an independently existing entity, represented by 'The Score' has been very influential. Musicologists including Richard Taruskin, Nicholas Cook, and Lydia Goehr have discussed and critiqued this separation of 'text' and 'act', which has led to the fetishisation of Urtext editions and a reverence for autograph manuscripts as holy relics. ${ }^{149}$

The developing concept of 'The Work' as a separate and unchanging entity is the topic of Lydia Goehr's The Imaginary Museum of Musical Works. While the 'work-concept' undoubtedly existed in the $18^{\text {th }}$ century and indeed as far back as Plato, Goehr concludes that it only became of cultural and aesthetic significance after $1800 .{ }^{150}$ It would therefore be senseless to apply the modern idea of the inviolable Work to earlier periods. ${ }^{151}$

The practical effect of the work-concept in the $19^{\text {th }}$ century is a subject for another study, but the survival of the culture of embellishment in one form or another is clear. Several of the earliest musical recordings, such as those by castrato Alessandro Moreschi and soprano Maria Galvany, serve as hard evidence that the practice of ornamentation survived into the early $20^{\text {th }}$ century. ${ }^{152}$

The idea of the performer's new role - execution, not interpretation - did not substantially take hold until the 1920s. Foremost among the advocates of this anti-Romantic or Neo-Classicist view was Igor Stravinsky, who wrote that "[t]he secret of perfection lies above all in [the performer's] consciousness of the law imposed on him by the work he is performing". ${ }^{153}$ Arnold Schoenberg allegedly took the idea slightly further with the statement that "[t]he performer, for all his intolerable arrogance, is totally unnecessary except as his interpretations make the music understandable to an audience unfortunate enough not to be able to read it in print." ${ }^{154}$ The implication here is that the score represents unattainable perfection, which is inevitably marred by the unfortunate necessity of performance.

This is incompatible with the culture which Mattheson described in 1739. A performance of a piece "without the slightest offence against directions" is necessary, but still constitutes "bad reading". A performer who wishes to achieve a "reading with expression and good style" must apply "much grace, ornament and artistry". 155

Rather than calling for performers to respect the integrity of the work itself, $18^{\text {th }}$-century theorists demanded that any alterations served the character of the work or movement. Calls for respect for the composer became more frequent over the course of the century, but unlike today, this motive was not

\footnotetext{
${ }^{148}$ Robert Phillip, Performing Music in the Age of Recording (Connecticut: Yale University Press, 2004).

${ }^{149}$ Richard Taruskin, Text and Act (Oxford; New York: Oxford University Press, 1995); Lydia Goehr, The Imaginary Museum of Musical Works (Oxford; New York: Oxford University Press, 1994); Nicholas Cook, Beyond the Score: Music as Performace (Oxford; New York: Oxford University Press, 2014). See also, to name but a few, the essays of Stanley Boorman, 'The Musical Text', and José A. Bowen 'Finding the Music in Musicology: Performance History and Musical Works' in Rethinking Music, ed. Nicholas Cook and M. Everist (Oxford; New York: Oxford University Press, 2001); and Barthold Kujiken, The Notation is not the Music (Bloomington: Indiana University Press, 2013).

${ }^{150}$ Lydia Goehr, The Imaginary Museum.

${ }^{151}$ For further discussion, see Michael Talbot, ed., The Musical Work - Reality or Invention (UK: Liverpool University Press, 2000).

${ }^{152} \mathrm{~A}$ more recent example is William Primrose, the first of the modern school of viola virtuosi, who made significant technical and aesthetic alterations to works such as William Walton's viola concerto.

${ }^{153}$ Igor Stravinsky, Poetics of Music in the Form of Six Lessons (Oxford; New York: Oxford University Press, 1947$), 127$.

${ }^{154}$ Dika Newlin, Schoenberg Remembered: Diaries and Recollections (1938-76) (New York: Pendragon Press, 1980$), 164$.

${ }^{155}$ Mattheson, Der Vollkommene Capellmeister, 2/3/6
} 
an end in its own right. On the subject of extempore variations, Quantz asks the performer to consider the composer's superior position in the generation of musical ideas:

[T] he more simply and correctly an Adagio is played with feeling, the more it charms the listeners, and the less it obscures or destroys the good ideas that the composer has created with care and reflection. For when you are playing it is unlikely that you will, on the spur of the moment, improve upon the inventions of the composer who may have considered his work at length. ${ }^{156}$

A similar concern is evident in Couperin's condemnation in 1722 of any alterations to his works:

I am always painfully surprised (after all the care I have taken to mark all the ornaments which are in keeping with my pieces, and of which I have given a separate and sufficiently intelligible explanation in a special Method entitled L'Art de toucher le clavecin) to hear my pieces played by people who have learnt them without troubling to follow my indications. This is unpardonable negligence, in that it is not a question of personal preference which ornaments one chooses to play. I therefore declare that my pieces should be played exactly as I have marked them; and that they will never make the desired impression on people of good taste unless everything I have marked is scrupulously observed, without addition or omission. ${ }^{157}$

In the next year, Tosi takes the opposite stance, representing the autonomy of the performer in a very different Italian musical culture. When discussing the extempore introduction of appoggiaturas, Tosi pauses to express his righteous outrage at composers who infringe on what he considers to be the domain of the performer.

Appoggiaturas become so familiar through regular practice that the student who has been correctly taught them, though just out of school, will laugh at composers who indicate them by notes because they either think this custom fashionable or want to give the impression that they know how to sing better than the singers themselves. If their talent is so great, why not also write out the extempore variations, which are much more difficult and even more important than the appoggiaturas? If they are indicating them so as not to lose the glorious title of stylish virtuosos, they should at least realise that this one added note requires little trouble and even less work. Poor Italy! Please tell me, do today's singers not know where the appoggiaturas should be placed, without having them pointed out to them? In my time, their own understanding served them therein. Eternal shame on those who first introduced this foreign infantile practice to our nation ... Oh the great weakness of those who follow this example! Oh libellous insult to you, modern singers, who submit to infantile instruction. $^{158}$

It would be an over-simplification to claim that Couperin and Tosi represented the prevailing opinions of France and Italy respectively. Evidence suggests that, while a certain tendency towards the above

\footnotetext{
${ }^{156}$ Quantz, Versuch, 14/24

${ }^{157}$ François Couperin, Third Book of Harpsichord Pieces (Paris, 1722).

${ }^{158}$ Agricola, Anleitung, 91 (Tosi, Opinioni, 22-23)
} 
views did exist in these countries, both writers represented extremes. As in the commonly observed pattern, it is likely that the range of opinions held by compatriots outweighed national differences to a large degree.

In keeping with the greater respect accorded to composers in later decades, Agricola glosses Tosi's condemnation of the notation of appoggiaturas in defence of the interests of the composer:

A composer would find it very distressing not to be able to make known within an aria, completely of his own invention, where a Vorschlag could or should be added. A composer who writes out the Vorschläge cannot be charged with any other greed for fame than this. ${ }^{159}$

In response to Tosi's challenge that composers could very well write out extempore variations, if they must add appoggiaturas, Agricola cites poor performers as a reason why composers might indeed wish to indicate both:

Singers having a thorough knowledge of the laws of harmony and endowed with an inventive spirit surely do not need the composer's help in this. But if an aria that is suitable for extempore variations falls into the hands of a bad singer - devoid of any knowledge of harmony, whose imagination is all dried out, and who either does not perceive the reigning passion of the aria or ignores its expression in sacrifice to his mania for variation - would it not do more honour to the singer and give more pleasure to the listener for the composer to make a careful effort to indicate how the plain melody of an aria could most skilfully be decorated with extempore variations? ${ }^{160}$

Concern with bad or excessive ornamentation (conspicuously absent from Tosi's treatise, and from Muffat's prefaces) features more and more prominently in critical writings from the mid-century on. One reason for this trend was the same cause which provoked the sudden explosion of pedagogical texts in the mid-century - an increased number of amateur musicians. Some of these players performed at the public concerts which gradually replaced exclusive performances at private residences as the most common mode of musical communication. ${ }^{161}$

This broadening of musical accessibility had far-reaching consequences, including on practices of ornamentation. A larger number of performers meant a reduction of the composer's control, possibly combined with an overall lower quality of performing musicians. It can hardly be denied that a presumption of performer additions requires a certain degree of faith on the part of the composer. Since the audience would often be unable to distinguish bad ornamentation from bad composition, this could be seriously damaging to a composer's reputation. This was among the influences which stimulated the mid- to late-century trend towards more thorough composition and greater concern with the accuracy of published editions.

The broader audiences also affected performance style. A common theme in musical criticism from the mid-century onwards is the differing tastes of this new majority and the 'elite' minority. Johann Adolf

\footnotetext{
${ }^{159}$ Agricola, Anleitung, 92. I have left the words appoggiatura and Vorschlag in their original languages.

${ }^{160}$ Agricola, Anleitung, 92.

${ }^{161}$ While it is hard to identify any watershed economic event within the years surveyed in this thesis, a general trend of growing prosperity for a larger number of people is in evidence. The German states may have benefited particularly from several generations of relative stability since the end of the Thirty Years War in 1648.
} 
Hasse describes this situation in a letter of 1770, discussing a former student:

With respect to [Elisabeth] Teyber, I have always feared that she would not be so successful the second time as she was in her first year ... in imitating many singers, even good ones (who do what is false and capricious to attract applause from the more common part of the audience, which usually likes only what astonishes), she is separating herself considerably from what is natural and true. But she knows music; therefore I hope that when she becomes aware that the more reasonable part of an audience wants from her something completely different from caprice, she will easily succeed in putting herself again on the right path. ${ }^{162}$

Competition between performers drove the expectations of growing audiences further towards displays of virtuosity, possibly at the expense of musicality. Charles Burney reflected on this trend in 1789:

It seems to be with musical effects as with medicinal, which are enfeebled and diminished by frequent use. Indeed, such execution as many of Farinelli's songs contain, and which excited such astonishment in 1734, would be hardly thought sufficiently brilliant in 1788 for a third-rate singer at the opera. The dose of difficulties to produce the same effects as 50 years ago, must be more than doubled. $^{163}$

Some modern writers take these influences to mean that, at least by the mid-century, extempore embellishment was simply a bad habit driven by the desires of listeners far removed from those of today. Imitation of such a practice, having no basis in aesthetics, would be senseless. I believe that, on the contrary, condemnation of bad or excessive ornamentation should be taken as exactly that, not as a blanket ban on the entire practice. ${ }^{164}$

\section{Conclusion}

If a modern performer follows the advice found in published treatises of the $18^{\text {th }}$ century, the result should be something which certain leading musicians of that period considered 'good'. In the absence of any objective measure of the quality of a musical performance, this is likely to be the best starting point. However, innovation is central to embellishment at a high level. Over the last century, countless new genres of music have arisen out of the same ideal as the $18^{\text {th }}$-century mixed style - that favoured aspects of different styles can be combined and adapted to create new and potentially better styles. In an age in which the mixing of genres is considered a matter of course, the embellishment of $18^{\text {th }}$ century music in other styles is an inevitable experiment. Examples such as the later $18^{\text {th }}$-century versions of Corelli's op. 5 demonstrate that in this period, it was quite acceptable to 'update' old music by applying current ornamental practices. In all such cases, the quality of the result can only be judged on subjective terms, but should not be considered categorically or ethically wrong.

\footnotetext{
${ }^{162}$ Johann Adolf Hasse e Giammaria Ortes: Lettere, 1760-1783, ed. L. Pancino (Turnhout, 1998), 204. Trans. Beverly Jerold in 'How Composer's Viewed Performer's Additions', Early Music, Vol. 36, No. 1, (February 2008), 103-04.

${ }^{163}$ Charles Burney, A General History of Music, from the Earliest Ages to the Present Period (London: published by the author, 1789), ed. F. Mercer (New York: Harcourt, Brace \& Co., 1935), part 2, 813-14.

${ }^{164}$ In this regard, my views align with those of Clive Brown in Classical and Romantic Performing Practice.
} 
It bears repeating, as many of the treatise writers quoted in this study also found, that ornamentation of any sort is not compulsory. With the exception of unwritten cadential trills, an unadorned version of a piece is always a valid option. However, in music of the $18^{\text {th }}$ century and earlier, this choice should never be considered 'fidelity' either to the composer or to the music itself.

The practical matter of the addition of both small and large ornaments is covered to a high level of detail in primary sources, although the contradictions between sources are sometimes more than superficial. The concentration of high-quality publications in German-speaking regions is among the best examples of this. However, even this wealth of information leaves one a significant distance away from effective and spontaneous use of these ornaments in performance.

Tosi concludes his treatise with the following advice:

[The motivated singer] will invent variations among which he will choose the best as the result of mature and closely considered comparisons ... he will keep on searching until he has found more and more other variations more worthy of his inclination and attention. Finally, he will arrive at an almost endless number of variations and turnings, by means of which he will have developed his insight to such a degree that the most hidden treasures of the art, which were furthest removed from his imagination, will reveal themselves to him voluntarily. If he is not blinded by arrogance, if studying does not make him irritable, and if his memory does not fail him, he will continue, in a way uniquely his own, to enlarge his store of the ornaments of melody and, so to speak, develop a taste of his own. This is the most noble aim of those who strive to win the greatest applause. ${ }^{165}$

Between the lines of this typically general and yet undeniably correct passage is the fact that one simply cannot learn the art of embellishment from a book. In this regard, classical musicians would also do well to take the advice of our jazz colleagues, who instruct students first to imitate their idols before attempting original musical expression. Although we will never hear a live performance by the great improvisers of the $18^{\text {th }}$ century, the many surviving written examples form a strong point of reference alongside the efforts of pioneering modern performers.

The final steps on Tosi's path to successful embellishment are the same one must take to achieve excellence in any discipline. What begins with study can only be fully realised through the liberal application of experimentation, critical reflection, and time.

${ }^{165}$ Agricola, Anleitung, 237 (Tosi, Opinioni, 116-17). 


\section{Bibliography}

\section{Primary Resources}

Agricola, Johann Friedrich. Anleitung zur Gesangkunst. Berlin: George Ludewig Winter, 1757.

Translation and commentary of Pier Francesco Tosi's Opinioni de' cantori antichi e moderni o sieno osservazioni sopra il canto figurato. Bologna: publisher unknown, 1723.

English translation of Agricola by Julianne Baird as Introduction to the Art of Singing. Cambridge: Cambridge University Press, 2006.

Bach, Carl Phillip Emanuel. Versuch über die wahre Art das Klavier zu spielen. Berlin: Christian Friedrich Henning, 1753.

Trans. William J. Mitchell as Essay on the True Art of Playing Keyboard Instruments. New York: W. W. Norton \& Co, 1949.

Burney, Charles. A General History of Music, from the Earliest Ages to the Present Period. London: published by the author, 1789.

Ed. F. Mercer. New York: Harcourt, Brace \& Co., 1935.

Couperin, François. Third Book of Harpsichord Pieces. Paris, 1722.

Farina, Carlo. Capriccio Stravagante. Dresden, 1627.

Geminiani, Francesco. The Art of Playing on the Violin. London: publisher unknown, 1751.

Mattheson, Johann. Der Vollkommene Capellmeister. Hamburg: Christian Herold, 1739.

Trans. Ernest C. Harriss as Johann Mattheson's Der Vollkommene Capellmeister: A Revised Translation with Critical Commentary. Michegan: UMI Research Press, 1981.

Mozart, Leopold. Versuch einer gründlichen Violinschule. Augsburg: Johann Jacob Lotter, 1756.

Trans. Editha Knocker as A Treatise on the Fundamental Principles of Violin Playing. Oxford; New York: Oxford University Press, 1951.

Muffat, Georg. Florilegium Primum. Augsburg: Koppmayr, 1695.

- Florilegium Secundum. Passau: publisher unknown, 1698.

- Auserlesene Instrumentalmusik. Passau: publisher unknown, 1701.

Trans. David K. Wilson as Georg Muffat on Performance Practice. Bloomington: Indiana University Press, 2001.

North, Roger. Assorted essays.

Ed. John Wilson as Roger North on Music: Being a Selection from his Essays written during the years c. 1695-1728. London: Novello, 1959.

Quantz, Johann Joachim. Versuch einer Anweisung die Flöte traversiere zu spielen. Berlin: Johann Friedrich Voß, 1752. 
Trans. Edward R. Reilly as On Playing the Flute. New York: The Free Press; London: Faber \& Faber, 1966.

Türk, Daniel Gottlob. Klavierschule. Leipzig: Schwickert; and Halle: Hemmerde und Schwetschke; 1789.

Trans. Raymond H. Haggh as School of Clavier Playing. Lincoln: University of Nebraska Press, 1983.

- $\quad$ Anweisung zum Generalbassspielen. Leipzig and Halle, 1791.

\section{Secondary Resources}

Boorman, Stanley. 'The Musical Text'. In Rethinking Music, ed. Nicholas Cook and M. Everist. Oxford; New York: Oxford University Press, 2001. 424-51.

Bowen, José A.. 'Finding the Music in Musicology: Performance History and Musical Works'. In Rethinking Music, ed. Nicholas Cook and M. Everist. Oxford; New York: Oxford University Press, 2001. 403-23.

Brewer, Charles E. The Instrumental Music of Schmeltzer, Biber, Muffat and their Contemporaries. Surrey; Burlington: Ashgate, 2011.

Brown, Clive. Classical and Romantic Performance Practice. Oxford; New York: Oxford University Press, 2004.

Butt, John. Music Education and the Art of Performance in the German Baroque. Cambridge: Cambridge University Press, 1994.

Cook, Nicholas. 'At the borders of Musical identity: Schenker, Corelli, and the Graces'. Music Analysis, Vol. 18, No. 2 (July 1999). 179-233.

- Beyond the Score: Music as Performance. Oxford; New York: Oxford University Press, 2013.

Dannreuther, Edward. Musical Ornamentation. London: Novello, Ewer \& Co, 1893-95.

Donington, Robert. The Interpretation of Early Music ('New Version'). London: Faber and Faber, 1974.

Ferrand, Ernest T. Improvisation in Nine Centuries of Western Music. Köln: Arno Volk Verlag, 1961.

Fuller, David. Review of Frederick Neumann's Ornamentation in Baroque and Post-Baroque Music. Journal of the American Musicological Society, Vol. 33, No. 2 (Summer 1980). 394-402.

Gjerdingen, Robert O. Music in the Galant Style. Oxford; New York: Oxford University Press, 2007.

Goehr, Lydia, The Imaginary Museum of Musical Works. Oxford; New York: Oxford University Press, 1994.

Heartz, Daniel. Music in European Capitals: The Galant Style 1720-1780. New York: W. W. Norton \& Co., 2003. 
Jerold, Beverley. 'How Composer's Viewed Performer's Additions'. Early Music, Vol. 36, No. 1, (2008). 95-109.

Kuijken, Barthold. The Notation is not the Music. Bloomington: Indiana University Press, 2013.

Neumann, Frederick. Ornamentation in Baroque and Post-Baroque Music. New Jersey: Princeton University Press, 1978.

- Performance Practices of the Seventeenth and Eighteenth Centuries. New York: Schirmer Books, 1993.

- 'The Use of Baroque Treatises on Musical Performance'. Music and Letters, Vol. 48, No. 4 (October 1967). 315-24.

- 'The Vibrato Controversy'. Performance Practice Review, Vol. 4, No. 1 (1991). 14-27.

Phillip, Robert. Performing Music in the Age of Recording. Connecticut: Yale University Press, 2004.

Reilly, Edward R. Quantz and his Versuch. New York: American Musicological Society, 1971.

Smiles, Joan E. 'Directions for Improvised Ornamentation in Italian Method Books of the Late Eighteenth Century'. Journal of the American Musicological Society, Vol. 31, No. 3 (Autumn 1978). 495-509.

Taruskin, Richard. Text and Act: Essays on Music and Performance. Oxford; New York: Oxford University Press, 1995.

Talbot, Michael (ed.). The Musical Work - Reality or Invention. UK: Liverpool University Press, 2000.

Walls, Peter. History, Imagination and the Performance of Music. UK: Boydell Press, 2003.

- '“Ill-compliments and arbitrary taste'? Geminiani's directions for performers'. Early Music, Vol. 14, No. 2 (May 1986). 221-35.

Zaslaw, Neal. 'Ornaments for Corelli's Violin Sonatas Op. 5'. Early Music, Vol. 24, No 1 (February 1996). 95-106.

- 'Robert Bremner's “The Compleat Orchestral Musician"'. Early Music, Vol. 7, No. 1 (January 1979). 46-47.

Zohn, Steven. Music for a Mixed Taste: Style, Genre, and Meaning in Telemann's Instrumental Works. Oxford; New York: Oxford University Press, 2008.

- 'New Light on Quantz's Advocacy of Telemann's Music'. Early Music, Vol. 25, No. 3 (August 1997). 441-61. 
